\title{
SIMULATED EFFECTS OF VARIED LANDSCAPE-SCALE FUEL TREATMENTS ON CARBON DYNAMICS AND FIRE BEHAVIOR IN THE KLAMATH MOUNTAINS OF CALIFORNIA
}

\author{
A Thesis Presented to the Faculty of California Polytechnic State University \\ In Partial Fulfillment of the Requirements for the Master of Science in Forestry Sciences
}

Kevin J. Osborne

December 2011 
(C) 2011

Kevin J. Osborne

ALL RIGHTS RESERVED 
COMMITTEE MEMBERSHIP

TITLE:

SIMULATED EFFECTS OF VARIED LANDSCAPE-

SCALE FUEL TREATMENTS ON CARBON

DYNAMICS AND FIRE BEHAVIOR IN THE

KLAMATH MOUNTAINS OF CALIFORNIA
AUTHOR:
Kevin J. Osborne
DATE SUBMITTED:
December 2011

COMMITTEE CHAIR: Dr. Christopher Dicus, Professor

COMMITTEE MEMBER: Dr. Scott Sink, Assistant Professor

COMMITTEE MEMBER: Walter Bremer, Professor Emeritus 


\title{
ABSTRACT
}

\section{SIMULATED EFFECTS OF VARIED LANDSCAPE-SCALE FUEL TREATMENTS}

\author{
ON CARBON DYNAMICS AND FIRE BEHAVIOR IN THE KLAMATH
}

MOUNTAINS OF CALIFORNIA

Kevin J. Osborne

I utilized forest growth model (FVS-FFE) and fire simulation software (FlamMap, Randig), integrated through GIS software (ArcMap9.3), to quantify the impacts varied landscape-scale fuel treatments have on short-term onsite carbon loss, long-term onsite carbon storage, burn probability, conditional flame length, and mean fire size. Thirteen fuel treatment scenarios were simulated on a 42,000 hectare landscape in northern California: one untreated, three proposed by the US Forest Service, and nine that were spatially-optimized and developed with the Treatment Optimization Model in FlamMap. The nine scenarios developed in FlamMap varied by treatment intensity $(10 \%, 20 \%$, and $30 \%$ of the landscape treated) and treatment type (prescribed fire, mastication and thin + burn). Each scenario was subjected to 10,000 simulated wildfires with random ignition locations in order to develop burn probability and average flame length values for each scenario. I also recorded mean fire size for each scenario. I used the burn probability values to represent the likelihood of future wildfire occurrence, which I incorporated into our long-term onsite carbon storage projections.

Our results suggest that the influence landscape-scale fuel treatments have on carbon dynamics and fire behavior metrics (mean burn probability, flame length and mean fire size) are highly dependent upon the treatment arrangement, type, and intensity. The results suggest that treating $20 \%$ of the landscape maximizes long-term carbon storage and that prescribed fire minimizes short-term carbon loss and maximizes onsite long-term carbon storage. Treating $20 \%$ of the landscape also appears to be the optimal treatment intensity for reducing fire behavior metrics, and treating beyond this level produces diminishing returns in reduction of fire behavior. When treating $20 \%$ of the landscape, site-specific treatments appear to perform well in comparison to spatially-optimized treatments.

Keywords: Wildland fire, WUI, carbon storage, carbon sequestration, simulation modeling, FVS, FlamMap, treatment optimization, ArcFuels 


\section{ACKNOWLEDGEMENTS}

I would like to start by recognizing the man who made my time at Cal Poly possible, my major professor, Dr. Christopher A. Dicus. I am truly grateful for his tireless work in gaining funding for this project and allowing me freedom in how I chose to accomplish it. Without his support and guidance I could not possibly have completed this work. Along with Dr. Dicus, I would like to thank the other members of my graduate committee, Dr. Scott Sink and Prof. Emeritus Walt Bremer. Their inputs and support were valuable in developing and completing my research.

I would also like to thank everyone who provided support and technical advice for this project. Particular thanks go to Mark Finney at the Missoula Fire Lab, USFS Rocky Mountain Research Station, who graciously provided me with the Randig software, Michael Landram of the US Forest Service for his inputs in developing the regeneration model, and Nathan Amboy and the staff of the US Forest Service Region 5 Remote Sensing Lab for their willingness to assist with various GIS-related technical roadblocks. Thanks also go out to the Klamath National Forest Staff and Clint Isbell for granting us easy access to the data for this project and for their input in the design and outcome of the research. I would not have been able to complete the project without Clint's input and expertise. I would also like to thank Dr. Karen McGaughey for her assistance with the statistical analysis; her advice gave me the confidence to know I could analyze my data in an appropriate manner. Also at Cal Poly, I would like to thank the entire support staff of the Natural Resources Management and Environmental Sciences Department and the Graduate Program staff for getting all of the administrative details in line.

Lastly, I would like to thank all of the friends and family who encouraged me throughout the process and helped me realize how important this work was to me. Their 
support did not go unnoticed. Included in this group are all of my fellow graduate students at Cal Poly in the Natural Resources Department, you know who you are and you are all the best.

This project was made possible by a grant from the California State University Agricultural Research Institute and funding from the McIntire-Stennis Cooperative Forestry Program.

Thank You All 


\section{TABLE OF CONTENTS}

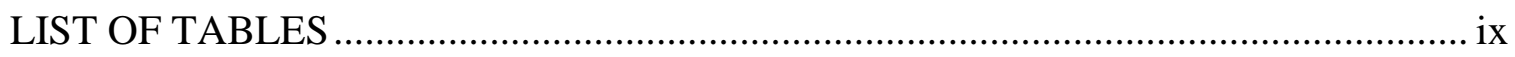

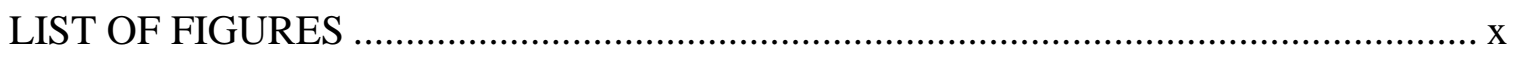

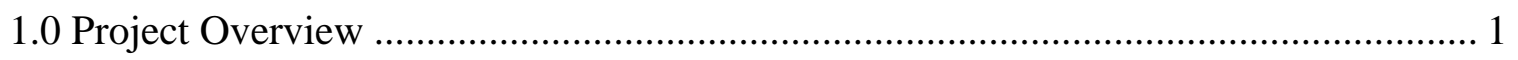

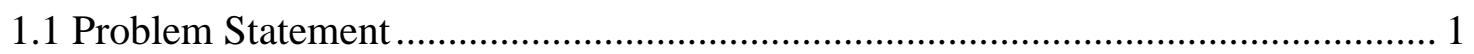

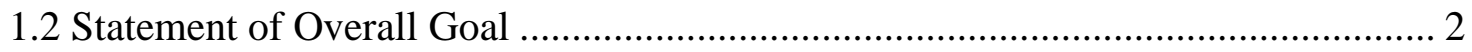

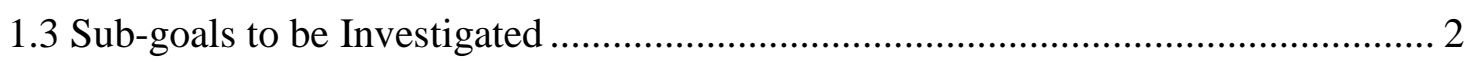

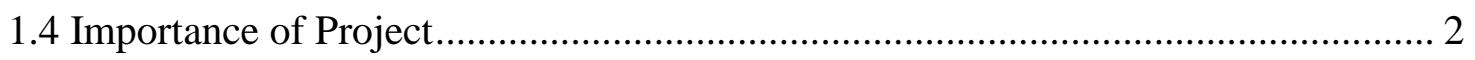

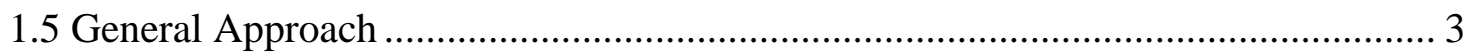

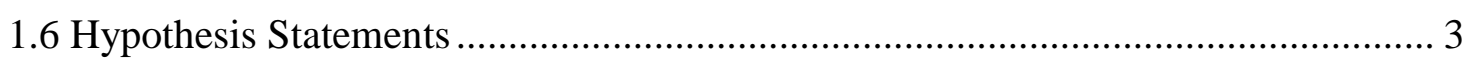

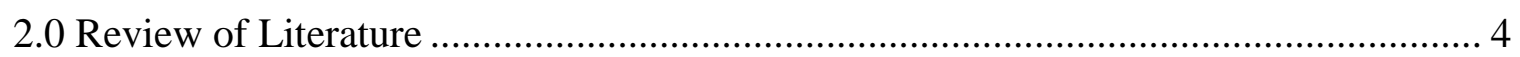

2.1 The Klamath Region and its Fire Regime........................................................... 4

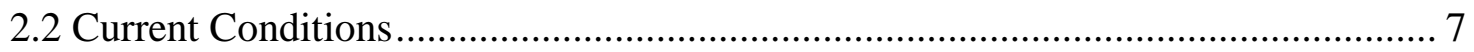

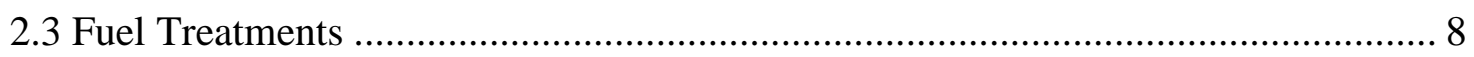

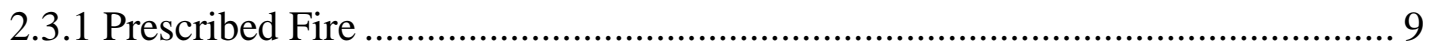

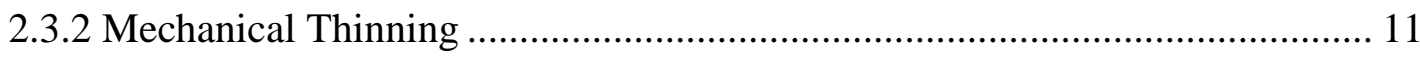

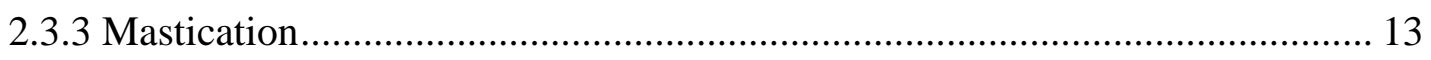

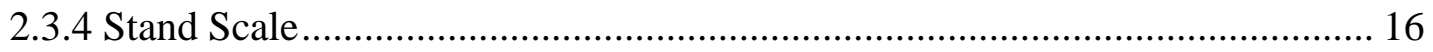

2.3.5 Landscape Scale ................................................................................... 17

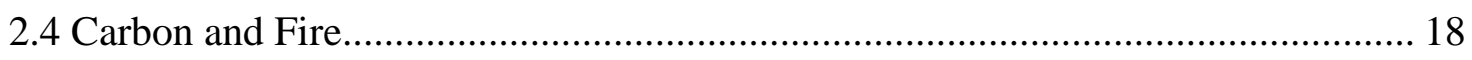

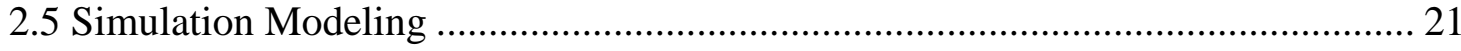

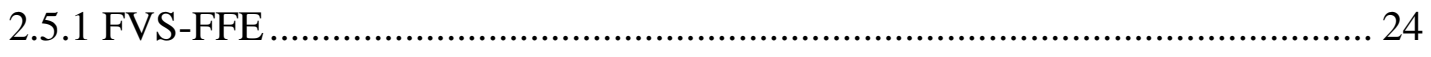

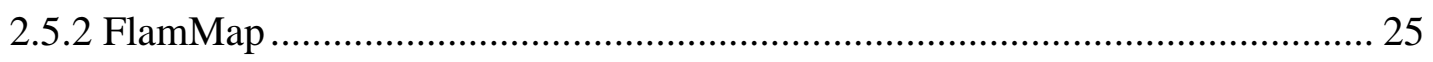

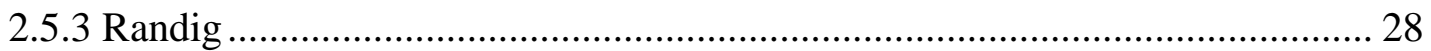

3.0 Impacts on carbon loss and storage from varied landscape-scale fuel treatment

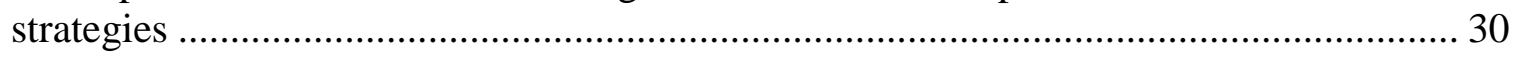

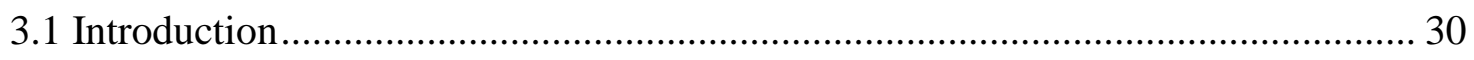

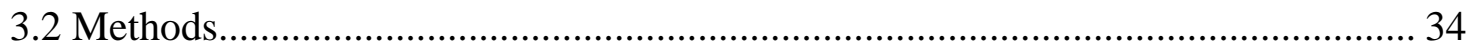

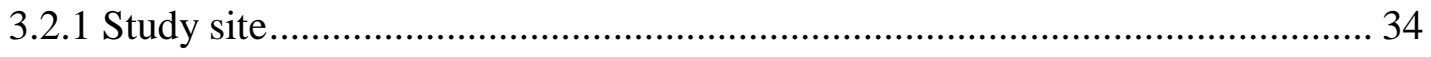

3.2.2 Landscape data + Treatment Scenarios ………………................................. 36

3.2.3 Modeling Procedure ..................................................................................... 45

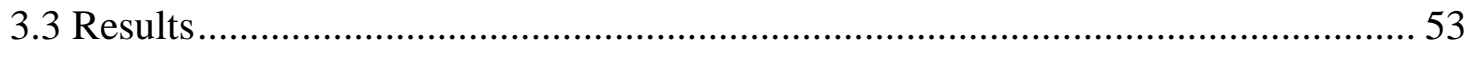




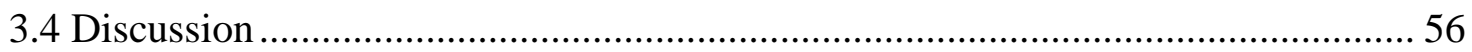

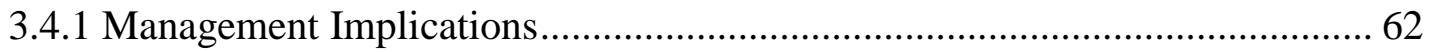

4.0 Impacts to burn probability, flame length, and fire size from varied landscape-scale

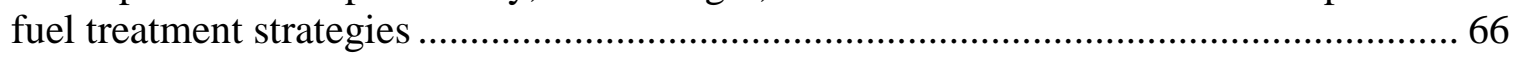

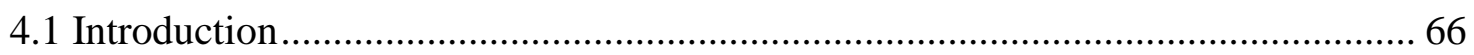

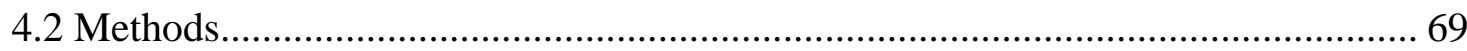



4.2.2 Landscape data + Treatment Scenarios ............................................................ 71

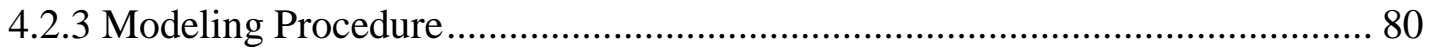

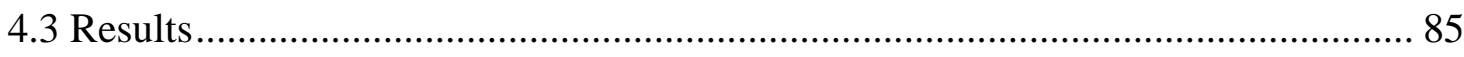

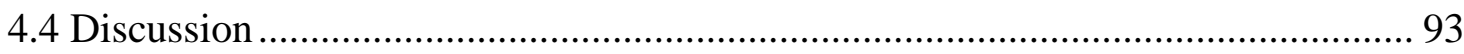

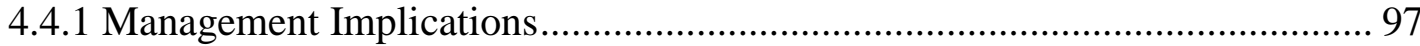

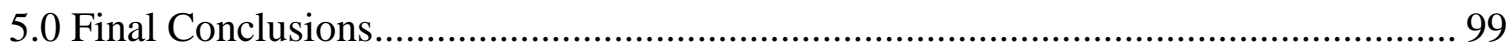

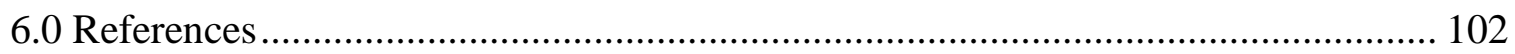




\section{LIST OF TABLES}

Table 3.1 Prescriptions for fuel treatments from the Eddy Gulch Project (USDA Forest Service, 2010) and subsequently coded in FVS key files.

Table 3.2 Area attributes of fuel treatment each scenario. Area assigned wildfire based on burn probability cutoff value for the highest $1 / 3$ of the untreated landscape. .. 40

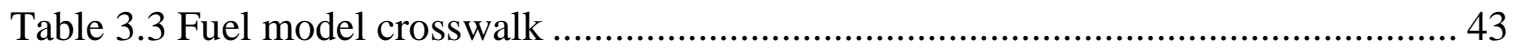

Table 3.4 Weather and fuel moisture variables used in fire simulations. ....................... 44

Table 3.5 Seedling data from FIA regeneration sampling in the Klamath NF. Range for each forest type is the mean number of softwood seedlings +/- one half standard deviation for a range of one standard deviation....

Table 3.6 Short-term carbon loss and long-term carbon storage values (Mg ha-1). Total carbon loss is the sum of carbon lost during treatments (from vegetation removal or prescribed fire carbon emissions) and carbon lost during a wildfire as smoke emissions.

Table 4.1 Description of each fuel treatment type from the Eddy Gulch Project (USDA Forest Service, 2010). 74

Table 4.2 Fuel model crosswalk used to implement fuel treatments in creation of

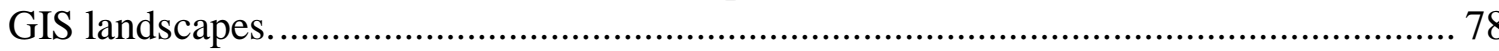

Table 4.3 Weather and fuel moisture variables used in fire simulations 79

Table 4.4 Maximum and mean burn probability values for the study site and WUI threat zones within the study site. WUI threat zones are 1.5 radius zones around designated WUI communities in or adjacent to the study site (USDA Forest Service 2002). 86

Table 4.5 Average and maximum conditional flame length $(\mathrm{m})$ for the study site and WUI threat zones within the study site. WUI threat zones are 1.5 mile radius zones around designated WUI communities in or adjacent to the study site (USDA Forest Service 2002).

Table 4.6 Fire size attributes for all treatment scenarios and the untreated scenario.

Fire size of 500 ha and greater was considered as a major fire event in our calibration so reductions in these large fires indicates effectiveness of treatments in reducing the potential severity of wildfires across the landscape. The number of ignitions is the number of random ignitions that landed inside our study site for each scenario during its Randig simulation. 


\section{LIST OF FIGURES}

Figure 3.1 Location of the study site, larger buffer used in fire modeling simulations, and adjacent WUI communities.

Figure 3.2 The 12 treatment scenarios within the project study site. Shaded areas represent treatment units. Part A represents proposed site-specific treatments. Mechanical units include mastication and thin + burn treatments and the total design includes all mechanical and prescribed fire units. Parts B, C and D represent spatiallyoptimized units developed with the Treatment Optimization Model.

Figure 3.3 Flow chart representing the major processes and inputs used to generate the carbon reports for the treatment scenarios.

Figure 3.4 Distribution of observed fire size vs. simulated fire sizes using 10,000 ignitions in Randig on an untreated landscape. Observed fires growth periods taken from daylight, single day, growth periods of fires in the Klamath Mountains from 2002 to 2008, representing 44 daily growth events over $500 \mathrm{Ha}$. I obtained observed daily growth records from 209 reports for large fires, accessed via https://fam.nwcg.gov/fam-web/.

Figure 3.5 Burn probability (\# of times a pixel burned /number of ignitions) maps and corresponding areas assigned wildfire 5 years after simulated treatment for the untreated scenario and the total site-specific design. Areas receiving wildfire correspond to areas with a burn probability greater than or equal to 0.0067 .

Figure 3.6 Onsite carbon losses $\left(\mathrm{Mg} \mathrm{ha}^{-1}\right)$ for each treatment scenario. Stacked bars for wildfire and treatment loss represent total onsite carbon loss for each scenario. Treatment losses include prescribed fire emissions and vegetation removed in thinning operations. Treatments inside the solid box are spatially-optimized; treatments outside the box are proposed site-specific treatments.

Figure 3.7 Onsite carbon storage $\left(\mathrm{Mg} \mathrm{ha}^{-1}\right)$ for each the untreated control scenario and for each treatment scenario. Treatment scenarios are grouped and each treatment intensity has a separate pattern to allow comparisons among treatment types and across treatment intensities (\% of landscape receiving treatment). Treatments inside the solid box are spatially-optimized; treatments outside the box are proposed site-specific treatments.

Figure 4.1 Location of the study site, larger buffer used in Randig simulations, and adjacent WUI communities.

Figure 4.2 The 12 treatment scenarios within the project study site. Shaded areas represent treatment units. Part A represents the site-specific treatments. Mechanical units are mastication and thin + burn and the total design is the combination of the mechanical and prescribed fire units. Parts B, C and D represent spatially-optimized units developed with the Treatment Optimization Model.

Figure 4.3 Flow chart showing the major steps utilized to obtain fire behavior outputs.. 73 
Figure 4.4 Distribution of observed fire size vs. simulated fire sizes using 10,000 ignitions in Randig on an untreated landscape. Observed fires come from day time single day growth periods from 2002 to 2008 , representing 44 daily growth events over $500 \mathrm{Ha}$

Figure 4.5 Burn probability and conditional flame length in the untreated scenario

Figure 4.6 Mean burn probability for the entire study site (A) and within WUI threat zones (B) for each treatment type at increasing treatment intensities. Site-specific treatments are not precisely at the $10 \% .20 \%$ and $30 \%$ levels but are approximates.

Figure 4.7 Mean conditional flame lengths within the entire study site (A) and the WUI threat zones (B) for each treatment type at increasing treatment intensities. Site-specific treatments are not precisely at the $10 \% .20 \%$ and $30 \%$ levels but are approximates.

Figure 4.8 Mean fire size for each treatment scenario. Scenarios that share a letter have median values that did not significantly differ from one another.

Significance was determined using a Kruskal-Wallis non-parametric test and a Dunn's multiple comparisons test with a pooled alpha of 0.05. Error bars represent $+/$ standard error. Treatments inside the solid box are spatially-optimized; treatments outside the box are site-specific treatment 


\subsection{Project Overview}

\subsection{Problem Statement}

Wildfires are a serious problem for much of the western United States, and each year firefighting agencies spend millions of dollars to fight wildfires and to protect lives and property. A common practice aimed at reducing suppression costs and the loss of life and property is pre-fire removal or alteration of the combustible vegetation that serves as a fire's fuel, collectively called fuel treatments (Reinhardt et al. 2008).

Such fuel treatments are often implemented at the stand level and a large body of work on stand-scale fuel treatments exists that demonstrate their ability to limit fire behavior (Sackett 1975; Stephens 1998; Vaillant et al. 2009; Large 2010; Hamma 2011). However, reducing wildfire risk is a landscape issue (Reinhardt et al. 2008; Collins et al. 2010), and a limited amount of work exists on fuel treatments when they are spread across a landscape with the goal of altering large scale fire behavior (Stratton 2004; Ager et al. 2007; Finney et al. 2007; Schmidt et al. 2008; Ager et al. 2010b; Moghaddas et al. 2010).

In particular, most work on landscape-scale fuel treatments does not account for the potential implications fuel treatments may have on ecosystem services when implemented at such a large scale. It is the goal of this research to improve upon existing research in the field of landscape-scale fuel treatments and account for the potential changes in ecosystem services that occur as a result of alterations to vegetation across a landscape. 


\subsection{Statement of Overall Goal}

My overall research goal was to assess the effectiveness of landscape-scale fuel treatments in regard to fire behavior while simultaneously accounting for potential negative impacts incurred due to the alteration and removal of vegetation. This information may aid land managers in making ecologically sound choices while still gaining the fire control benefits of landscape-scale fuel treatments.

\subsection{Sub-goals to be Investigated}

To accomplish the overall goal, this project focused on assessing the effects landscape-scale fuel treatments have on short-term onsite carbon loss, long-term onsite carbon storage, burn probability, conditional flame length, and mean fire size.

\subsection{Importance of Project}

A complete understanding of the costs and benefits of fuel treatments at the landscape-scale is needed to more fully account for the trade-offs land managers make in order to limit the damage resulting from future wildfires. This work aimed to improve this understanding by analyzing not only the gains made from landscape-scale fuel treatments, but the potential implications on carbon dynamics that may be valuable to the public in an intrinsic sense and may also have economic value as carbon markets become a larger part of forest management in the coming decades. 


\subsection{General Approach}

Working at the landscape-scale offered a challenge for testing multiple fuel treatment scenarios. The same landscape can only be subjected to one fuel treatment design at a time and the time frame for such treatments to recover to pre-treatment conditions can be decades. Implementing treatments across 42,000 hectares is also expensive and time consuming. To overcome the financial, temporal and spatial challenges of research at this scale, I utilized simulation and modeling software to test the performance of multiple, independent, landscape-scale fuel treatment scenarios.

\subsection{Hypothesis Statements}

Null Hypothesis 1: Varied landscape-scale fuel treatment scenarios do not differ in their effects on burn probability, conditional flame length, and mean fire size. Alternative Hypothesis 1: Varied landscape-scale fuel treatment scenarios differ in their effects on burn probability, conditional flame length, and mean fire size.

Null Hypothesis 2: Varied landscape-scale fuel treatment scenarios do not differ in their effects on short-term onsite carbon loss and long-term onsite carbon storage. Alternative Hypothesis 2: Varied landscape-scale fuel treatment scenarios differ in their effects on short-term onsite carbon loss and long-term onsite carbon storage. 


\subsection{Review of Literature}

\subsection{The Klamath Region and its Fire Regime}

The Klamath Mountain region covers a large portion of land is located in northern California and southern Oregon. The region covers $22,500 \mathrm{~km}^{2}\left(8,690 \mathrm{mi}^{2}\right)$ in California alone, accounting for approximately $6 \%$ of the state's land area (Skinner et al. 2006). The area is characterized by very steep topography, ranging in elevation from $30 \mathrm{~m}$ to nearly 2,800 $\mathrm{m}$. The steep topography, with a highly varied gradient of climate, elevation, and substrate, drives a highly diversified set of plant communities, particularly in regard to conifer species composition (Whittaker 1960; Taylor and Skinner 1998; Frost and Sweeny 2000).

Climate in the area is Mediterranean, with hot, dry summers and cool, wet winters. The very dry summers are a significant factor in determining the fire history of the region, with the majority of vegetation dry enough to support fire spread by the mid to late summer season. Because of this, the majority of the fires in the region occur from May to November when vegetation is dry and thunderstorms are not uncommon (Taylor and Skinner 2003; Skinner at al. 2006; Agee 2007). In addition, a strong temperature and precipitation gradient dominates from west to east due to the influence of the Pacific

Ocean. Because of the ocean influence, the western portion of the region has a cooler and moister climate than the more eastern portions of the region (Skinner et al. 2006; Agee 2007).

Vegetation consists largely of multi-layered, multi-aged forests. The distribution of vegetation is highly correlated to topography and climate, resulting in a wide variety of vegetation types in areas relatively close to one another but with differing elevations and 
aspects. Douglas-fir (Pseudotsuga menziesii Mirb.) and ponderosa pine (Pinus ponderosa C. Lawson) in association with Pacific madrone (Arbutus menziesii Pursh) and other understory evergreen shrubs dominate at lower elevations. Douglas-fir, white fir (Abies concolor Gord. \& Glend.), and red fir (Abies magnifica A. Murray) dominate at higher elevations where moisture is more abundant (Taylor and Skinner, 1998). Incense cedar (Calocedrus decurrens Torr.), sugar pine (Pinus lambertiana Douglas), and Jeffrey pine (Pinus jeffreyi Balf.) can occur across all elevations and specific site distributions are highly influenced by elevation and site moisture levels (Taylor and Skinner 2003; Skinner et al. 2006).

The fire ecology of the region is driven by both the complex terrain and the seasonal drought, experienced during the summer months. The majority of fires occur in the summer months (Taylor and Skinner 2003), but the severity of fires varies widely across the region, resulting in a mixed severity fire regime. The highest severity fires occur on the upper third of south or southwest facing slopes as well as non-forested areas that consist of chaparral communities (Taylor and Skinner 1998; Miller et al. in press). However, fire frequency is higher on the lower slopes due to drier conditions and a longer fire season (Taylor and Skinner 2003).

The number and size of fires varies greatly by year as well, with region-wide lightning events responsible for the years with the largest number of fires and the largest number of acres burned (Skinner et al. 2006; Agee 2007; Miller et al. in press). The years with the highest area burned are often also characterized by below average winter and spring precipitation, which results in drier, more receptive fuels for lightning events (Miller et al. in press). However, anthropogenic fires do occur in the region. Areas with a 
high road density and large human influence (such as plantations) experience a larger percentage of high severity fires than areas that experience lower human influence (Odion et al. 2004; Miller et al. in press).

The area is characterized as a mixed severity fire regime, with the effects of fire on vegetation ranging from very low mortality surface fires to high mortality crown fires. Under historic conditions, the majority of fires burned with low to moderate severity, and only a smaller portion of fires resulted in high severity fire (Taylor and Skinner 2003; Odion et al. 2004). This trend remains in place today, often due to strong inversions in the region that limit rapid fire growth and result in low severity fires that burn for long durations (Odion et al. 2004; Skinner et al. 2006; Agee 2007). However, though the percentage of fires resulting in high severity is still low, the frequency and size of recent high severity fires appear to be increasing (Taylor and Skinner 1998; Taylor and Skinner 2003; Odion et al. 2004).

Reported historic mean fire return intervals in the Klamath mountain region is around 12 years (Taylor and Skinner 1998; Taylor and Skinner 2003). However, due to fire exclusion in the previous century, fire return intervals have increased to an average of almost 22 years (Taylor and Skinner 1998; Taylor and Skinner 2003). This increase in fire return interval may have resulted in an increase of fuels that has led to the increased size of high severity fires experienced today. In contrast, a recent study has found that areas with longer fire return intervals in the Klamath Region actually experience less high severity fire as compared to areas that have more frequent fire (Odion et al. 2004). However, this same study found that the majority of the high severity fires occurred in areas highly impacted by humans and that future changes in the climate of the region may 
continue to exacerbate the trend of more frequent, larger and potentially higher severity fires that result in simplified forest complexity or non-forest vegetation that is more likely to continue burning with high severity fires into the future (Odion et al. 2004).

\subsection{Current Conditions}

The United States has a policy of wildland fire suppression reaching back well over 100 years, into the late decades of the 1800's, beginning with early fire suppression efforts in Yellowstone during the formative years of the National Park concept (Agee 1974). Events of the early 1900's, including the formation of the US Forest Service under direction of Gifford Pinchot and the massive fires that swept the northern Rocky Mountains of the United States and Canada in 1910, solidified the policy of suppressing all wildfires, regardless of size and location (Pyne 1982). This policy was later formalized in 1935 with the implementation of the "10 am policy," which called for the control of any wildfire by 10 am the morning following its discovery (Pyne 1982). Though this culture began to slowly change in the 1960's and 1970's with the work of fire ecologists in the Sierra Nevada Mountains of California, fire suppression continues as a part of wildland fire management throughout the United States today (Carle 2002).

The results of the many decades of fire exclusion in many ponderosa pine and mixed conifer forests of the western US are elevated fuel loads and increased stand densities (Jenkins et al. 1998) that have the potential to create large, damaging fires that destroy forest resources and threaten property (Keane et al. 2002; Taylor and Skinner 2003; Agee and Skinner 2005; Stephens and Ruth 2005). Along with the increase in fuel loading and subsequent fire danger, more and more people are choosing to move into 
rural wildlands, increasing the area of the fire prone land included in the wildland-urban interface (WUI) (Butler 1974 In Cohen 1999; Nowak et al. 2005). The WUI is any area where vegetation with the potential to experience wildfire is in close proximity to manmade (urban) structures and facilities. The increased danger from wildfire and the increase in human interactions in the wildland has led to the need for land managers across the United States to look for ways to mitigate the danger and return the land they manage to a state where wildfires are smaller, less destructive and pose a reduced threat to life, property and resources (Reinhardt et al. 2008). One of the most common ways to manage the increase in fuels is with fuel reduction treatments that remove burnable vegetation (Reinhardt et al. 2008).

\subsection{Fuel Treatments}

Fuel is defined as the live and dead vegetation present in the wildland, and a fuel treatment as any action designed to alter this fuel to reduce some aspect of fire behavior (National Wildfire Coordinating Group 2011). Described generally, the goal for fuel treatments is to reduce fire intensity, rate of spread or any other measurable variable in order to reduce risk to lives, property and resources. Fuel treatments often facilitate either suppression activities or restore habitats to conditions that resemble a pre-European settlement state (Reinhardt et al. 2008). Wildland fuels are distributed in multiple layers, ranging from the forest floor to the forest canopy, and fire can occur in one or more of these layers (Agee 2002; Graham et al. 2004). The goal of any fuel treatment is to alter one or more of these layers of fuel. Often fuel treatments remove the middle layers of vegetation, referred to as ladder fuels, thereby reducing the likelihood of a fire on the 
forest floor from 'climbing' into the canopy of the trees, where it is more likely to kill trees and spread at a rapid rate (Graham et al. 2004; Agee and Skinner 2005; Reinhardt et al. 2008). When attempting to alter forest fuels, three methods are generally employed, either individually or in combination: prescribed fire, mechanical thinning and mastication.

\subsubsection{Prescribed Fire}

Prescribed fire is the practice of igniting fires intentionally, under predetermined conditions, with specific goals. There are two main goals, and often prescribed fire is used with the intent of reaching a combination of the two: reducing accumulated vegetation to limit the intensity of subsequent wildfires, and restoring forest structure and health to conditions similar to those prior the era of fire exclusion (Weaver 1943; Sackett 1975; van Wagtendonk 1996; Miller and Urban 2000; Agee and Skinner 2005).

A prescribed fire's ability to achieve these goals is tied to the timing of the fire, the structure of the forest prior to the implementation of the treatment, and the weather conditions at the time of the fire (Sackett 1975; Miller and Urban 2000). If a prescribed fire is implemented at too high a humidity level, poor fuel consumption occurs and goals for fuel reduction are not attained. If a prescribed fire is implemented when weather is too dry or windy, consumption rates are too high and the result can be greater than intended mortality of larger trees as well as an increased likelihood of an unintended wildfire (Sackett 1975).

Prescribed fire has the ability to alter multiple layers of fuel within the treatment area, with the strongest influence usually being on surface fuels such as down and dead 
logs, leaf litter and herbaceous fuels (van Wagtendonk 1996; Stephens and Moghaddas 2005; Vaillant et al. 2009). The reductions in fuels from prescribed fires has been shown to reduce the risk of crown fire, both in simulations (Stephens 1998; Stephens and Moghaddas, 2005; Finney et al. 2007; Vaillant et al. 2009; Large 2010; Hamma 2011) and in actual fires that have burned through prescribed fire treatments (Pollet and Omi 2002; Agee and Skinner 2005; Murphy et al. 2007). Prescribed fire achieves this by limiting flame lengths, fireline intensity, fuel bed continuity, and spread rates, all of which reduce the heat transmitted to the canopy, which subsequently reduces the likelihood of crown fire (Sackett 1975; van Wagtendonk 1996; Stephens 1998; Graham et al. 2004; Stephens and Moghaddas, 2005).

If intense enough, prescribed fire can also alter the lower layers of ladder fuels, including shrubs, small trees and the lower branches of larger trees (Miller and Urban 2000; Graham et al. 2004), but does not usually alter these layers as much as other mechanical thinning methods (Vaillant et al. 2009). By altering these fuel layers prescribed fire treatments have been shown effective at reducing scorch height and reducing tree mortality (Martinson and Omi 2003) These activities serve to protect large overstory trees and can result in a return to stand structure that mimics pre-suppression conditions (Miller and Urban 2000; Ritchie et al. 2007).

Prescribed fire can also be combined with other treatment types (van Wagtendonk 1996; Stephens 1998; Pollet and Omi 2002; Ritchie et al. 2007) or used multiple times (Finney et al. 2007) to achieve desired stand conditions. Doing so can closely mimic historical fire regimes that had relatively frequent fires (Jenkins et al. 1998; Martinson and Omi 2003). Because vegetation grows back after a fire, repeated prescribed fires act 
to maintain treatment effectiveness over an extended period of time (Agee and Skinner 2005).

\subsubsection{Mechanical Thinning}

Mechanical thinning is the process of removing live vegetation with some sort of tool or machinery (Graham et al. 1999; Graham et al. 2004). The principle of thinning is based on established methods in silviculture, where the goal is to influence the growth of merchantable timber in some way. As a fuel treatment, thinning is the removal of vegetation with the goal of reducing measureable fire behavior parameters, increasing efficacy of fire suppression or protecting ecosystems and habitats from unnaturally severe fires (Stephens 1998; Graham et al.1999). I distinguish thinning here from mastication in that thinning involves cutting trees in a way that resembles a timber harvest (though commercial value is not explicitly included) and mastication involves a shredding or chopping of material in a way that does not resemble a commercial timber operation.

Graham et al. (1999) identified 5 main types of thinning operations that can alter species composition, fuel arrangement, wind, and moisture in ways that alter fire behavior: thin from below, thin from above, selection thinning, free thinning, and mechanical thinning. All of these thinning types can be done at various intensities and each has a varied set of impacts on the stand structure and potential fire behavior (Graham et al. 1999). With combinations of these 5 thinning types, all layers of the forest structure can be affected (Stephens 1998; Graham et al. 1999).

Typically, thinning removes midstory vegetation, raising the height of crown bases and removing suppressed trees (Stephens 1998; Graham et al. 1999). This moves 
the stand composition towards larger diameter trees, resembling a pre-suppression composition (Miller and Urban 2000; Martinson and Omi 2003). Thinning smaller trees is common because it offers the largest reduction in fire behavior for a given cost (Hugget et al. 2008). This type of mechanical thinning reduces the amount of fuel in the midstory and increases the space between surface fuels and canopy (crown) fuels, reducing the likelihood of a fire transitioning from the surface to the crowns of overstory trees (Stephens 1998; Graham et al. 1999; Agee 2002). Removal of overstory trees is another thinning method, called thin from above or crown thinning. Crown thinning can reduce crown fire potential by increasing the spacing between trees (Agee 2002). This can prevent a single tree torching from becoming a running crown fire (Graham et al. 1999)

Thinning is not without drawbacks, however. Removing the midstory can result in increased wind speed as the spacing between trees increases (Rothermel 1983). Thinning can also result in an increase of surface fuels if the slash from the thinning operation is not removed from the stand (Graham et al. 2004; Agee and Skinner 2005; Vaillant et al. 2009). This increased wind and surface fuel load can result in a more intense, faster moving surface fire after treatment. However, if the crown height was increased and midstory (ladder) fuels were removed sufficiently, flame lengths and likelihood of a crown fire can still be reduced (Graham et al. 1999; Vaillant et al. 2009).

A method for mitigating the potential increase in fire behavior resulting from treatments is combining thinning treatments with a slash reduction method to prevent the increased surface fuel load from influencing a future wildfire. This can be accomplished with a prescribed fire following the thinning (Graham et al. 1999; Agee and Skinner 
2005; Ritchie et al. 2007), piling and burning the slash (Johnson and Peterson 2005), removal of the slash at the time of the thinning (Graham et al. 2004), or a lop and scatter process that reduces the size of slash fuels and spreads them out, preventing pockets of heavy fuel loading (Stephens 1998; Agee and Skinner 2005). These combinations reduce the surface fuel, limiting the increased flame lengths that would result if left untreated after a mechanical thinning treatment. In simulations, the most effective thinning treatments appear to be those combined with a slash treatment, such as prescribed fire (Stephens 1998; Stephens and Moghaddas 2005). Further research where wildfires have burned through thinning treatments has shown that those combined with a slash treatment were more effective at protecting large trees and maintaining intact stands after the passage of wildfires (Agee and Skinner 2005).

By creating stands with reduced crown fire potential, thinning can be used to return forest structure to a pre-fire suppression condition (Stephens and Moghaddas 2005). This increases the stands resiliency to future fire and reduces the mortality of overstory trees in future wildfires. By reducing fire intensity and tree mortality (Martinson and Omi 2003), thinning can improve fire suppression efforts and ecosystem health (Agee 2002; Agee and Skinner 2005).

\subsubsection{Mastication}

Mastication is a type of mechanical fuel treatment that uses either a rotary chopping head (usually mounted on a tracked vehicle with a boom arm) or a drum chopping device to alter surface and mid-story (ladder) fuels (Kane et al. 2006; Reiner and Decker 2009). These methods alter the fire behavior in the stand by moving fuel from 
the mid-story to the surface and significantly altering the size composition of surface fuels (Knapp et al. 2008; Kane et al. 2009). Mastication can be used independently (Reiner and Decker 2009; Reiner et al. 2009; Kane et al. 2009) or it can be used in combination with other mechanical treatments or prescribed fire (Stephens and Moghaddas 2005; Reiner et al. 2009; Reinhardt et al. 2010) to achieve alterations in future fire behavior.

The removal of vegetation from the mid-story and placing it on the surface increases the available fuel for a surface fire to consume (Reiner et al. 2009). With the larger surface fuel load, the residence time during a post mastication fire may be higher with larger amounts of heat released (Busse et al. 2005). The increased heat and residence time may result in greater overstory tree mortality when a masticated stand experiences fire (Varner et al. 2007). Mastication also reduces the fuel bed depth by eliminating the lower shrubs (live and dead standing ladder fuels) (Reiner et al. 2009), and by compacting the surface fuel (Knapp et al. 2008; Kane et al. 2009). Reducing fuel bed depth lowers surface fuels away from the crowns of the overstory trees, reducing flame length and limiting potential for future crown fires (Reiner et al. 2009). The composition of the surface fuel in a masticated fuel bed is skewed towards the $1-\mathrm{hr}(<0.64 \mathrm{~cm}$ diameter) and 10-hr (0.64 - $2.54 \mathrm{~cm}$ diameter $)$, fuel classes, with a much smaller percentage in the 100-hr (2.54 cm diameter) and greater fuel classes (Brown, 1974; Kane et al. 2006; Knapp et al. 2008; Reiner and Decker 2009).

Mastication also alters the overall shape and surface area-to-volume ratio of surface fuels. The shredding action of mastication equipment fragments woody surface fuels, moving the general shape of fuels from being round to more rectangular in cross 
section (Kane et al. 2009). This limits the ability of managers to use standard fuel loading measurement techniques, such as the planar intercept method, that assume a circular cross section of the surface fuels (Brown 1974). The surface area-to-volume ratio of fuels in a masticated treatment is much greater than it was prior to the treatment (Kane et al. 2009). The combination of size alteration and increase in surface area-to-volume ratio can increase fire behavior (Rothermel 1972; 1983). Time since mastication also appears to be a significant factor in the overall composition of masticated fuel beds, with influences on fire behavior diminishing with age (Reiner and Decker 2009). Given the combination of high surface fuel loading and compacted fuel bed, current standard fuel models do not model the behavior of fire in masticated fuels and custom fuel models are required (Kane et al. 2006; Knapp et al. 2008; Reiner and Decker 2009).

Fire behavior in masticated fuel beds is generally characterized by lower flame lengths (and subsequently lower scorch heights and reduced overstory mortality) and slower rates of spread, due in large part to their compact nature and the reduction of ladder fuels (Kane et al. 2009; Reiner and Decker 2009). However, the fireline intensity and residence time can increase due to the increased surface fuel loading, compacted arrangement of particles, and the increased surface to volume ratio (Busse et al. 2005; Kane et al. 2009; Reiner and Decker 2009; Reiner et al. 2009). The reduction in ladder fuels resulting from a mastication treatment can also increase the wind speed required to initiate and sustain crown fire activity (Stephens and Moghaddas 2005). Differences in fire behavior appear to be due to the size and shape alterations of the fuel, not to alterations in moisture/drying time in masticated fuels. Drying time and moisture retention do not appear to be affected by mastication (Knapp et al. 2008). However, the 
moisture content of masticated fuels does appear to influence the effects a post-treatment fire will have on surrounding vegetation. In all but the driest soils, masticated fuels do not appear to generate heat sufficient to impact soil roots and organisms, alleviating fears of more severe soil heating resultant from longer fire residence times (Busse et al. 2005; Knapp 2008).

\subsubsection{Stand Scale}

Most fuel treatments in the past have been implemented at the stand scale, treating a relatively homogeneous section of forest with the same treatment type and intensity. A large body of work on stand-scale fuel treatments exists, demonstrating their ability to reduce fuel loading (Sackett 1975; Stephens 1998; Vaillant et al. 2009; Large 2010; Hamma 2011), limit initiation of crown fires (Martinson and Omi 2003; Murphy et al. 2007; Vaillant et al. 2009), and slow rates of spread (Stephens 1998; Vaillant et al. 2009). These treatments can also restore areas to a pre-suppression condition and improve the ecological state of the stand (Agee 2002; Graham et al. 2004; Stephens and Moghaddas 2005).

Stand scale treatments are also important for protecting discrete resources adjacent to high risk forest stands. In particular, locating treatments near WUI developments can limit fire spread and make protecting homes and property easier for firefighting resources (Murphy et al. 2007). Embers are also an important threat to homes in the WUI and treating stands adjacent to the WUI zone can reduce the impact heat and embers have on home loss (Cohen 1995; Cohen 2000; Murphy et al. 2007). 


\subsubsection{Landscape Scale}

As large fires increase in size, become more frequent, and increase in severity in the western United States (Westerling et al. 2006; Keane et al. 2008), it has become more important for land managers to consider the amount and arrangement of treatments across large landscapes in addition to the type of treatment that they plan to implement (Agee and Skinner 2005). Landscape-scale fuel treatments treat a large number of stands across a given landscape, and are designed to protect that landscape as a whole, not one specific resource or location (Finney 2001; Stratton 2004; Schmidt et al. 2008; Ager et al. 2010b).

Placing a series of treatments across a landscape to limit fire risk (Scott 2006) and fire size can be done in a number of ways (Schmidt et al. 2008; Ager et al. 2010b). Possible methods for treatment location include random, spatially-optimized for reducing rate of spread, and site-specific. A site-specific placement design is tailored to a particular landscape and resembles the traditional USFS defensible fuel profile zone (Schmidt et al. 2008). Other methods include prioritizing stands based on fire risk or present tree density (Ager et al. 2007; Ager et al. 2010b). Of these, simulation studies indicate that spatially-optimized treatments are the most effective at reducing fire size and spread rate (Finney 2001; Schmidt et al. 2008). However, there are numerous constraints and limitations to implementing spatially-optimized treatments, which range from physical limitations to complex government regulations that make implementing purely spatially-optimized treatments essentially impossible (Collins et al. 2010). The result is that treatments often do not fully resemble spatially-optimized designs. Fortunately, modeling studies suggest that other landscape-scale fuel treatment designs can limit fire growth and reduce overall burn probability (Ager et al. 2007; Finney et al. 
2007; Ager et al. 2010b; Moghaddas et al. 2010). In fact, including landscape-scale treatments can help to make individual stand treatments more effective at limiting fire behavior (Stephens 1998).

Also important in the design and implementation of landscape-scale fuel treatments is timing (Agee and Skinner 2005; Finney et al. 2007). Fuel treatments alter vegetation and the vegetation eventually recovers to pre-treatment levels if the treatments are not maintained. Finney et al. (2007) used a complex modeling study to demonstrate that rotating treatments throughout the landscape can generate cumulative effects that benefit the entire landscape, even when treating a relatively small portion of the landscape each year.

\subsection{Carbon and Fire}

Regardless of one's personal belief in the impacts increased atmospheric carbon dioxide has on climate, it is undeniable that carbon has become an important topic and area of concern for people in the United States and across the globe. Trends in carbon trading and offset sales indicate that people care about this issue, and that economic pressure has begun to influence the way businesses approach carbon (Hamilton et al. 2007).

Forests offer an attractive source of potential carbon offsets because wood nearly $50 \%$ of the mass of wood is carbon (Boerner et al. 2008; Tao and Allen 2010). Forests of the United States are also an attractive target for carbon storage because it appears that they have lost close to $50 \%$ of their carbon storage in the late $20^{\text {th }}$ century when compared with the amount of carbon they stored in 1700 (Houghton and Hackler 2000). 
Not only this, but recent years have shown a recovery of forest carbon stocks, but the levels have not yet come close to recovering to 1700 levels (Houghton and Hackler 2000).

Given the possible role of forests in carbon storage, and the growing economic interest in carbon, forest managers are beginning to assess how their management practices influence carbon storage (Seely et al. 2002). In this way, forests may prove to be a benefit to those interested in reducing atmospheric carbon (Tavoni et al. 2007).

In the Western United States, fire is one of the major disturbances that influence forests and forest growth. Because of this, fire has always been a concern for land managers. However, the emerging concern over carbon complicates the issue, because fire has the potential not only to destroy the forests themselves, but it removes the carbon stored in vegetation and releases it into the atmosphere through smoke and gas emissions (Kasischke et al. 2005; Schultz et al. 2008). However, one of the most commonly used methods for reducing the severity of fires is fuel treatment (Murphy et al. 2007; Reinhardt et al. 2008), which alters vegetation and therefore has the potential to alter carbon cycles (Boerner et al. 2008; Large 2010; Hamma 2011). This leaves land managers with a paradox, needing to maintain a balance between immediate carbon losses resulting from the fuel treatment and future carbon losses from potential wildfires (Hurteau and North 2010).

Current simulations suggest that alterations in short-term carbon emissions and long-term carbon storage do occur following fuel treatments (Hurteau and North 2009; Large 2010; Reinhardt and Holsinger 2010; Hamma 2011; North and Hurteau 2011), with the effects dependent upon the ecosystem and treatment type (Reinhardt et al. 2010; 
Wiedinmyer and Hurteau 2010; Hurteau et. al. 2011). Studies in multiple forest types suggest that fuel treatments with combinations of prescribed burning and mechanical thinning do remove significant amounts of carbon from a stand, either through emissions or harvesting (Finkral and Evans 2008; Hurteau and North 2009; North et al. 2009; Stephens at el. 2009; Ager et al. 2010a; Tao and Allen 2010). However, the same fuel treatments also reduce the amount of carbon predicted to be lost in a wildfire by reducing the fuel available to burn (Hurteau et al. 2008; Wiedinmyer and Hurteau 2010), as well as reducing the severity of potential fires, thus further limiting carbon losses during a fire event (Finkral and Evans 2008; Hurteau and North 2009; North et al. 2009; Stephens at el. 2009; Hurteau and North 2010). One such study indicates that if harvested wood products are placed in long-term use, mechanical thinning in dry forest types can result in a net carbon storage increase (Finkral and Evans 2008). Another study indicates maximum carbon storage is reached when a stand is altered to mimic pre-European settlement, with large fire-resistant pines and a more open stand structure (Hurteau and North 2010). Returning stands to pre-European settlement condition is often a result of fuel treatments, which improve the retention and protection of large trees during post treatment wildfire events (Stephens et al. 2009; Ager et al. 2010b). Improved carbon storage resulting from stand conditions dominated by large trees compliments results that suggest large carbon losses results from overstory thinning used as a means of increasing crown spacing (North et al. 2009; Hurteau and North 2010). The weakness of many of these studies is that they look at present storage or sequestration rates and do not include a long-term component (Stephens et al. 2009; Ager et al. 2010a; Tao and Allen 2010). 
One study did include a long-term projection but did not account for probabilistic future wildfire events (Hurteau and North 2009).

In many locations, the need for fuel treatments to reduce severity of wildfires is a result of fire exclusion and a resulting buildup of fuels (Jenkins et al. 1998, Keane et al. 2002, Taylor and Skinner 2003; Agee and Skinner 2005; Stephens and Ruth 2005). The result is a carbon stock that is higher than historical levels and may not be sustainable (Hurteau et al. 2011). In this situation, it may be best for land managers to accept a shortterm carbon loss from fuel treatments in order to reduce the risk of a catastrophic wildfire. This would not maximize the carbon stored by a forest but would create a more stable, sustainable level of carbon than was present in the forest with higher carbon levels (Hurteau and Brooks 2011).

A final advantage that fuel treatments may have for carbon retention in a forest setting is the long-term carbon loss induced from decomposition of trees killed in a wildfire. As mentioned previously, fuel treatments have the ability to reduce tree mortality during a wildfire event (Stephens et al. 2009). This reduction in mortality will reduce the long-term carbon lost to the atmosphere through decomposition of a large number of trees simultaneously (North and Hurteau 2011).

\subsection{Simulation Modeling}

Because of the time and spatial scales involved, research in forestry and wildland fire management often requires the use of sophisticated modeling techniques. When conducting stand level research, temporal and spatial limitations are lower, as multiple stands can be treated and monitored in order to compare various treatments in a replicated 
study (Stephens 1998; Large 2010; Hamma 2011). However, at the landscape scale, the temporal and spatial limitations prevent a replicated study (Stratton 2006). It would not be possible to treat a landscape multiple times and subject it to wildfire each time to see how the treatments perform. Even less practical would be growing a forest for 50 years in the same location multiple times, under variable treatment scenarios, in order to determine how the treatments affect the growth of the forest. Overcoming the spatial and temporal limitations requires the use of simulation modeling, which requires the acceptance of a large number of assumptions, but is the only tool available (Stratton 2006).

The type of model used in any given situation is dictated by the needs of the user and can range from stand by stand simulations of fire behavior and fire effects in models such as BehavePlus (Heinsch and Andrews 2010) and FOFEM (Reinhardt et al. 1997), to large-scale predictive models that generate fire growth patterns and predict fire behavior in programs such as FARSITE (Finney and Andrews 1998) and FlamMap (Finney 2006). These models are used primarily to inform decision making in the absence of our ability to see into future (Finney 2004). They can be used in live fire situations to make real time decisions regarding suppression activities (FARSITE, FsPro) or to determine the best method for reducing fuels and limit future fire danger (FARSITE, FlamMap) (Andrews and Queen 2001). Simulation models predict the short and long-term outcomes of decisions regarding fire and fuels management. The outputs of the models allow managers to compare potential outcomes for fuel levels and fire behavior over a specified time frame (Andrews and Queen 2001; Finney 2004). 
In order to develop simulation models, simplified versions of actual conditions have been created to represent the complex nature of actual conditions. Many of the simulation models require simplified inputs that describe the fuels that can carry fire. These inputs are referred to as fuel models, which have standardized values for arrangement and amount of fuel for specific fuel types (Anderson 1982; Andrews and Queen 2001; Scott and Burgan 2005). Another set of simplified inputs for many fire models are weather and fuel moister values. These are often derived through the use of tools such as FireFamilyPlus (Rocky Mountain Research Station Fire Lab and Systems for Environmental Management 2002) that compile historical weather data from remote weather stations and report data in terms of percentage of the time weather meets or exceeds certain temperatures, winds speeds and wind directions.

Not only are the inputs for the models simplifications, the models themselves simplify the behavior and effects of fire by using equations developed to generalize fire behavior. Rothermel's (1972) models for computing fire spread rate are the classic simplification of fire spread in a mathematical equation and are still used today in numerous fire modeling programs such as BehavePlus and FARSITE (Andrews and Queen 2001). Other simplified spread models exist, including modeling fire spread as a wave front using Huygens' principle and modeling the spread of fire as an elliptical wave front, as is done in some portions of the FARSITE and FlamMap models (Finney 2002; Finney 2006; Finney 2007).

Though fire simulation models have been improved and validated since the first ones were developed in the 1970's (Andrews and Queen 2001), the results do not perfectly predict actual fire behavior. The results differ from the actual outcomes for 
various reasons, including the simplification and assumptions inherent in each model, unpredicted changes in weather in the field and human error in recording input observations. However, the process can be continually improved with validation against field observations and revisions to model designs (Andrews and Queen 2001).

\subsubsection{FVS-FFE}

The Forest Vegetation Simulator (FVS) is a growth and yield model available from the US Forest Service (Dixon 2002). FVS simulates changes to overstory vegetation for a given stand during a time frame specified by the user. FVS also provides the user with the capability to manipulate vegetation in order to simulate management activities at any point during the specified time frame (Dixon 2002). The FVS software program uses input data collected from actual trees in the field, alters each individual tree based on user specified activities, and reports multiple growth and volume related outputs (Teck et al. 1996). The input trees are used to represent an entire stand and FVS reports values in terms of unit per area (i.e. board feet per acre). FVS adjusts growth based on the specific variant for different geographic areas and specific species within each geographic variant of the model (Dixon 2002).

The FVS model includes a number of useful extensions, which enable it to do more than just report timber volumes and growth rates. One of these is the Fire and Fuels Extension (FFE) (Rebain 2010). This extension uses many of the same fire spread equations (Rothermel 1972) as other fire modeling packages (e.g. BehavePlus) in order to produce linkages between stand management activities and potential short-term and longterm fire behavior (Rebain 2010). This is important for understanding how fuel 
treatments alter future fire behavior (Finney 2004). The FFE extension also includes carbon reports, which inform land managers about the carbon accumulated or lost over time through management actions and wildfires at the point in time specified by the user. FVS-FFE carbon reports are limited to carbon in woody material and do not include soil carbon pools other than roots of live and dead trees. Even with the soil carbon limitation, FVS-FFE is approved as a growth and yield model for carbon calculations by the Climate Action Reserve (Climate Action Reserve 2009).

A relatively major assumption in the FVS-FFE model is the way in which it accounts for herbaceous and understory plants (Rebain 2010). The model was designed as a growth and yield model for timber calculations (Dixon 2002), and as such, the required inputs and the majority of the calculations omit the understory vegetation. The FFE extension does account for the understory vegetation in smoke emissions, but not in the growth portion of the model. When FFE burns these layers in a fire simulation, it assumes that they return to the stand in the next cycle of the simulation (Rebain 2010). FVS-FFE is also because it is based solely on the standard fuel models (Anderson 1982; Scott and Burgan 2005) and not actual fuels. This is important because fuel treatments can create slash at levels not included in any of the standard fuel models (Johnson and Peterson 2005). Because of this, accurate fire behavior calculations often require alteration of the standard fuel models (Collins et al. 2010; Ager et al. in press).

\subsubsection{FlamMap}

FlamMap is a landscape scale fire modeling software package that is extremely useful for comparing treatment alternatives and their resulting alterations in fire behavior 
(Stratton 2004; Finney 2006). FlamMap is a raster based system that requires inputs formatted as a grid (30 m x $30 \mathrm{~m}$ cells for example) and calculates fire behavior outputs, such as flame length and fireline intensity, for each cell across a given landscape. Users must input a grid with fuel model, elevation and aspect values assigned to each cell. The user must also input values for wind speed, wind direction, temperature, and fuel moisture (Finney 2006).

The gridded outputs of FlamMap can easily be saved in formats available for importing into ArcGIS (ESRI 2009; Finney 2006; Ager et al. in press), allowing them to be used in a wide variety of mapping and management activities (e.g. fuel treatment placement and prioritization; Noonan 2003; Davis and Miller 2004). FlamMap is particularly useful for comparisons between scenarios on a landscape because it does not alter wind, weather, and moisture parameters, but instead holds these factors constant and calculates fire behavior parameters for the entire landscape being investigated (Finney 2006). This allows the user to input several landscape scenarios in succession and compare the outputs for each (Stratton 2004). FlamMap is also useful for identifying the need to implement some sort of treatment on an untreated landscape. Given a landscape and specific weather conditions, FlamMap can indicate where extreme fire behavior is likely to occur and thus aid a land manager in prioritizing treatment locations (Noonan 2003).

FlamMap includes another tool that calculates fire spread rates, called the Minimum Travel Time (MTT) algorithm. The MTT concept uses the underlying fire behavior data created in the basic FlamMap simulation to create a lattice across which the fastest spread paths of fire are calculated. These paths are then used to calculate elliptical 
growth patterns of a fire, accounting for wind and slope (Finney 2002). This tool can be used with a single ignition to generate a fire growth pattern under constant weather and wind input by the user or random ignitions can be selected to generate a burn probability for each pixel on the landscape (Finney 2006). Just as with other FlamMap outputs, the calculations for this tool are cell by cell, and the fire behavior in any cell (including spread rate across the cell) is independent of fire behavior in adjacent cells (Finney 2006). This cell independence is a limitation of the model because fire behavior at a given location is regularly influenced by adjacent locations.

The final tool in the FlamMap program is the Treatment Optimization Model (TOM). Given constant wind, weather, and moisture parameters, the TOM uses the MTT algorithm to calculate arrival time contours and the paths where fire can move fastest across the landscape (Finney 2002; Finney 2004; Finney 2006), and then places treatments to optimally reduce the overall landscape rate of spread (ROS) of a fire given the area treated (Finney 2007). The TOM requires the user to input two separate sets of raster data. The first is untreated, where the fuel model attributes of the raster represent present conditions. The second, called the ideal, has the fuel model attributes of the raster modified to represent a fuel treatment in all possible locations a fuel treatment could be placed. The TOM calculates the arrival contours and flow paths for both rasters and selects the locations from the ideal raster that maximize reductions in ROS on the untreated landscape (Finney 2007). The program iterates through creating flow paths/arrival contours and placing treatments until it treats a percentage of the landscape defined by the user (Finney 2006; Finney 2007). Placing treatments in the path of a fire slows the heading spread of a wildfire so that the time to burn through a treatment unit 
equals the time to flank around a treatment unit, thereby reducing the fire's ROS (Finney 2001; Finney 2007). The reductions in ROS are most effective when a sufficient percentage of the landscape is treated to allow for some overlapping of treatment units in the direction of the spread of the fire, eliminating corridors where fire does not encounter a treatment unit (Finney 2001). This tool is useful for managers seeking to place treatments across a landscape to limit the growth of large fires moving in an anticipated direction (dictated by the wind input) without planning for a specific ignition point (Finney 2006).

\subsubsection{Randig}

Randig is a command line version of FlamMap developed by Mark Finney (USDA Missoula Fire Science Laboratory). Randig uses the same MTT algorithm as FlamMap to generate fire sizes and pixel by pixel burn probabilities for a specified number of random ignitions given a specified simulation length (duration in minutes) and user-defined weather conditions (Ager et al. 2010b). Studies that use this modeling software to develop a burn probability grid for an entire landscape often calibrate the duration of the burn period against existing burn period distributions on real fire events in

the study area (Ager at al. 2006; Ager et al. 2010b; Collins et al. 2011). Randig also calculates the flame length for every pixel each time it experiences a fire. These values can be used to calculate a conditional flame length that represents the average flame length for each pixel when it experiences fire, independent of the probability of that pixel burning (Ager et al. 2010b). 
The usefulness of this program is its ability to calculate large area burn probabilities and conditional flame lengths with user-defined parameters for burn period while allowing variations in weather. The MTT tool in FlamMap does not allow for variations in weather and bur period even when used with multiple random ignitions. The burn probability output from Randig can be used as an initial measure of the success of fuel treatments when the program is run with a treated and an untreated landscape (Ager et al. 2006; Ager et al. 2010b). It can also measure the length of time treatments produce effects by simulating repeatedly over time in conjunction with a growth model such as FVS (Collins et al. 2011). The burn probability output can be used as a probabilistic framework to predict future fire risk and the effects future fires have on variables ranging from forest growth to carbon sequestration (Ager et al. 2010a). The flame length outputs can be used to indicate immediate post treatment risk, danger to resources, or risk to adjacent WUI communities (Ager et al. 2010b). 


\subsection{Impacts on carbon loss and storage from varied landscape-scale fuel treatment strategies}

\subsection{Introduction}

Fuel reduction projects alter vegetation in order to reduce fire behavior and losses and are a common and proven means for protecting wildland-urban interface (WUI) communities and forest resources in the western US (Stephens 1998; Stratton 2004; Agee and Skinner 2005; Schmidt et al. 2008). A large body of work on stand-scale fuel treatments exists, demonstrating their ability to reduce fuel loading (Sackett 1975; Stephens 1998; Vaillant et al. 2009; Large 2010; Hamma 2011), limit initiation of crown fires (Martinson and Omi 2003; Murphy et al. 2007; Vaillant et al. 2009), and slow rates of spread (Stephens 1998; Vaillant et al. 2009). However, reducing wildfire risk is a landscape issue (Reinhardt et al. 2008; Collins et al. 2010) and less work exists quantifying the impacts of landscape-scale fuel treatments. Existing work suggests that the treatment type, spatial arrangement, and intensity (percentage of the landscape treated) play a role in the effectiveness of landscape-scale fuel treatments (Stratton 2004; Ager et al. 2007; Finney et al. 2007; Schmidt et al. 2008; Ager et al., 2010b; Moghaddas et al. 2010). Modeling suggests that landscape-scale fuel treatments are most effective at limiting wildfire impacts when placed in spatially-optimized patterns focused on reducing a fire's forward rate of spread (ROS) (Finney 2001; Schmidt et al. 2008). However, land management restrictions and topographic features across much of the fire prone forests in the Western United States make treatments spatially-optimized for ROS reduction impractical, typically resulting in site-specific fuel treatment designs, each tailored to an individual landscape. 
In contrast to the benefits they potentially provide, fuel treatments can also carry adverse ecological impacts, especially with respect to carbon through alterations in forest productivity (Tiedemann et al. 2000). Because the vegetation altered by fuel treatments can store up to half of the carbon on a landscape (Boerner et al. 2008), fuel treatments have the potential to alter short-term carbon loss and long-term onsite carbon storage (Dicus 2009; Dicus et al. 2009; Large 2010; Hamma 2011). These alterations in carbon dynamics are of growing concern in the fire management community because of the potential to influence global climates and the potential financial implications of developing carbon markets (Westerling et al. 2006; Hamilton et al. 2007; Mignone et al. 2009). Stand level simulations suggest that alterations in short-term carbon emissions and long-term carbon storage do occur following fuel treatments (Hurteau and North 2009; Large 2010; Reinhardt and Holsinger 2010; Hamma 2011; North and Hurteau 2011), with the effects dependent upon the ecosystem and treatment type (Reinhardt et al. 2010; Wiedinmyer and Hurteau 2010; Hurteau et. al. 2011). Existing work documenting similar alterations to carbon loss and carbon storage resulting from landscape-scale fuel treatments is limited but does indicate that landscape-scale fuel treatments can alter shortterm carbon loss, though the results appear mixed depending on the type of treatment modeled and whether or not the model included post treatment wildfires. These previous simulations are confined to density dependent thinning treatment designs (Ager et al. 2010a), fire hazard assessments on individual stands across a landscape scale (Huggett et al. 2008) and large-scale prescribed fire simulations that do not include spatial placement of treatments (Wiedinmyer and Hurteau 2010). These studies lack a comparison of carbon accounting between spatially-optimized treatments designed to reduce fire ROS 
and site-specific designs, focus on one treatment type, and only one included potential future wildfires in carbon emissions and carbon storage calculations (Ager et al. 2010a).

To investigate the influence landscape-scale fuel treatment strategies have on carbon dynamics, I selected a fire-prone 42,000 ha landscape in northern California that is the subject of a landscape-scale fuel reduction project proposed by the Klamath National Forest. Specifically, the forest has proposed a site-specific landscape level fuel treatment project (not spatially-optimized for ROS reduction) for the Eddy Gulch Late Successional Reserve (LSR) (USDA Forest Service, DoI, Bureau of Land Management, 1994) to protect critical habitats and adjacent WUI communities (Figure 3.1), making this landscape an ideal study site (USDA Forest Service 2010). The presence of site-specific treatment prescriptions and spatial arrangements for the Eddy Gulch LSR provided a location to compare the impacts of site-specific landscape-scale fuel treatment scenarios and spatially-optimized treatment scenarios on potential carbon loss and carbon storages. 


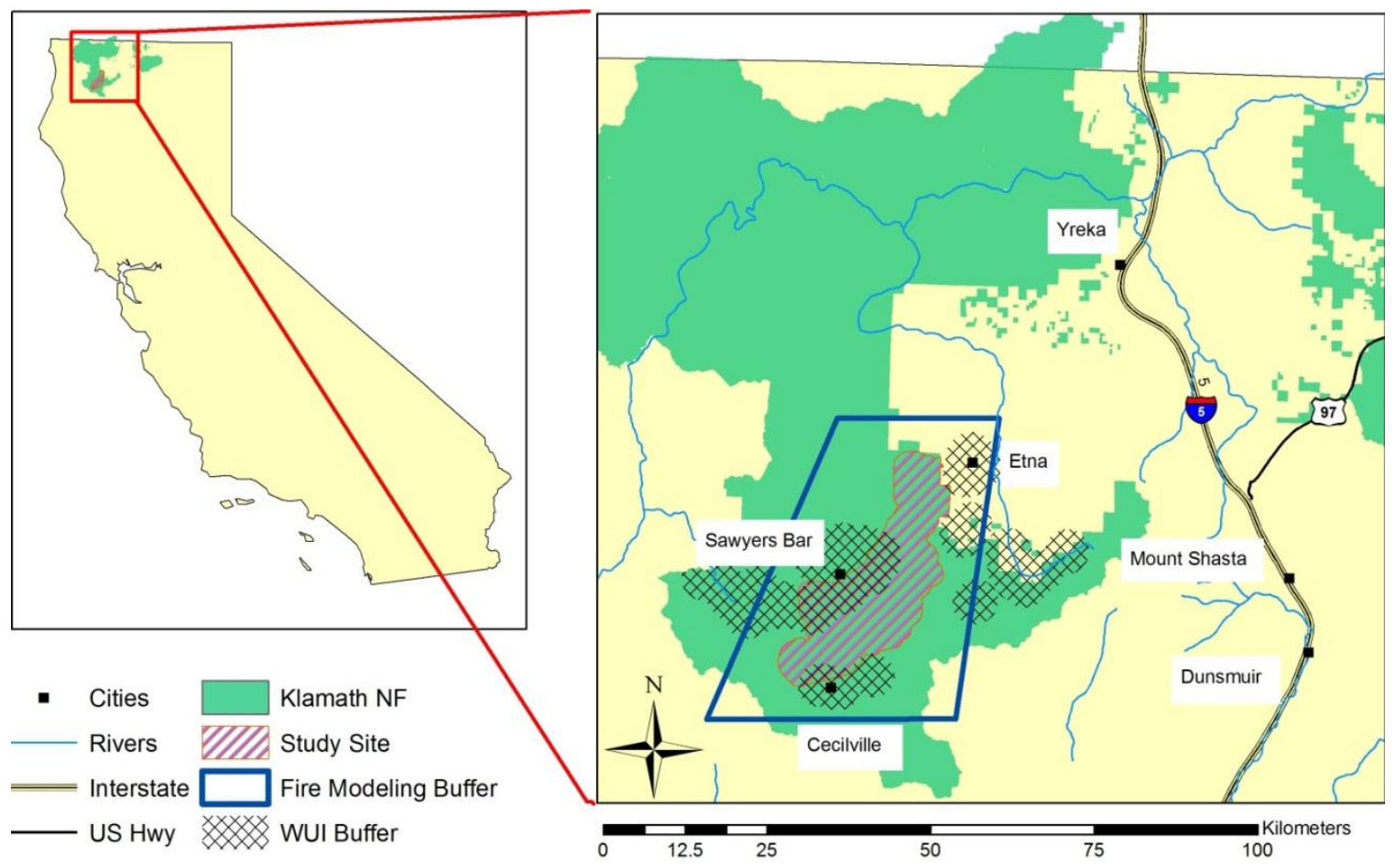

Figure 3.1 Location of the study site, larger buffer used in fire modeling simulations, and adjacent WUI communities.

I compared the onsite short-term carbon loss (5 years) and long-term onsite carbon storage (50 years) on an untreated landscape to three site-specific treatment scenarios and nine treatment scenarios spatially-optimized for ROS reduction. I derived the three site-specific scenarios from the Eddy Gulch project proposal, and then developed spatially-optimized designs that consisted of three treatment types (prescribed fire, mastication, and thin + burn), at three treatment intensities $(10 \%, 20 \%$ and $30 \%$ of the landscape treated). To understand the long-term effectiveness of treatments, I used simulation modeling to estimate burn probability for each post-treatment scenario. I then assumed wildfires would burn areas of the landscape that had an average burn probability above a designated a cut-off. In contrast to previous work, I incorporated probabilistic wildfire modeling into carbon loss and carbon storage calculations. The inclusion of 
multiple treatment types in site-specific and spatially-optimized arrangements, along with the probabilistic wildfire model, allowed me to analyze the interaction of spatial arrangement and treatment type on short-term carbon loss and long-term onsite carbon storage at the landscape-scale.

\subsection{Methods}

\subsubsection{Study site}

The 42,000 hectare study site (Figure 3.1) included the Eddy Gulch LSR and a surrounding buffer on the Salmon River Ranger District, Klamath National Forest, Siskiyou County, California (123 4.72 W 411554 N). Elevation within the area ranges from approximately $300 \mathrm{~m}$ to $2,500 \mathrm{~m}$, with the steep terrain crossed by numerous ridges and creeks (USDA Forest Service 2010). Climate in the area is Mediterranean, with hot, dry summers and cool, wet winters. A strong precipitation gradient dominates from west to east due to the influence of the Pacific Ocean (Skinner at al. 2006; Agee 2007).

Vegetation consists largely of multi-layered, multi-aged forests. Douglas-fir (Pseudotsuga menziesii Mirb.) and ponderosa pine (Pinus ponderosa C. Lawson) in association with Pacific madrone (Arbutus menziesii Pursh) and other understory evergreens shrubs dominate at lower elevations. Douglas-fir, white fir (Abies concolor Gord. \& Glend.), and red fir (Abies magnifica A. Murray) dominate at higher elevations where moisture is more abundant (Taylor and Skinner, 1998). Incense cedar (Calocedrus decurrens Torr.), sugar pine (Pinus lambertiana Douglas), and Jeffrey pine (Pinus jeffreyi Balf.) can occur across all elevations and specific site distributions are highly 
influenced by elevation and site moisture levels (Taylor and Skinner 2003; Skinner et al. 2006).

Reported historic mean fire return intervals in the Klamath mountain region is 12 years, with the majority of the fires occurring in the summer months (Skinner and Taylor 2003). However, due to fire exclusion in the previous century, fire return intervals have increased to an average of almost 22 years (Taylor and Skinner 1998; Taylor and Skinner 2003). Lightning ignitions are common in the Klamath region and account for the majority of the acres burned (Skinner et al. 2006). Though fire intensity is usually low to moderate due to frequent high pressure inversions, more intense fire behavior can occur during the passage of frontal systems (Skinner et al. 2006).

In many regions of the western US with understory and mixed-severity fire regimes, fire exclusion has lengthened the mean fire return interval (Mohr et al. 2000), resulting in a buildup of fuels (Jenkins et al. 1998), thus increasing the fire danger to adjacent communities and critical habitat. This is the case in the Eddy Gulch LSR, as indicated by the increase in the fire return interval (Taylor and Skinner 1998; Taylor and Skinner 2003). At present as much as $73 \%$ of the area within the LSR is at risk for passive or active crown fire activity under extreme weather conditions (USDA Forest Service 2010). Crown fire across such a high percentage of the LSR would remove a large portion of the large trees that provide habitat for late successional species such as the spotted owl, and act as a large pool of carbon storage (Hurteau et al. 2011). The potential for large scale loss (Keane et al. 2002; Stephens and Ruth 2005) is the impetus for the Forest Service's proposed project in the LSR and other landscape-level fuel reduction programs. 


\subsubsection{Landscape data + Treatment Scenarios}

I assessed 13 fuel treatment scenarios, including an untreated scenario, three scenarios derived from the Forest Service proposal (USDA Forest Service 2010) and nine spatially-optimized treatment scenarios. Initial landscape vegetation data were derived from forest inventory and analysis (FIA) data for the Klamath National Forest. I obtained this vegetation data and accompanying GIS stand layers from the USFS Region 5 Remote Sensing Lab (RSL) (USDA Forest Service 2009). The RSL also provided a digital elevation model (DEM), fuel model data, and GIS vegetation attribute layers (canopy base height, crown bulk density, crown height, and height to live crown). I used the DEM to develop elevation, slope, and aspect layers. I then combined the FIA data, stand data, DEM layers, and vegetation attribute data to build an ArcFuels project (Ager et al. in press) within ESRI's ArcGIS software (V. 9.3.1; ESRI 2009). The ArcFuels extension streamlines fire and fuels analysis by integrating the Forest Vegetation Simulator (FVS) (Dixon 2002) and a number of fire modeling software programs within ArcGIS software (Ager et al. in press). I then used the ArcFuels project to build a GIS landscape that served as our untreated control landscape as well as the initial point for developing the 12 treated landscapes. 
A Site-specific Eddy Gulch Project Units
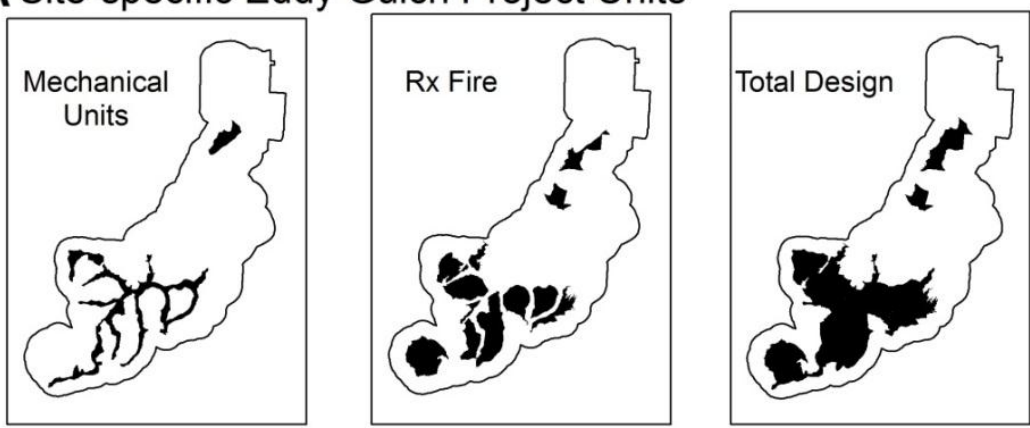

B Optimized Prescribed Fire Units
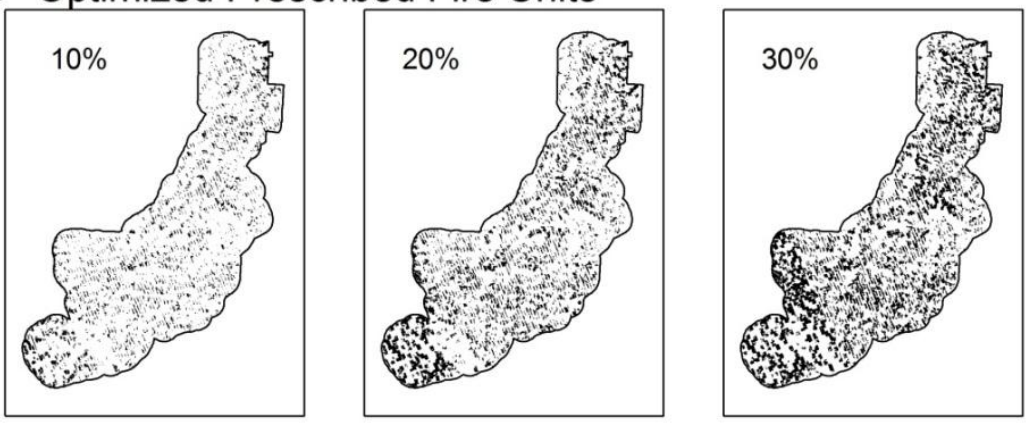

C Optimized Mastication Units
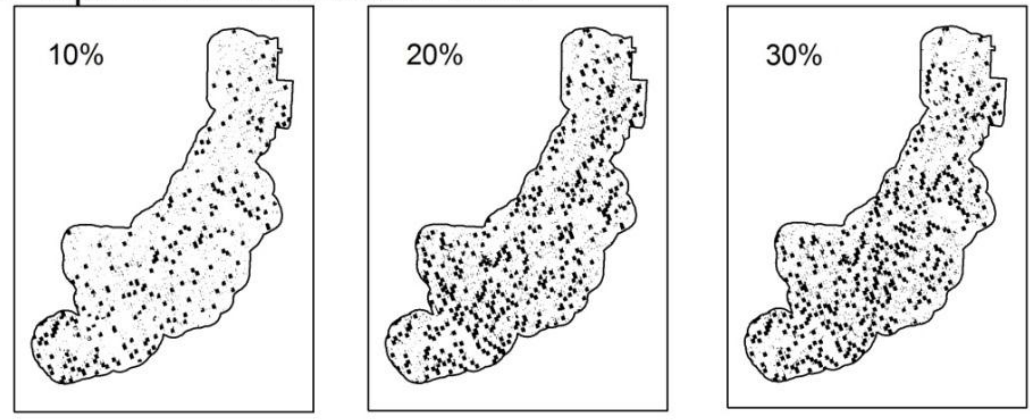

D Optimized Thin + Burn Units
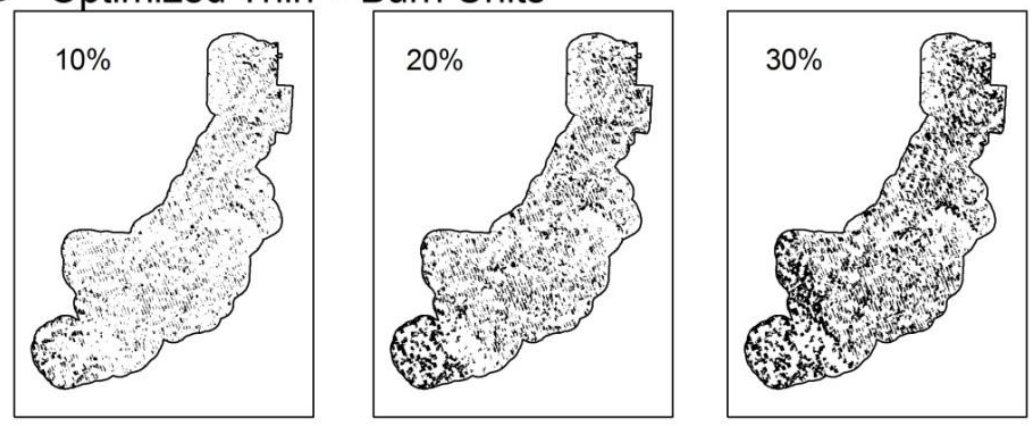

Figure 3.2 The 12 treatment scenarios within the project study site. Shaded areas represent treatment units. Part A represents proposed site-specific treatments. Mechanical units include mastication and thin + burn treatments and the total design includes all mechanical and prescribed fire units. Parts B, C and D represent spatially-optimized units developed with the Treatment Optimization Model. 
The site-specific fuel treatment proposal for the LSR is composed of mechanical units and prescribed fire units (Figure 3.2A; Table 3.1; USDA Forest Service 2010). The mechanical units, composed of thin + burn treatments and mastication treatments, were located along ridge tops and were intended to reduce fire spread across the landscape and provide locations suitable for fire suppression activities (USDA Forest Service 2010). Large prescribed fire units located primarily on south and southwest aspects were intended to reduce surface fuels and increase habitat resiliency to fire. These areas were those most likely to experience significant crown fire activity due to slope position, solar radiation, and wind alignment (Alexander et al. 2006; USDA Forest Service 2010). The proposal for the LSR also includes road side treatments designed for emergency access and improved suppression activities. However, these roadside treatments were not included in our analysis because they were not likely to directly influence landscape-scale fire growth patterns. Using the two categories of treatments (mechanical units and prescribed fire units), I derived three distinct site-specific landscape treatment scenarios (Figure 3.2A). The first site-specific treatment scenario was the mechanical units that included mastication treatments and thin + burn treatments, which covered the lowest percent of the study site (9\%). The second scenario was composed of the prescribed fire units, mostly on the south and southwest aspects, covering $17 \%$ of the study site. The final site-specific treatment scenario was the total design, including all mechanical and prescribed fire units, which covered the highest percent (26\%) of the study site (USDA Forest Service 2010). 
Table 3.1 Prescriptions for fuel treatments from the Eddy Gulch Project (USDA Forest Service, 2010) and subsequently coded in FVS key files.

\begin{tabular}{|c|c|}
\hline $\begin{array}{c}\text { Treatment } \\
\text { Type }\end{array}$ & Prescription \\
\hline $\begin{array}{l}\text { Prescribed } \\
\text { Fire }\end{array}$ & $\begin{array}{l}\text { Broadcast burning, ignited by hand or aerial ignition, would be } \\
\text { used to remove ground and small ladder fuels (less than } 4 \text { inches } \\
\text { dbh) and to achieve post-treatment flame lengths of less than } 2 \\
\text { feet, with fuel loads maintained to achieve flame lengths of less } \\
\text { than } 4 \text { feet over time. Implementation of prescribed burns would } \\
\text { not be consistent across each Rx Unit, but rather small patches of } \\
\text { heavier fuels would be maintained in burn areas. Burns may be } \\
\text { accomplished when air quality, weather, and fuel moisture } \\
\text { conditions could be met. }\end{array}$ \\
\hline Mastication & $\begin{array}{l}\text { Ground and ladder fuels (conifer trees up to } 10 \text { inches dbh) would } \\
\text { be masticated on slopes less than } 45 \% \text { with prescribed fire used to } \\
\text { reduce surface fuels on slopes greater than } 45 \% \text {. In TOM } \\
\text { scenarios only mastication treatments used, regardless of slope. }\end{array}$ \\
\hline Thin + burn & $\begin{array}{l}\text { Tree removal would thin from below, removing trees } 8-28 \text { inches } \\
\text { diameter at breast height (dbh). Following completion of } \\
\text { thinning, all slash would be broadcast burned. }\end{array}$ \\
\hline
\end{tabular}

I also created nine spatially-optimized fuel treatment scenarios utilizing the Treatment Optimization Model (TOM) within FlamMap (v 3.0) (Finney 2006; Finney 2007). These nine scenarios included three treatment types (prescribed fire, mastication, and thin + burn), each at a low, a medium, and a high intensity $(10 \%, 20 \%$, and $30 \%$ of the landscape treated, respectively). The percentage of area treated represented logical increases and closely matched the percentage of the landscape treated in each of the sitespecific treatment scenarios (Table 3.2). The treatment intensity levels also mirrored those used in previous work with landscape fuel treatment arrangements on the Klamath NF (Schmidt et al. 2008). Finney et al. (2007) also demonstrated that cumulative yearly benefits from spatially-optimized treatments reach a maximum at $30 \%$ treatment intensity. 
Table 3.2 Area attributes of fuel treatment each scenario. Area assigned wildfire based on burn probability cutoff value for the highest $1 / 3$ of the untreated landscape.

\begin{tabular}{lrrr}
\hline \multicolumn{1}{c}{ Scenario } & \% Area treated & Wildfire Hectares & Wildfire \% of Area \\
\hline Untreated & $0 \%$ & $14,194.14$ & $33.7 \%$ \\
Site-specific Treatments & & & \\
Mech. Units & $9 \%$ & $9,114.19$ & $21.6 \%$ \\
Rx Fire & $17 \%$ & $8,487.54$ & $20.1 \%$ \\
Total Design & $26 \%$ & $6,787.77$ & $16.1 \%$ \\
Spatially-optimized Rx Fire & & & \\
$10 \%$ & $10 \%$ & $12,318.38$ & $29.2 \%$ \\
$20 \%$ & $20 \%$ & 848.49 & $2.0 \%$ \\
$30 \%$ & $30 \%$ & 942.52 & $2.2 \%$ \\
Spatially-optimized Mastication & & & \\
$10 \%$ & $10 \%$ & $8,044.29$ & $19.1 \%$ \\
$20 \%$ & $20 \%$ & $1,951.60$ & $4.6 \%$ \\
$30 \%$ & $30 \%$ & $1,268.09$ & $3.0 \%$ \\
Spatially-optimized Thin + Burn & & & \\
$10 \%$ & $10 \%$ & $12,753.18$ & $30.2 \%$ \\
$20 \%$ & $20 \%$ & $4,471.11$ & $10.6 \%$ \\
$30 \%$ & $30 \%$ & 60.45 & $0.1 \%$ \\
\hline
\end{tabular}

To assign treatments across the landscape, the TOM compares fire behavior on two landscapes, an untreated and an ideal. The ideal landscape contains vegetation attributes altered to represent fuel treatments in all possible treatment locations (Figure 3.3). To generate our ideal landscapes, I used the FVS-Fire and Fuels Extension (FFE; Inland California variant) (Rebain 2010) within ArcFuels (Ager et al. in press) to implement treatment vegetation alterations in all stands within our study site. I did this for each treatment type (prescribed fire, mastication, and thin + burn), resulting in three ideal landscapes. The ideal landscapes used the same treatment prescriptions as the sitespecific treatment scenarios (Table 3.1). While creating the idealized treatments in FVSFFE, I determined that the post-treatment fuel models assigned by FVS-FFE did not represent reasonable post-treatment conditions (Collins et al. 2010; Large 2010; Ager et 
al. in press). To overcome this, I assigned fuel models to each stand based on pretreatment conditions and expected post-treatment conditions for each type of treatment (Fites-Kaufman et al. 2007), overriding the fuel models assigned by FVS-FFE. Table 3.3 illustrates the crosswalk of pre-treatment and post-treatment fuel models. Current standard fuel models do not accurately represent the fuel bed generated by mastication treatments, requiring the creation of a custom fuel model to represent post-treatment mastication units (Kane et al. 2006; Knapp et al. 2008; Reiner and Decker 2009). I based our custom mastication fuel model on an average of slash fuel models, as described by Knapp et al. (2008). 


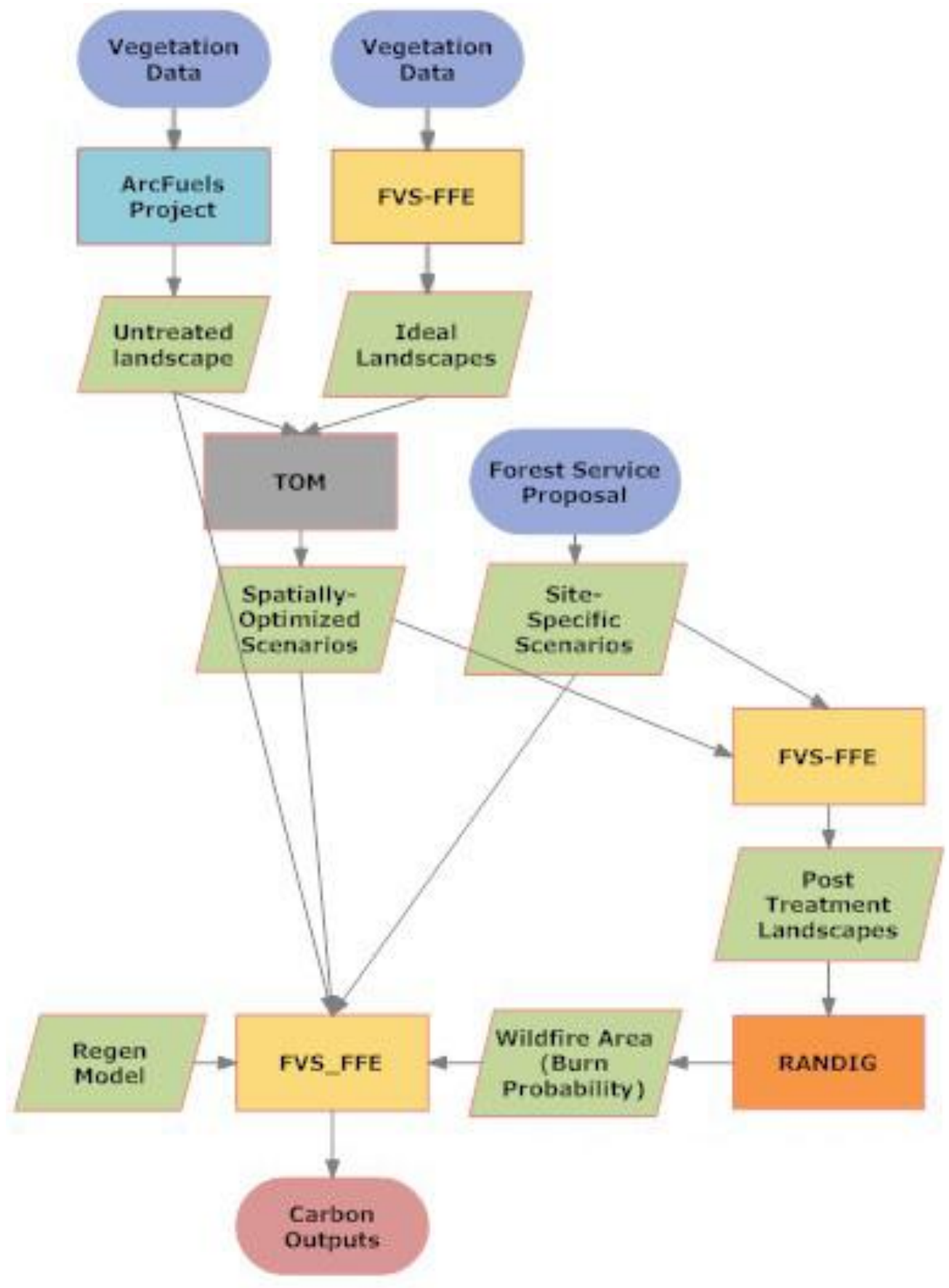

Figure 3.3 Flow chart representing the major processes and inputs used to generate the carbon reports for the treatment scenarios. 
Table 3.3 Fuel model crosswalk

\begin{tabular}{cccc}
\hline Pre-Treat Fuel Model & \multicolumn{3}{c}{ Post-Treat fuel Models } \\
& Prescribed Fire & Thin + Burn & Mastication \\
\hline 1 & 101 & 101 & 1 \\
5 & 121 & 121 & 14 \\
6 & 121 & 121 & 14 \\
11 & 201 & 201 & 14 \\
99 & 99 & 99 & 99 \\
102 & 101 & 101 & 102 \\
\hline 107 & 101 & 101 & 107 \\
121 & 101 & 101 & 14 \\
\hline 122 & 121 & 121 & 14 \\
141 & 121 & 121 & 14 \\
\hline 142 & 121 & 121 & 14 \\
145 & 121 & 121 & 14 \\
\hline 161 & 121 & 121 & 14 \\
165 & 161 & 161 & 14 \\
\hline 181 & 161 & 161 & 14 \\
182 & 181 & 181 & 14 \\
\hline 183 & 181 & 181 & 14 \\
\hline 184 & 181 & 181 & 14 \\
\hline 186 & 181 & 181 & 14 \\
\hline 188 & 183 & 183 & 14 \\
\hline 189 & 183 & 183 & 14 \\
\hline 202 & 183 & 183 & 14 \\
\hline 203 & 201 & 201 & 14 \\
\hline 203 & 201 & 201 & 14 \\
\hline & & & \\
\hline
\end{tabular}

FVS also required fuel moisture and weather conditions to simulate the prescribed fire and thin + burn treatments. I used FireFamilyPlus (v 4.1) (Rocky Mountain Research Station Fire Lab and Systems for Environmental Management 2002) and historical fire weather data from the Blue Ridge Remote Automated Weather Station (RAWS) to develop our fuel moisture parameters. Moderate values for wind and temperature were based on 20-year (1984 -2004) RAWS data for May through October, discussions with Klamath National Forest fire management staff, and values used by Large (2010), whose 
work was conducted in the Klamath Mountains (Table 3.4). The fuel moisture and weather parameter values used for prescribed fire simulations approximate the $50^{\text {th }}$ percentile level, which previous work has used to represent moderate fire behavior (Ager et al. 2010b; Large 2010). I also consulted local fire managers to match prescribed fire parameters with conditions under which they would consider prescribed fire operations (Table 3.4).

Table 3.4 Weather and fuel moisture variables used in fire simulations.

\begin{tabular}{|c|c|c|c|}
\hline Weather & & $\begin{array}{c}\mathrm{Rx} \text { fire }(50 \\
\%)\end{array}$ & Wildfire (97\%) \\
\hline Wind speed & $(\mathrm{Km} / \mathrm{h})$ & 16.09 & 48.28 \\
\hline Wind Direction & Azimuth & 238 & 238 \\
\hline Temperature & ${ }^{\circ} \mathrm{C}$ & 21.11 & 32.22 \\
\hline \multicolumn{4}{|l|}{ Fuel moisture } \\
\hline 1 -hour & $(\%)$ & 4 & 2 \\
\hline 10 -hour & $(\%)$ & 5 & 3 \\
\hline 100 -hour & $(\%)$ & 10 & 5 \\
\hline 1000-hour & $(\%)$ & 11 & 8 \\
\hline Duff moisture content & $(\%)$ & 30 & 10 \\
\hline $\begin{array}{r}\text { Live woody moisture } \\
\text { content }\end{array}$ & $(\%)$ & 77 & 70 \\
\hline Foliar moisture content & $(\%)$ & 100 & 80 \\
\hline
\end{tabular}

Given constant wind and moisture parameters, the TOM uses Finney's minimum travel time (MTT) algorithm to calculate arrival time contours and the paths where fire moves fastest across the landscape (Finney 2002; Finney 2004; Finney 2006), and then places treatments to optimally reduce the overall landscape ROS given the area treated (Finney 2007). The TOM calculates the arrival contours and flow paths for both landscapes and selects the locations from the ideal landscape that maximize reductions in ROS on the untreated landscape (Finney 2007). The program iterates through creating flow paths/arrival contours and placing treatments until it treats a percentage of the landscape defined by the user (Finney 2006; Finney 2007). Placing treatments in the path 
of a fire slows the heading spread of a wildfire so that the time to burn through a treatment unit equals the time to flank around a treatment unit, thereby reducing the fire's ROS.

The TOM assumed constant wind, weather, and fuel moisture parameters, derived from the same sources as the prescribed fire conditions, but at the $97^{\text {th }}$ percentile level (Table 3.4). I chose the $97^{\text {th }}$ percentile weather to represent an extreme fire event because the purpose of landscape level treatments, as described in the Eddy Gulch project, is to reduce the damage and spread of high severity fire events (USDA Forest Service, 2010). Previous studies have used this level of weather severity to represent the extreme wind, heat, and moisture conditions under which to expect high severity fire events (Schmidt et al. 2008; Ager et al. 2010b; Large 2010).

The FlamMap treatment location outputs created with the TOM were converted into ArcGIS raster files within ArcFuels. I then used these raster layers to assign treatments to stands based on the percentage of stands covered by treatment cells when I overlaid the stand polygon layer with a treatment raster. Any stand with at least $1 / 3$ of its area overlapped by treatment cells received the treatment for that scenario.

\subsubsection{Modeling Procedure}

I quantified the onsite short-term carbon loss and long-term carbon storage across the landscape for each treatment scenario using the carbon reports from FVS-FFE simulations. Each simulation used six 10 year cycles, for a total of 60 years. FVS-FFE converts live and dead biomass into carbon values using 0.5 as the multiplier and converts litter and duff to carbon with a 0.37 multiplier (Rebain 2010). I considered the 
onsite total stand carbon as the sum of the following carbon pools: aboveground live and dead, belowground live and dead, forest floor (litter and duff), herbs, shrubs, and dead/down woody debris. FVS-FFE also reported harvested carbon values, which I considered for this study as lost carbon and not part of onsite storage. The carbon reports also include carbon emissions due to fire (it does not distinguish between prescribed fire and wildfire), which I grouped with harvested carbon as the carbon lost from our site. FVS-FFE carbon reports do not include soil carbon pools other than roots of live and dead trees, and therefore soil carbon is not included in our carbon values. Even with the soil carbon limitation, FVS-FFE is approved as a growth and yield model for carbon calculations by the Climate Action Reserve (Climate Action Reserve 2009). To accurately model over such a long time period, I felt it important to include potential future wildfires and regeneration (which is not included in the FVS variant used in our simulations). I developed both a regeneration model and a procedure for assigning wildfire to areas of each landscape 5 years post-treatment. Figure 3.3 depicts the overall modeling procedure used to generate carbon reports from our initial vegetation data.

I developed the regeneration model using FIA seedling survey data to modify a simple regeneration model within ArcFuels (USDA Forest Service 2009; Ager et al. in press; M. Landram, pers. comm.). For each stand, I based the range of seedlings on the FIA plots taken in that stand's forest type and subsequently assigned a random number of seedlings from that range to each stand (Table 3.5). The random number was then partitioned by species based on the percentage of the stand occupied by that species in the previous FVS cycle. I included this model in all FVS cycles for each stand, resulting in an input of seedlings into all stands every 10 years. 
Table 3.5 Seedling data from FIA regeneration sampling in the Klamath NF. Range for each forest type is the mean number of softwood seedlings $+/$ - one half standard deviation for a range of one standard deviation.

\begin{tabular}{|c|c|c|c|}
\hline Klamath Forest Type & Mean Seedlings & & Range \\
\hline Alpine & 75 & 44 & -106 \\
\hline Douglas-fir & 260 & 173 & -347 \\
\hline Eastside Mixed Conifer & 1219 & 1077 & - 1361 \\
\hline $\begin{array}{l}\text { Productive Hardwoods } \\
\text { Non-Productive }\end{array}$ & 38 & 11 & -65 \\
\hline Hardwoods & 42 & 6 & -78 \\
\hline Jeffery Pine & 589 & 288 & -890 \\
\hline Knobcone Pine & 187 & 55 & - 319 \\
\hline Lodgepole Pine & $187^{\mathrm{A}}$ & 55 & $-319^{A}$ \\
\hline Westside mixed Confer & 399 & 153 & -645 \\
\hline Ponderosa Pine & 38 & 11 & -65 \\
\hline Red Fir & 262 & 111 & -413 \\
\hline Non-Forest & 0 & 0 & -0 \\
\hline White Fir & 429 & 236 & -622 \\
\hline Productive Shrub & $140^{\mathrm{B}}$ & 140 & $-140^{\mathrm{B}}$ \\
\hline Non-Productive Shrub & 54 & 34 & -74 \\
\hline
\end{tabular}

${ }^{\mathrm{A}}$ Lodgepole Pine forest type had no plots in the FIA data so seedling numbers from Knobcone pine were used because of similarity in cone type and seeding habit. ${ }^{\mathrm{B}}$ Productive shrub forest type had only one plot so no range of values could be created.

To incorporate future wildfire into the long-term FVS-FFE simulations, I used burn probability to represent areas with the highest chance of experiencing wildfire posttreatment. To accomplish this, a shorter 5-year FVS-FFE simulation was completed for each treatment scenario in order to represent immediate post-treatment conditions. Fuel model overrides used in creating idealized landscapes were also used to represent posttreatment fuel models in the treatment simulations (Table 3.3). Variables included in the output databases (canopy bulk density $\left(\mathrm{kg} \mathrm{m}^{-3}\right)$, height to live crown $(\mathrm{m})$, total stand height (m), canopy cover (\%), and fuel model) were then used to build $30 \mathrm{~m} \times 30 \mathrm{~m}$ raster files utilized in ArcFuels to build GIS landscape files representing post-treatment conditions for each scenario. 
I placed each post-treatment landscape into Randig, a command line version of FlamMap developed by Mark Finney. Randig uses the same MTT algorithm as FlamMap to generate fire sizes and pixel by pixel burn probabilities for a specified number of random ignitions. Like FlamMap, Randig uses a pre-determined burn period (duration in minutes.) and static weather conditions. Burn probability for each pixel (raster cell) of the study site was the number of times the pixel burned divided by the number of ignitions in the simulation $(10,000)$. The weather conditions for the Randig simulations were the same as the $97^{\text {th }}$ percentile weather used previously in FlamMap and FVS-FFE to represent probable weather conditions leading to an extreme fire event. Each ignition had a fixed duration, but Randig allowed for variation in duration between each ignition. Each specific simulation length was assigned a specified percentage of the simulated ignitions. I used burn periods ranging from 600 to 1100 mins. with 10,000 random ignitions in order to create a distribution of fire sizes that mirrored an observed distribution of extreme growth events (Figure 3.4). The observed distribution was derived from observed single-day fire growth events $>500$ ha in the Klamath Mountains from 2002 to 2008. I obtained this data from 209 reports for large fires, accessed via https://fam.nwcg.gov/fam-web/. The observed data included only $12 \mathrm{hr}$. daylight periods in order to limit the inclusion of overnight burnout operations that can artificially create large growth of wildfires. Large spread events due to burn-out operations during daylight may be included, but I had no way of determining when fire growth was attributable to suppression operations or to actual fire spread. Also, some large growth events (> 500ha) may not have been included because daily growth reports were only available when fires were managed by Type 1 or Type 2 Incident Management Teams. 


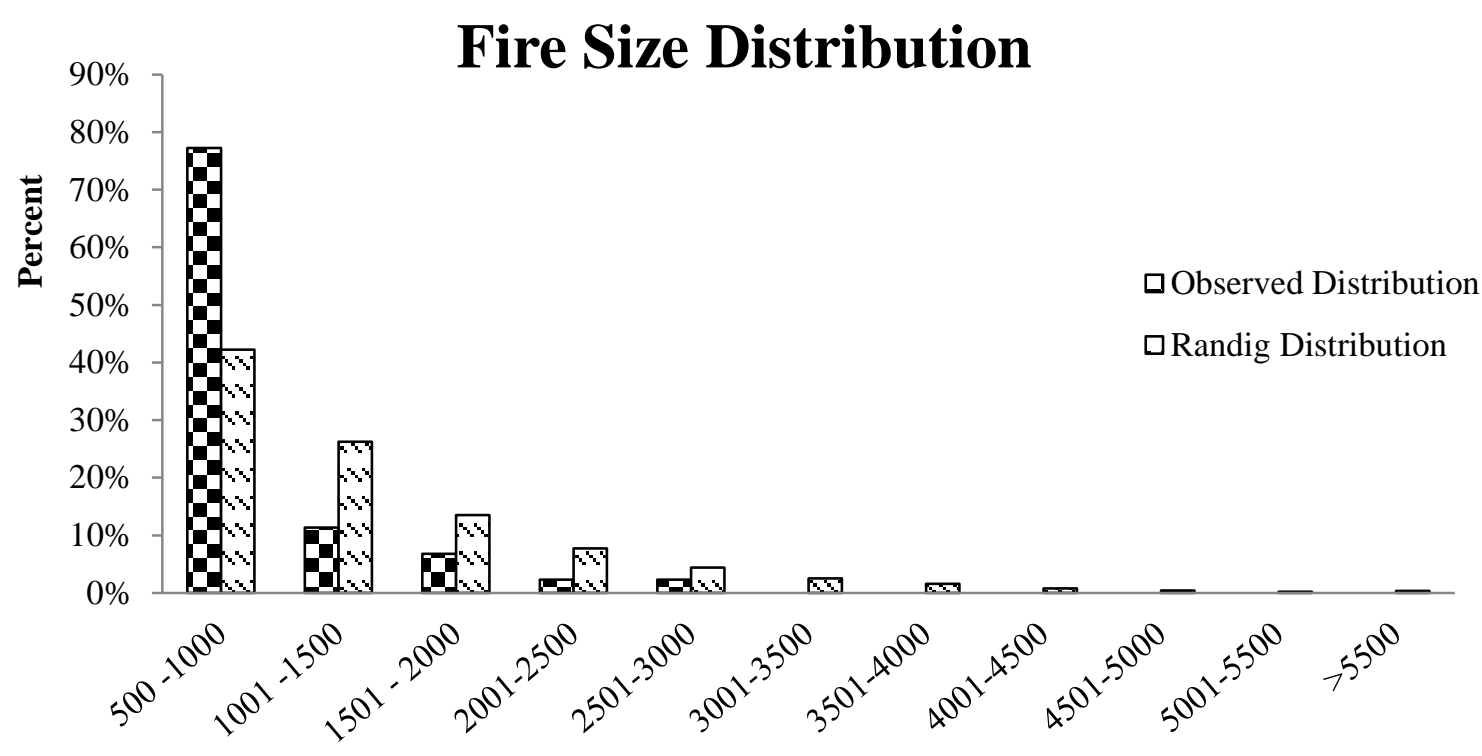

Fire Growth (ha)

Figure 3.4 Distribution of observed fire size vs. simulated fire sizes using 10,000 ignitions in Randig on an untreated landscape. Observed fires growth periods taken from daylight, single day, growth periods of fires in the Klamath Mountains from 2002 to 2008, representing 44 daily growth events over $500 \mathrm{Ha}$. I obtained observed daily growth records from 209 reports for large fires, accessed via https://fam.nwcg.gov/fam-web/.

The Randig simulations used a buffer larger than our actual study site (Figure 3.1) to eliminate edge effect within the study site. This large buffer allowed ignitions to fall outside of the study site and burn in, preventing the edges of the study site from experiencing artificially reduced burn probabilities.

The burn probability output from each Randig simulation was used to incorporate future wildfire occurrence into the long-term carbon simulations in FVS-FFE. Stands with a mean burn probability over 0.0067 were assigned wildfire. I chose this threshold based on the percentage of the untreated landscape (33.86\%) that received a wildfire assignment. This percentage fell within the range ( $1 \%$ to $66 \%$, median of $4.6 \%$ ) of annual area burned on a similar landscape in the Klamath Mountains (Taylor and Skinner in 2003). Table 3.2 shows the area assigned wildfire in each treatment scenario. Maintaining 
a fixed burn probability threshold reduced the amount of area assigned wildfire as the treatment intensity increased, accounting for the reduced fire risk associated with fuel reduction projects. Though the actual shape of the areas assigned wildfire may not precisely mirror the shape of wildfires, the areas with higher burn probability tended to be clumped, offering a general area of potential wildfire as opposed to individual pixels scattered across the landscape (Figure 3.5). The simulated wildfires occurred 5 years post-treatment to account for the range in which I expect treatments to be effective. Treatment effectiveness ranges from 2 to 5 years (van Wagtendonk 1987) for surface fuels, and up to nine years for the overall influence of individual treatments on fuel loading (Finney et al. 2005). Given this, simulating wildfires 5 years post-treatment was the maximum range at which surface fuels would be influenced by fuel treatments (van Wagtendonk 1987) and within the range of expected change of overall fire behavior due to treatments (Finney et al. 2005). 


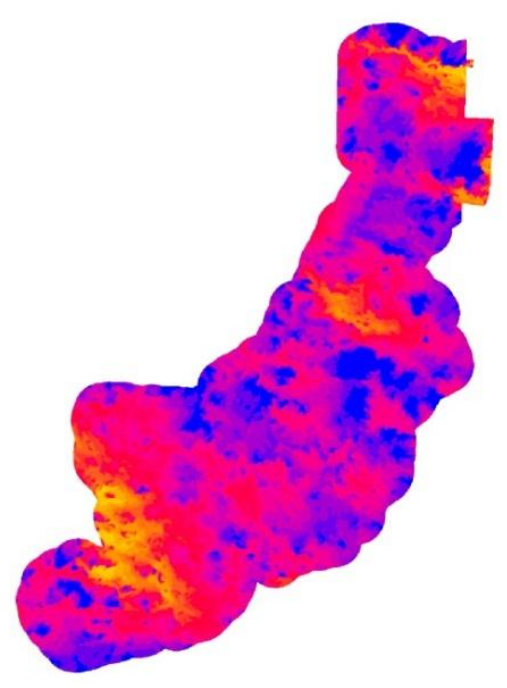

Burn Probability - Total Site-SpecificDesign

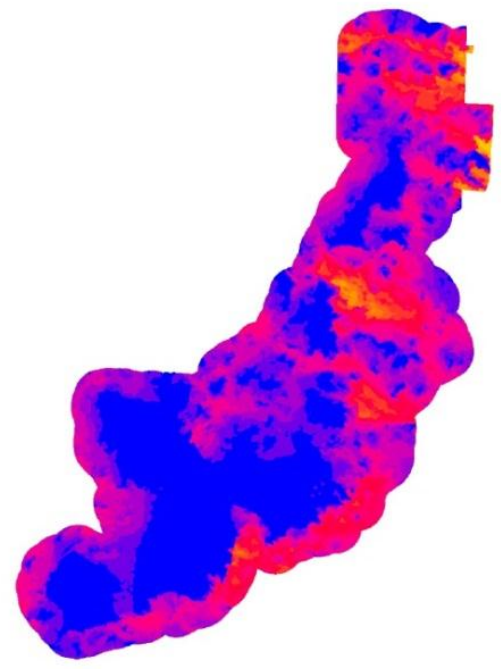

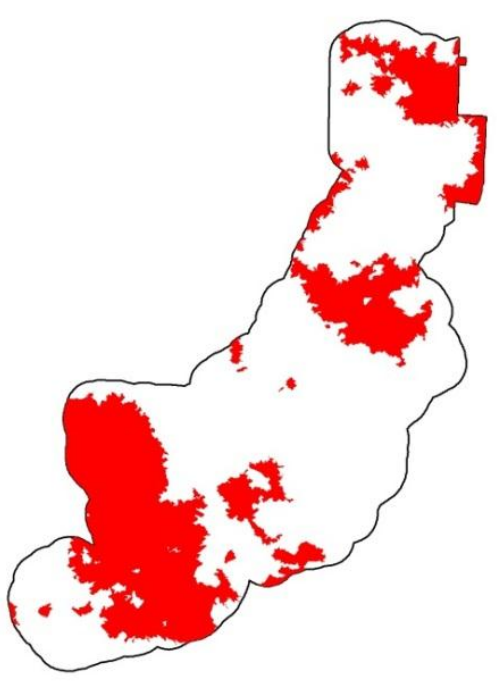

Wildfire Area - Total Site-SpecificDesign

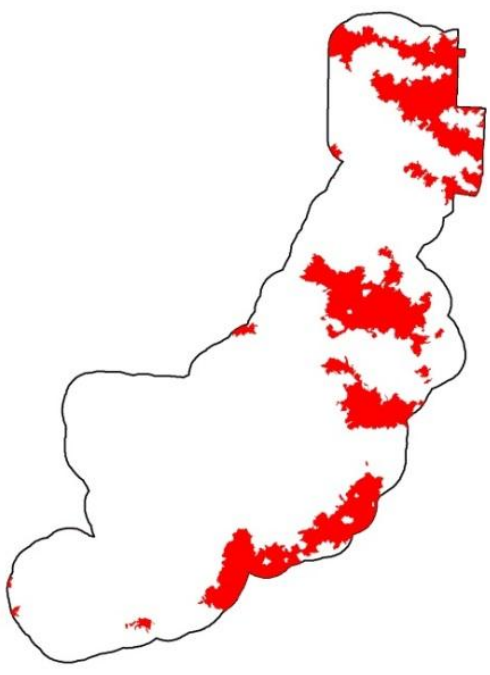

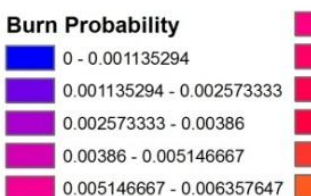

י

$0.006357647-0.007492941$ $0.007492941-0.008628236$ $0.008628236-0.00976353$ $0.00976353-0.01097451$ $0.01097451-0.012185491$ $0.012185491-0.013396471$
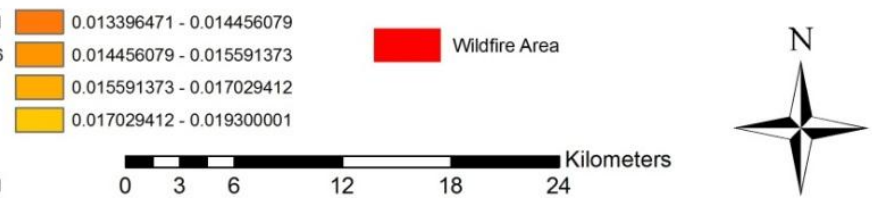

Figure 3.5 Burn probability (\# of times a pixel burned /number of ignitions) maps and corresponding areas assigned wildfire 5 years after simulated treatment for the untreated scenario and the total site-specific design. Areas receiving wildfire correspond to areas with a burn probability greater than or equal to $\mathbf{0 . 0 0 6 7}$. 
After assigning wildfire locations and creating the regeneration model, I completed a separate FVS-FFE simulation for each of the 13 scenarios (1 untreated, 12 treatment designs). These FVS-FFE simulations used the same weather conditions for prescribed fire $\left(50^{\text {th }}\right.$ percentile $)$ and wildfire $\left(97^{\text {th }}\right.$ percentile $)$ as previous simulations (Table 3.4). After completing the 13 FVS-FFE simulations, I used the FFE carbon report to compile short-term carbon loss from fuel treatments, short-term carbon loss from wildfire, and long-term carbon storage 50 years post-treatment for each treatment scenario.

Carbon loss and carbon storage in our work are considered as either short-term or long-term and are confined exclusively to the study site (thus, I did not account for offsite carbon storage from thinning in the present study). The short-term refers to carbon lost from fuel treatments and wildfires during the first 5 years post-treatment. Treatmentinduced loss was the carbon removed from the site either from prescribed fire carbon emissions or from thinning operations. Wildfire carbon loss was carbon lost as emissions from the wildfires I assigned to the landscape 5 years post-treatment. Long-term carbon storage in this study was the amount of onsite total stand carbon reported 50 years posttreatment and represented a snapshot of the total carbon at that specific point in time.

Statistical significance between treatments was precluded because the outputs represent the entire population. As a result, I compared outputs across the entirety of the population, not sample means with their associated statistical significance and errors. 


\subsection{Results}

With no treatment, the landscape did not experience short-term carbon loss from treatments, but lost $6.24 \mathrm{Mg} \mathrm{ha}^{-1}$ of carbon through wildfire emissions. Long-term storage on the untreated landscape was $386.35 \mathrm{Mg} \mathrm{ha}^{-1}$ of carbon at the end of 50 years (Table 3.6).

Table 3.6 Short-term carbon loss and long-term carbon storage values (Mg ha-1). Total carbon loss is the sum of carbon lost during treatments (from vegetation removal or prescribed fire carbon emissions) and carbon lost during a wildfire as smoke emissions.

\begin{tabular}{lcccc}
\hline \multicolumn{1}{c}{ Scenario } & $\begin{array}{c}\text { Treatment } \\
\text { Loss }\left(\mathrm{Mg} \mathrm{ha}^{-1}\right)\end{array}$ & $\begin{array}{c}\text { Wildfire Loss } \\
\left(\mathrm{Mg} \mathrm{ha}^{-1}\right)\end{array}$ & $\begin{array}{c}\text { Total Loss } \\
\left(\mathrm{Mg} \mathrm{ha}^{-1}\right)\end{array}$ & $\begin{array}{c}\text { Storage Yr. 50 } \\
\left(\mathrm{Mg} \mathrm{ha}^{-1}\right)\end{array}$ \\
\hline $\begin{array}{l}\text { Untreated } \\
\text { Site-specific }\end{array}$ & 0.00 & 6.24 & 6.24 & 386.35 \\
Treatments & & & & \\
Mech. Units & 1.76 & 4.06 & 5.82 & 366.93 \\
Rx Fire & 1.49 & 3.92 & 5.41 & 370.63 \\
Total Design & 3.25 & 3.20 & 6.45 & 369.22 \\
Spatially-optimized & & & & \\
Rx Fire & & & & \\
$10 \%$ & 0.79 & 4.98 & 5.77 & 362.55 \\
20\% & 2.17 & 0.36 & 2.53 & 397.06 \\
$30 \%$ & 3.64 & 0.42 & 4.07 & 387.65 \\
Spatially-optimized & & & & \\
Mastication & & 3.40 & 3.40 & 374.72 \\
$10 \%$ & 0.00 & 0.98 & 0.98 & 389.52 \\
$20 \%$ & 0.00 & 0.65 & 0.65 & 386.57 \\
$30 \%$ & 0.00 & & & \\
Spatially-optimized & & 5.15 & 8.63 & 356.04 \\
Thin + Burn & & 1.69 & 11.73 & 366.34 \\
$10 \%$ & 3.48 & 0.02 & 15.62 & 364.55 \\
$20 \%$ & 10.04 & & & \\
$30 \%$ & 15.62 & & & \\
\hline
\end{tabular}

As expected, increasing the amount of area treated reduced carbon emissions from wildfire, but increased onsite treatment-induced carbon loss. The relationships were not equal however. As the proportion of the landscape treated increased, the treatment- 
induced carbon loss grew more rapidly than decreases in carbon lost from wildfire emissions (Figure 3.6). This was true for all treatment types except spatially-optimized mastication treatments, which did not have any treatment-induced losses since they did not include thinning or prescribed fire. For all spatially-optimized treatment types, the long-term carbon storage increased from $10 \%$ of the area treated to the $20 \%$ of area treated, but then decreased from $20 \%$ to $30 \%$ of the area treated (Figure 3.7). Of the sitespecific treatments, the prescribed fire units, which treated the medium (17\%) percentage of the landscape, had the largest long-term carbon storage (Table 3.6).

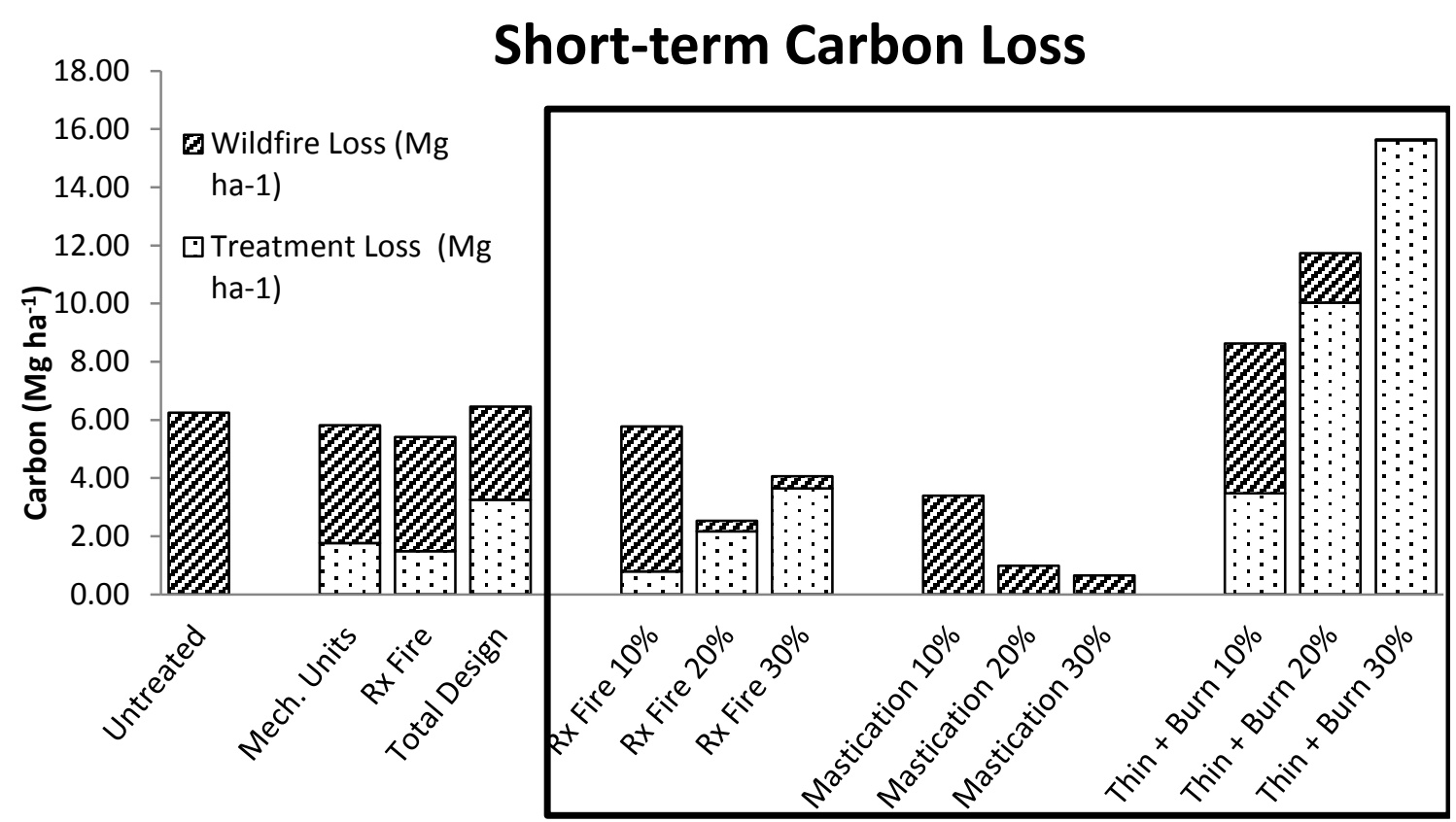

Figure 3.6 Onsite carbon losses $\left(\mathrm{Mg} \mathrm{ha}^{-1}\right)$ for each treatment scenario. Stacked bars for wildfire and treatment loss represent total onsite carbon loss for each scenario. Treatment losses include prescribed fire emissions and vegetation removed in thinning operations. Treatments inside the solid box are spatially-optimized; treatments outside the box are proposed site-specific treatments.

The proposed site-specific treatment designs showed a pattern of decreasing wildfire emissions with increasing treatment-induced loss. The total short-term carbon losses for the mechanical units and the prescribed fire units individually were $5.82 \mathrm{Mg}$ 
$\mathrm{ha}^{-1}$ and $5.41 \mathrm{Mg} \mathrm{ha}^{-1}$ of carbon respectively, both less than the untreated landscape. Total short-term carbon loss for the complete design was $6.45 \mathrm{Mg} \mathrm{ha}^{-1}$ of carbon, slightly larger than the untreated landscape (Table 3.6). Short-term carbon loss for the spatiallyoptimized treatments was highly variable and depended upon the treatment type and intensity (Figure 3.6). Of all spatially-optimized treatment designs, mastication at the $30 \%$ treatment intensity had the lowest short-term carbon loss $\left(0.65 \mathrm{Mg} \mathrm{ha}^{-1}\right)$ and thin + burn at the $30 \%$ treatment intensity had the largest short-term carbon loss $\left(15.72 \mathrm{Mg} \mathrm{ha}^{-1}\right.$; Table 3.6). All other spatially-optimized treatment types and intensity levels had shortterm carbon losses that fell between these two values.

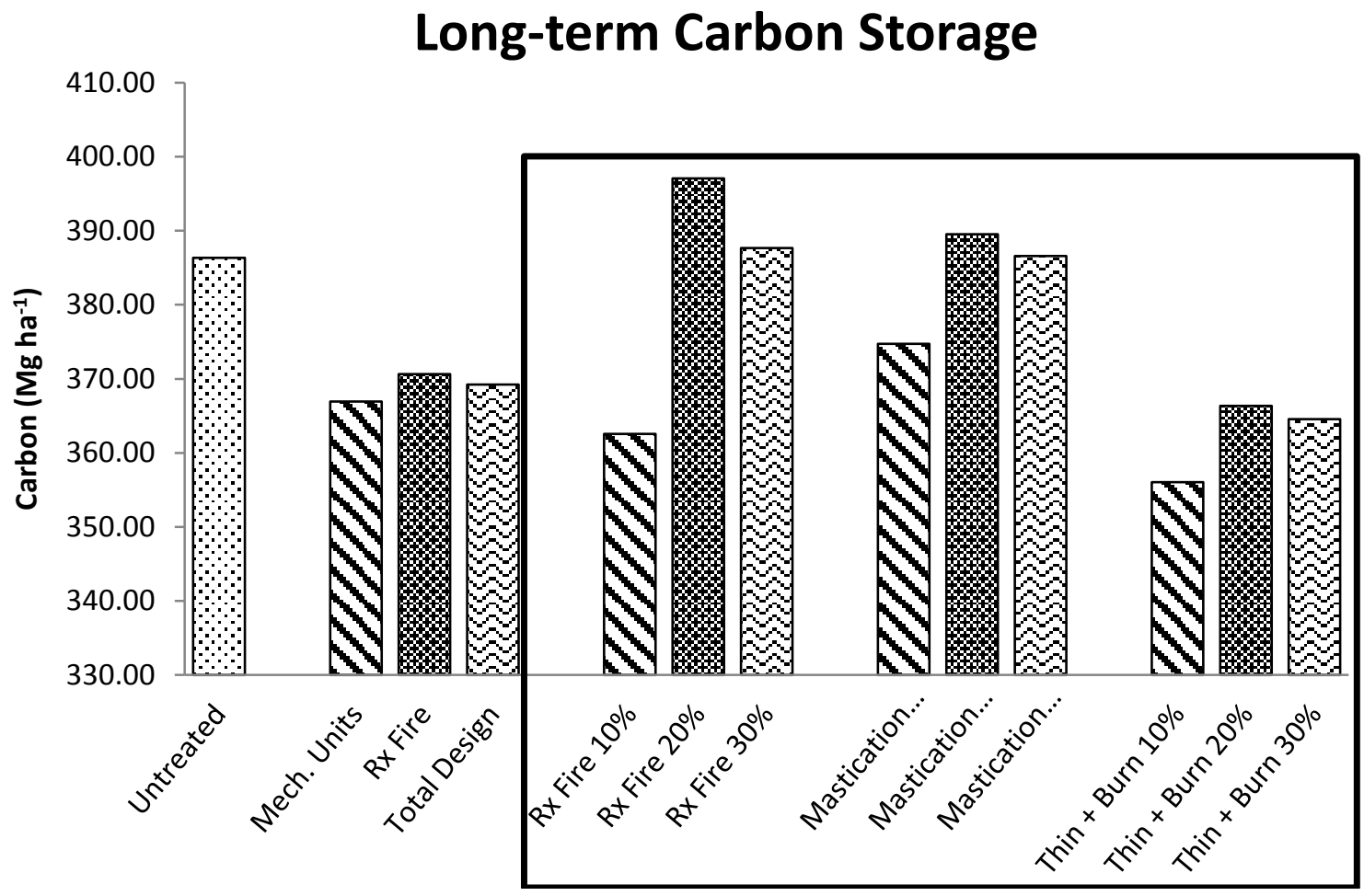

Figure 3.7 Onsite carbon storage $\left(\mathrm{Mg} \mathrm{ha}^{-1}\right)$ for each the untreated control scenario and for each treatment scenario. Treatment scenarios are grouped and each treatment intensity has a separate pattern to allow comparisons among treatment types and across treatment intensities (\% of landscape receiving treatment). Treatments inside the solid box are spatially-optimized; treatments outside the box are proposed site-specific treatments. 
The onsite long-term carbon storage of the three site-specific treatment scenarios was less than that of the untreated landscape, with the largest long-term carbon storage present in the prescribed fire only scenario (medium percent treated; $370.63 \mathrm{Mg} \mathrm{ha}^{-1}$ of carbon). All three spatially-optimized treatment types had a similar pattern of long-term carbon storage as the site-specific treatments, with the $20 \%$ treatment intensity (the medium intensity) storing the largest pool of carbon 50 years post-treatment (Figure 3.7). For the spatially-optimized treatments, the smallest long-term storage was with thin + burn at the $10 \%$ treatment intensity $\left(356.04 \mathrm{Mg} \mathrm{ha}^{-1}\right)$, which was less than the carbon stored on the untreated landscape. The greatest long-term carbon storage level was with prescribed fire at the $20 \%$ treatment intensity (397.06 $\mathrm{Mg} \mathrm{ha}^{-1}$; Table 3.6), larger than the amount of long-term carbon storage on the untreated landscape.

\subsection{Discussion}

The complex nature of modeling requires accepting a number of assumptions, including constant weather, a defined burn period, fire spread algorithm accuracy, and the accuracy of the growth and yield models. However, all the treatments were subject to the same assumptions, resulting in outputs that should be looked at as relative comparisons between treatments rather than precise predictive values. Our study site represents an individual set of fuel loading values, topographic features, and assumed weather parameters, and therefore our results may not be representative of all locations. However, the process utilized here could be utilized on other landscapes to determine the potential impacts varied landscape-scale fuel treatment scenarios have on onsite short-term carbon loss and long-term onsite carbon storage. 
In addition to the inherent assumptions of modeling, our procedure included an attempt to account for the fact that it is impossible to predict the size and location of future wildfires. I attempted to account for future fires using a conditional burn probability measure with sufficient random ignitions; however, if over the given time period more or less fires were to occur, the resulting carbon dynamics may differ from our predictions. Given the size of the landscape, it is a question that can never be answered fully as only one actual treatment scenario could be implemented at any point in time. The results here assume that treatments have no effect on fire frequency and that actual fire ignitions will be determined by factors outside of a land manager's control. Using sufficient random ignitions, I attempted to determine the best treatment alternative given any random ignition on the landscape, as well as those areas of the landscape most likely to experience fire given a random ignition. Though ignitions are often clustered, I was willing to accept such an assumption in order to maximize protection of all locations on the landscape.

Minimizing short-term carbon loss and maximizing long-term carbon storage are goals that land managers may include in fuel treatment planning in order to meet growing concerns regarding the impact that fuel treatments and wildfires may have on carbon emissions and carbon storage (Fried et al. 2004; Westerling et al. 2006; Mignone et al. 2009; Wiedinmyer and Hurteau 2010). Based on the results of this study, it appears that the performance of treatment scenarios in terms of short-term carbon loss vary widely with treatment design, treatment type, and intensity (Figure 3.6), a fact that has not been examined in previous studies. Long-term carbon storage values show similar patterns across treatment intensities for all treatment types but the specific values varied between 
arrangement and treatment type (Figure 3.7). The range of variation in values for each treatment scenario is likely due to specific factors relating to each treatment type and its arrangement.

The results indicate that if onsite short-term carbon loss and long-term onsite carbon storage are concerns for land managers, fuel treatments that include commercial thinning (thin + burn treatments) may not be desirable given our set of assumed weather and wildfire parameters (Figures 3.5 and 3.6). This is most likely due to be the removal of trees up to $28 "$ dbh during commercial thinning (Table 3.1). Since the biomass of wood is approximately $50 \%$ carbon (Tao and Allen 2010), the removal of large diameter trees removed a significant amount of carbon, leading to large short-term carbon loss. I assumed the harvested carbon was a loss in the model, as it was no longer part of onsite carbon storage. However, some of this carbon would likely remain in offsite storage over a period beyond our long-term measurement ( $\geq 100 \mathrm{yrs}$ ), depending upon its use (Skog and Nicholson 1998). The thin + burn treatments also had large short-term carbon loss because the slash left from thinning activities increased surface fuel loading, thus increasing the amount of carbon released during prescribed fire (North et al. 2009; Tao and Allen 2010). These results are consistent with short-term stand-level analysis of this treatment type (Stephens et al. 2009). Thin + burn units did have the lowest area impacted by wildfire fire at the $30 \%$ treatment intensity, resulting in reduced carbon loss from wildfire emissions (Table 3.3, Figure 3.6). This result is consistent with stand-level studies that show reductions in carbon loss from wildfire following thin + burn treatments (Finkral and Evans 2008; Hurteau et al. 2008; Hurteau and North 2009). However, the 
reduction in carbon emissions from wildfire at our level of simulation was not sufficient to offset the large onsite losses from thinning and prescribed fire emissions.

The mechanisms that altered short-term carbon loss in the thin + burn scenarios also altered long-term carbon storage. The thinning activity removed large trees that account for the majority of carbon storage, immediately reducing carbon storage on the landscape. The thinning activity also removed healthy, rapidly growing trees (Nowak and Dwyer 2007), reducing the rate of carbon sequestration, and resulting in a slower recovery to pre-treatment carbon storage levels. Increasing the percentage of the area treated should increase storage by reducing the area that experiences wildfire, thus reducing emissions from fire and improving sequestration by preventing the death of vigorously growing trees (Hurteau and North, 2009; Stephens et al. 2009; Hurteau and North 2010). However, in this study, the loss in carbon sequestration rate and storage from thinning was greater than the increased carbon that resulted from reduced wildfire. As mentioned previously, our model of carbon storage only considers onsite carbon; if some or all of the carbon removed as commercial timber were placed in offsite storage based on its use (such as home construction), it would not be classified as lost carbon and the amount of stored carbon in year 50 could be increased (Skog and Nicholson 1998).

For minimizing onsite short-term carbon loss, mastication treatments appear to be the most effective. The low carbon loss shown for mastication treatments (Figure 3.6) resulted from there being no harvested carbon and no prescribed fire carbon emissions. As the area treated with mastication increased, the carbon loss decreased due to less area being affected by wildfire, resulting in very low short-term carbon loss for mastication at the $30 \%$ treatment intensity (Figure 3.6). 
Over 50 years, the mastication treatments do not have the largest carbon storage but are capable of increasing storage beyond the level of the untreated landscape (Figure 3.7). A probable cause for this is the removal of the young, vigorously growing trees. Though large trees are the largest pool of carbon, smaller, more rapidly growing trees are a large source of sequestration, which influences storage levels over time (Nowak and Dwyer 2007). Removing large numbers of intermediate and small trees does not alter current storage, but can alters future storage by reducing the present sequestration rate (Hurteau and North 2009; Large 2010). However, these small trees are often suppressed, so their removal may allow for the reaming trees to increase growth rates through reduced competition, allowing the long-term onsite storage under this treatment type to outperform the proposed site-specific treatment scenarios (Figure 3.7). Increasing mastication treatment intensity reduced the area burned in wildfire (Table 3.2), subsequently reducing carbon loss from wildfire emissions and maintaining storage by reducing large tree mortality (Hurteau and North 2009; Stephens et al. 2009; Hurteau and North 2010). However, the reduction in small trees slowed sequestration rates sufficiently to limit carbon storage at year 50, resulting in lower carbon accumulation rates and ultimately lower carbon storage at the $30 \%$ treatment intensity when compared to the $20 \%$ treatment intensity.

Spatially-optimized prescribed fire treatments demonstrated an inverse relationship between treatment-induced carbon emissions and wildfire-induced carbon emissions (Figure 3.6). The relationship is not linear however, indicating that if spatiallyoptimized, the reductions in wildfire-induced emissions were large early, but became smaller as the treatment intensity increased. In this study, it appears that the balance point 
between increasing emissions from prescribed fire and decreasing emissions from wildfire is at the $20 \%$ treatment intensity. Balancing the treatment-induced emissions with wildfire-induced emissions resulted in the $20 \%$ treatment intensity having the smallest short-term carbon loss of the prescribed fire treatment scenarios (Figure 3.6).

Over a 50 year cycle, prescribed fire at the $20 \%$ (medium) treatment intensity had the largest pool of carbon storage of all treatment designs and intensities (Figure 3.7). Prescribed fire reduced surface fuels and protected large trees from experiencing wildfire mortality, thereby creating fire-resistant stand structures (Hurteau and North 2009; Hurteau and North 2010). This is similar to thin + burn treatments but without the large tree removal or increased slash fuels prior to burning (Stephens et al. 2009). When compared to mastication treatments, prescribed fire scenarios lost more carbon in the short-term, but did not remove as many of the small to medium trees, and therefore did not reduce the sequestration rate, allowing for the long-term carbon storage level to increase more rapidly than in mastication treatments, more than compensating for the loss of carbon from the prescribed fire. At the $20 \%$ treatment intensity, the reduction in wildfire-induced emissions and saving of large tress due to reduced area experiencing wildfire balanced the treatment-induced carbon emissions, while increasing to the $30 \%$ treatment intensity caused sufficient increase in treatment-induced loss to reduce the long-term storage level.

The site-specific Eddy Gulch Project (USDA Forest Service 2010) designs all experienced a short-term loss of carbon that was close in value to the untreated landscape (Figure 3.6). Of note is the amount of carbon lost from wildfire (Figure 3.6), which was not as strongly influenced by treatment intensity as it was when treatments were arranged 
in spatially-optimized patterns. This illustrates that though the proposed site-specific treatments in the Eddy Gulch Project may be more practical to implement than the spatially-optimized designs, they were not as effective at reducing the area that experienced wildfire (Table 3.2), and as such, were not as effective at reducing short-term carbon loss from wildfires (Stephens et al. 2009). Again, however, I did not account for offsite carbon storage which could alter the overall carbon pools.

Over 50 years, all site-specific treatment scenarios had lower carbon storage than the untreated landscape and similar or lower carbon storage than all optimized designs at the analogous treatment intensities (Figure 3.7). An explanation for this is that the limited ability of these treatments to influence wildfire area (Table 3.2) resulted in a reduced ability of these treatments to protect large trees from wildfire. This resulted in high mortality of mature trees during wildfire, removing the largest source of carbon storage over a larger portion of the landscape (Nowak and Dwyer 2007; Hurteau et al. 2011). Just as with the spatially-optimized treatment designs, the carbon storage was greatest at the medium treatment intensity (prescribed fire), indicating that as treatment intensities increase past the medium treatment intensity $(\sim 20 \%)$, the prescribed fire-induced carbon emissions and vegetation removals outweigh the protection of mature trees from wildfire and reductions in wildfire carbon emissions.

\subsubsection{Management Implications}

Land managers seeking to minimize onsite short-term carbon loss and maximize onsite long-term carbon storage should avoid large areas of thin + burn treatments as they remove large amounts of carbon, from the landscape through vegetation removal and 
produce prescribed fire emissions, that are not overcome by reduced wildfire emissions and reduced area burned given our method of simulating future wildfires (Figures 3.4 and 3.5). Again, I did not consider offsite carbon storage (e.g. home construction) in this study, which has the potential to impact our results.

Mastication may be the best treatment type for managers seeking to minimize onsite short-term carbon loss, because it creates no treatment-induced carbon loss (Figure 3.6). This may be of particular interest for WUI areas where short-term smoke emissions are of great concern. However, the carbon emissions from mastication machinery could be included in future studies to determine if the short-term carbon loss is still minimized. Also to note with mastication treatments is their limitation on slope and proximity to roads for implementation. Of all spatially-optimized treatments these are the most unrealistic in terms of on the ground implementation because of steep nature of the study site terrain and limited road access within the LSR.

Prescribed fire under moderate conditions appears to be the best option for balancing onsite short-term carbon loss with onsite long-term carbon storage (Figures 3.5 and 3.6) and has the added benefit of being closest to a natural process of the treatment options included in this study. However, future accounting of carbon emissions from treatment implementation may increase the short-term carbon loss, particularly if helicopter ignition is used (due to fossil fuel carbon emissions from helicopter operation). The strong performance of the spatially-optimized prescribed fire treatments should also be considered theoretical in the sense that implementing this type of treatment is not practical in the purest sense given the rugged terrain present in our study site. 
Site specific treatments in this study did reduce onsite short-term carbon loss below untreated levels with the prescribed fire scenario, which was also the scenario that had the largest site-specific long-term carbon storage. However, because the long-term carbon storage of all site specific treatments was below that of the untreated landscape, it appears that if long-term storage is important, land managers may want to spatiallyoptimize treatments as much as possible.

Overall, the medium treatment intensity ( $20 \%$ of the landscape) appears to be the best treatment intensity for maximizing onsite long-term carbon storage. For each treatment type and arrangement, the medium intensity had the largest long-term carbon storage pool. However, across treatment types and arrangements at the medium intensity, the amount of carbon in the storage pools was not equal (Figure 3.7). This indicates that if long-term carbon storage is a concern for land managers, once the treatment type and design are selected, the percentage of the landscape treated should not exceed $20 \%$. In our study site, this result is valuable because it indicates that the more practical sitespecific treatments can minimize onsite short-term carbon loss and maximize long-term carbon storage at the same treatment intensity (Figures 3.6 and 3.7).

As mentioned previously, future work on carbon cycling over the short and longterm should take a more life cycle approach to the problem, tracking carbon that may be stored offsite and accounting for other short-term carbon emissions stemming from the implementation of fuel treatments. I did not have the specialized knowledge to include these factors in this study.

Also of concern is the implementation of wildfire only one time (5 years post treatment) during the 50 year cycle. Over 50 years it is likely that far more fire would be 
present on the landscape (Taylor and Skinner 2003) and one would therefore need to recursively implement fire simulations on the landscape, accounting for the impacts previous fires would have on fire spread and intensity as well as carbon emissions. Doing this would be possible using the Randig and FVS programs in a repetitive loop, assigning fire based on burn probabilities generated from the previously burned landscape. The implementation of such a process was logistically impractical for this study given the time consuming nature of the modeling: each combination of Randig and FVS simulation takes 20 to 24 hours. However, such a process could create a more complete picture of the duration of fuel treatment influence on carbon storage across a landscape of this scale. 


\subsection{Impacts to burn probability, flame length, and fire size from varied landscape- scale fuel treatment strategies}

\subsection{Introduction}

Fuel treatments, which most commonly incorporate prescribed fire, mechanical manipulation, or combinations thereof (Graham et al. 1999; 2004; Reinhardt et al. 2008; Sackett 1975), target one or more vegetative strata (surface, mid-story or canopy) to alter fire behavior in a given stand (Agee and Skinner 2005; Weatherspoon and Skinner 2006). The goal of altering vegetation to reduce fire behavior is not new (Weaver 1943; Sackett 1975). In fact, numerous modeling studies (Stephens 1998; Sexton 2006; Vaillant et al. 2009; Large 2010; Hamma 2011) and real-world studies (Sackett 1975; Finney et al. 2005; Murphy et al. 2007) suggest that small, stand-scale fuel treatments can be highly effective at reducing wildfire intensity, rate of spread, or crown fire potential. The effectiveness of such treatments is dependent on forest composition and structure, type of treatment, and which vegetation layer(s) the treatment alters (Martinson and Omi 2003; Graham et al. 2004; Schmidt et al. 2008; Large, 2010).

However, while critical to an individual stand's resiliency to fire, isolated fuel treatments may have little impact on the spread of fire across the landscape (Finney et al. 2005). Therefore, land managers across the western US are focusing on landscape-scale vegetation management strategies to alter fuel conditions and subsequently protect both the natural and built environment (Sexton 2006; Weatherspoon and Skinner 2006; Reinhardt et al. 2008; Collins et al. 2010). A landscape is a large, heterogeneous land area that is composed of a large number of contiguous stands. Landscape-level fire behavior is influenced by a number of factors, including the extent of the landscape 
treated, the types of treatments, and how those treatments are spatially arranged (Ager et al. 2007; Finney et al. 2007; Schmidt et al. 2008).

For a given landscape treatment intensity under fixed weather conditions, simulation studies suggest that that both spatial arrangement and treatment unit dimension are important factors determining treatment effectiveness as measured by a fires the rate of spread (ROS) (Finney 2001; Graham et al. 2004; Loehle 2004; Finney et al. 2007; Schmidt et al. 2008). For example, widely dispersed fuel treatments would likely be more effective at impacting large fire spread compared to aggregated treatments. In this concept of a spatially-optimized arrangement (Finney 2001), multiple stand-level fuel treatments are placed so as to minimize ROS across that landscape. Strategic location and orientation of treatments in the most likely flow paths of a wildfire maximizes the reduction in forward spread per area treated. Moreover, the dimensions of fuel treatment units can be specified such that the time to burn through a treatment unit equals the time to flank around a treatment unit, thereby reducing the fire's forward ROS (Finney 2001). Simulation modeling suggests that this approach can reduce the overall wildfire exposure on a landscape, the potential fire intensity, and the potential wildfire size (Finney 2001; Schmidt et al. 2008; Vaillant 2008; Ager et al. 2010).

The spatial optimization approach to landscape-scale fuel management is difficult to implement due to multiple administrative and operational constraints. Logistic constraints such as steep slope, sensitive habitat, access for equipment, and erosion potential may make certain treatment types (particularly mechanical thinning and mastication operations) unfeasible in locations where treatments might be highly effective. Spatially optimized-treatment designs also do not consider the potential needs 
for fire suppression activities, such as anchor points, safety zones, and the arrangement of features for containment. Other constraints include prioritization of treatments to protect highly valued resources such as sensitive habitat and wildland-urban interface areas (WUI). Further, public perceptions of fuel treatments and their potential impacts on scenic quality and ecological factors may often constrain the location of fuel treatments (Dicus and Scott 2006; Johnson et al. 2006). As a result of these constraints, the implementation of landscape-scale fuel management strategies often target topographic features (e.g. ridges) to anchor fuel reduction zones and large-area prescribed fire units (Agee et al. 2000; Moghaddas et al. 2010). These locations are often chosen because they provide safe and potentially effective locations to anchor fire suppression activities in the event of a wildfire that threatens values of concern and are not designed specifically to limit a fires ROS.

In this study, I used simulation modeling to analyze how various landscape-scale fuel management strategies affected fire behavior on a fire-prone, mixed-conifer forest in the Klamath Mountains of northern California. I chose to use a modeling approach because of the spatial and temporal limitations inherent in the implementation of a study at such a large scale. Specifically, I first examined the effects of three fuel treatment proposals by the Klamath National Forest (USDA Forest Service 2010), on wildfire likelihood (burn probability), fire intensity (flame length), and fire size. I then compared the Forest's proposal to multiple spatially-optimized landscape treatment scenarios that varied in treatment type (including prescribe fire, mastication, and thin + burn) and treatment intensity $(10 \%, 20 \%$, and $30 \%$ of the landscape treated). Modeling fire effects (such as tree mortality) would be a desirable output as well but due to modeling 
limitations, I chose to report fire intensity, which can be highly correlated to the effects fire has on the ecosystem (often referred to as fire severity) (Keeley 2009).

\subsection{Methods}

\subsubsection{Study Site}

The 42,000 hectares study site (Figure 4.1) included the Eddy Gulch Late Successional Reserve (LSR) and a surrounding buffer on the Salmon River Ranger District, Klamath National Forest, Siskiyou County, California (123 4.72 W 411554 N). An LSR is defined by the Northwest Forest Plan as land "designed to serve as habitat for late-successional and old-growth related species including the northern spotted owl" (USDA Forest Service, UDoI, Bureau of Land Management 1994). Elevation within the area ranges from approximately $300 \mathrm{~m}$ to $2,500 \mathrm{~m}$, with the steep terrain crossed by numerous ridges and creeks (USDA Forest Service 2010). Climate in the area is Mediterranean, with hot, dry summers and cool, wet winters. A strong precipitation gradient dominates from west to east due to the influence of the Pacific Ocean (Skinner et al. 2006; Agee 2007).

Vegetation consists largely of multi-layered, multi-aged forests. Douglas-fir (Pseudotsuga menziesii Mirb.) and ponderosa pine (Pinus ponderosa C. Lawson) in association with Pacific madrone (Arbutus menziesii Pursh) and other understory evergreens shrubs dominate at lower elevations. Douglas-fir, white fir (Abies concolor Gord. \& Glend.), and red fir (Abies magnifica A. Murray) dominate at higher elevations where moisture is more abundant (Taylor and Skinner, 1998). Incense cedar (Calocedrus decurrens Torr.), sugar pine (Pinus lambertiana Douglas), and Jeffrey pine (Pinus 
jeffreyi Balf.) can occur across all elevations and specific site distributions are highly influenced by elevation and site moisture levels (Taylor and Skinner 2003; Skinner et al. 2006).

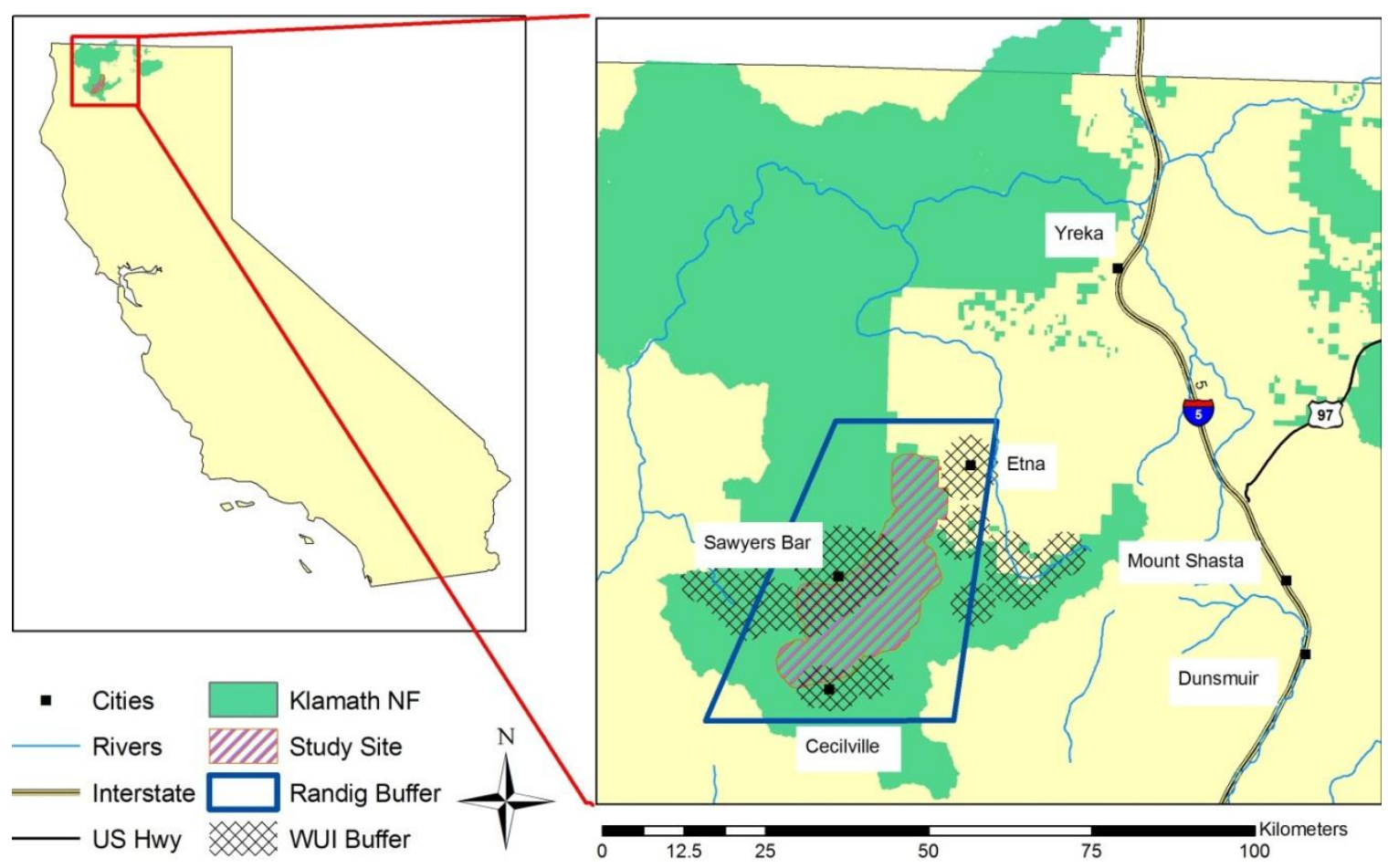

Figure 4.1 Location of the study site, larger buffer used in Randig simulations, and adjacent WUI communities.

Reported historic mean fire return intervals in the Klamath mountain region are near 12 years, with the majority of the fires taking place in the summer months (Skinner and Taylor 2003). However, due to fire exclusion in the previous century, the mean fire return interval has increased to an average of almost 22 years, with some locations going much longer without experiencing fire (Taylor and Skinner 1998; Taylor and Skinner 2003). Lightning ignitions are common in the Klamath region and account for the majority of the acres burned (Skinner et al. 2006). Though fire intensity is usually low to moderate due to frequent high pressure inversions, more intense fire behavior can occur during the passage of frontal systems (Skinner et al. 2006). 
Like many regions in the western US with understory and mixed-severity fire regimes (Jenkins et al. 1998), fire exclusion in the LSR has lengthened the mean fire return interval (Mohr et al. 2000), resulting in a buildup of fuels, thus increasing the fire danger to adjacent communities and critical habitat. At present, as much as $73 \%$ of the area within the LSR is at risk for passive or active crown fire activity under extreme weather conditions (USDA Forest Service 2010). Crown fire across such a high percentage of the LSR would remove a large portion of the large trees that provide habitat for sensitive species such as the spotted owl. The potential for large-scale loss is the impetus for the Forest Service's proposed project in the LSR and other landscape level fuel reduction programs (Keane et al. 2002; Stephens and Ruth 2005).

\subsubsection{Landscape data + Treatment Scenarios}

We assessed 13 fuel treatment scenarios (Figure 4.2) including, an untreated scenario, three site-specific scenarios derived from the Forest Service proposal (USDA Forest Service 2010), and nine spatially-optimized treatment scenarios that varied in treatment type and proportion of the landscape treated. Figure 4.3 illustrates the processes used to generate landscape treatments and subsequent fire behavior outputs. 
A Site-specific Eddy Gulch Project Units
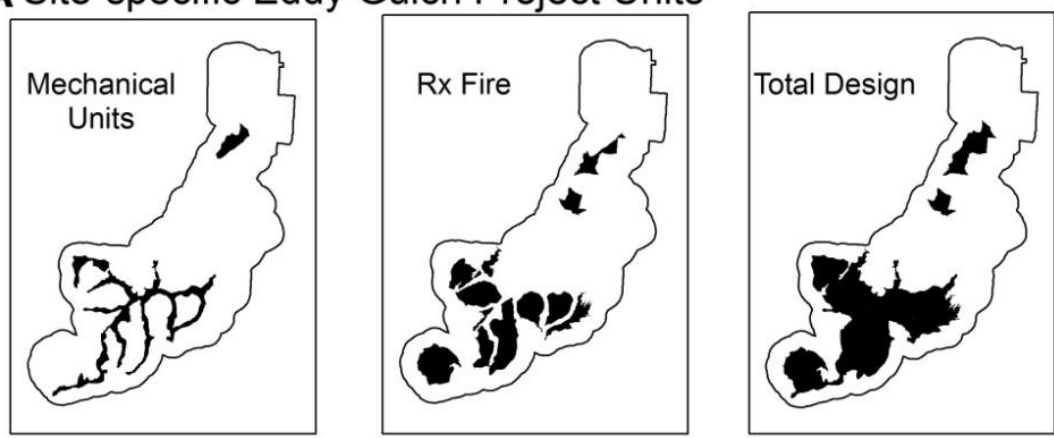

B Optimized Prescribed Fire Units
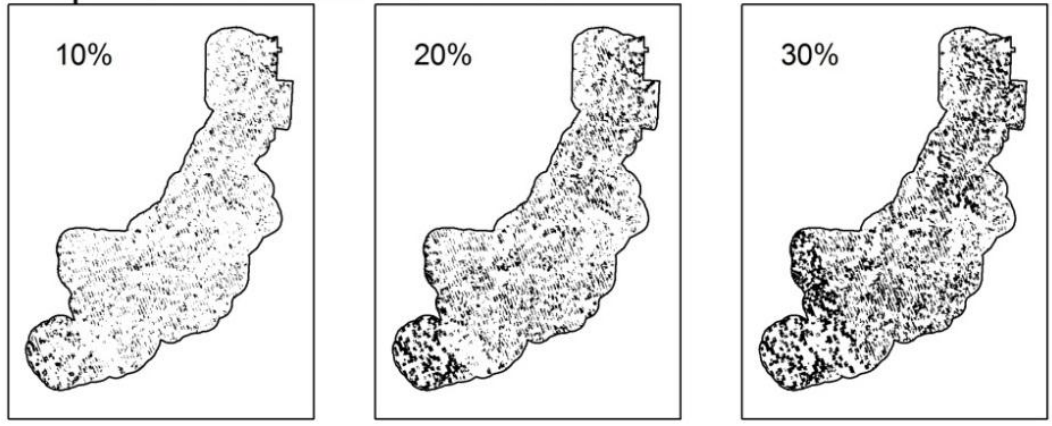

C Optimized Mastication Units
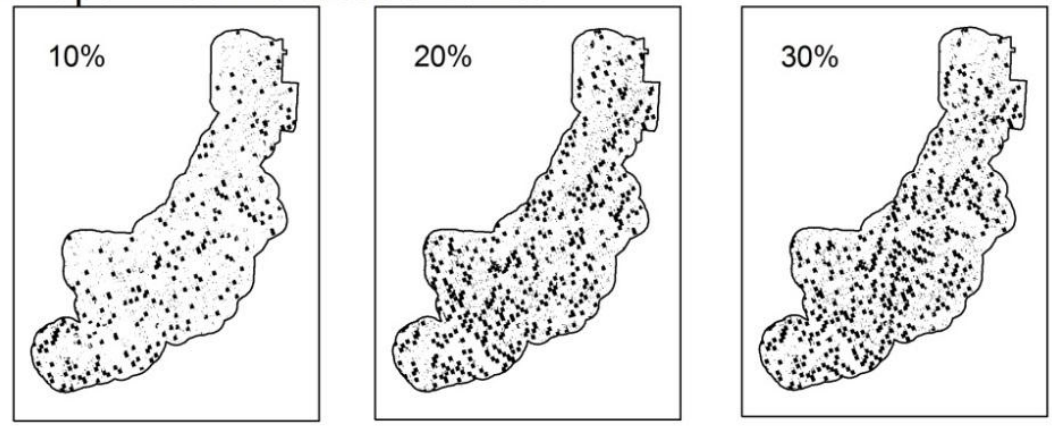

D Optimized Thin + Burn Units
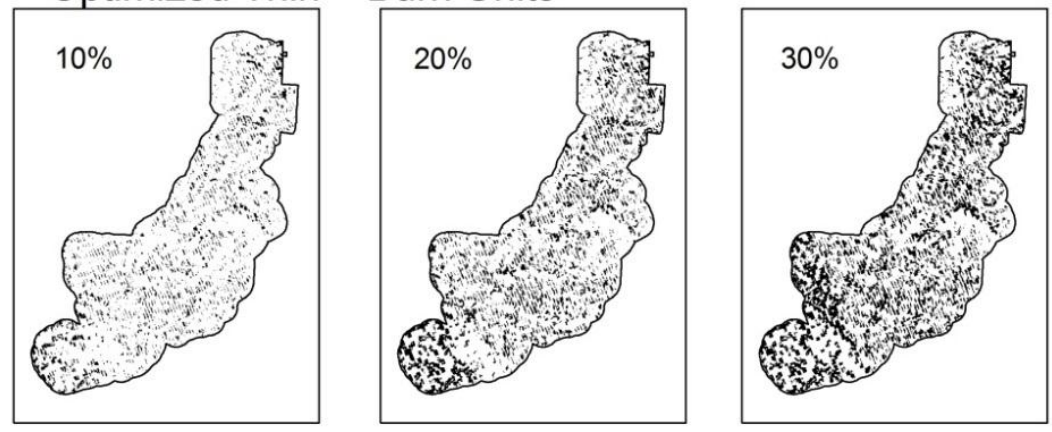

Figure 4.2 The 12 treatment scenarios within the project study site. Shaded areas represent treatment units. Part A represents the site-specific treatments. Mechanical units are mastication and thin + burn and the total design is the combination of the mechanical and prescribed fire units. Parts $B, C$ and $D$ represent spatially-optimized units developed with the Treatment Optimization Model. 


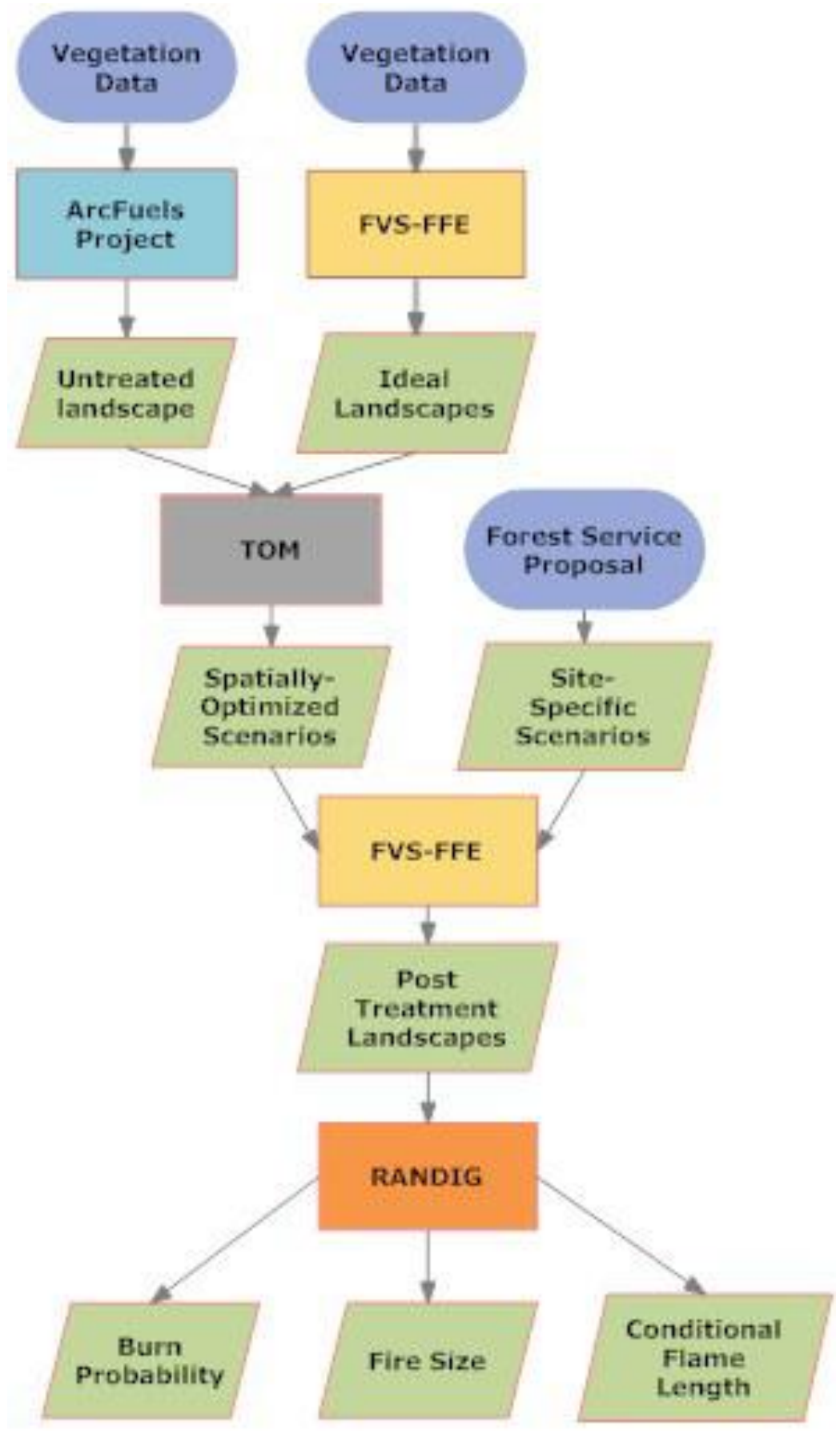

Figure 4.3 Flow chart showing the major steps utilized to obtain fire behavior outputs

Initial landscape vegetation data were derived from forest inventory and analysis (FIA) data for the Klamath National Forest. I obtained this vegetation data and accompanying GIS stand layers from the USFS Region 5 Remote Sensing Lab (RSL) 
(USDA Forest Service 2009). The RSL also provided a digital elevation model (DEM), fuel model data, and GIS vegetation attribute layers (canopy base height, crown bulk density, crown height, and height to live crown). I used the DEM to develop elevation, slope, and aspect layers. I then combined the FIA data, stand data, DEM layers, and vegetation attribute data to build an ArcFuels project (Ager et al. in press) within ESRI's ArcGIS software (V. 9.3.1) (ESRI 2009). The ArcFuels extension streamlines fire and fuels analysis by integrating the Forest Vegetation Simulator (FVS) (Dixon 2002) and a number of fire modeling software programs within ArcGIS software (Ager et al. in press). I then used the ArcFuels project to build a GIS landscape that served as our untreated control landscape as well as the initial point for developing the 12 treated landscapes.

Table 4.1 Description of each fuel treatment type from the Eddy Gulch Project (USDA Forest Service, 2010).

\begin{tabular}{cl}
$\begin{array}{c}\text { Treatment } \\
\text { Type }\end{array}$ & \multicolumn{1}{c}{ Prescription } \\
\hline & $\begin{array}{l}\text { Broadcast burning, ignited by hand or aerial ignition would } \\
\text { be used to remove ground and small ladder fuels (less than } \\
4 \text { inches dbh) and to achieve post-treatment flame lengths } \\
\text { of less than 2 feet, with fuel loads maintained to achieve } \\
\text { flame lengths of less than } 4 \text { feet over time. Implementation } \\
\text { of prescribed burns would not be consistent across each Rx } \\
\text { Unit, but rather small patches of heavier fuels would be } \\
\text { maintained in burn areas. Burns may be accomplished when } \\
\text { air quality, weather, and fuel moisture conditions could be } \\
\text { met. }\end{array}$ \\
\hline Mastication & $\begin{array}{l}\text { Ground and ladder fuels (conifer trees up to 10 inches dbh) } \\
\text { would be masticated on slopes less than 45\% with } \\
\text { prescribed fire used to reduce surface fuels on slopes } \\
\text { greater than 45\%. In TOM scenarios only mastication } \\
\text { treatments used, regardless of slope. }\end{array}$ \\
\hline Thin + burn & $\begin{array}{l}\text { Tree removal would thin from below, removing trees 8- } \\
\text { 28 inches diameter at breast height (dbh). Following } \\
\text { completion of thinning, all slash would be broadcast } \\
\text { burned. }\end{array}$ \\
\hline
\end{tabular}


The proposed site-specific fuel treatment for the LSR includes both mechanical units and prescribed fire units (Figure 4.2A; Table 4.1; USDA Forest Service 2010). The mechanical units, composed of thin + burn treatments and mastication treatments, were located along ridge tops and were intended to reduce fire spread across the landscape and provide locations suitable for fire suppression activities (USDA Forest Service 2010). Large prescribed fire units located primarily on south and southwest facing aspects are intended to reduce surface fuels and increase habitat resiliency. These are the areas most likely to experience significant crown fire activity due to slope position, solar radiation, and wind alignment (Alexander et al. 2006; USDA Forest Service 2010). The proposal for the LSR also included roadside treatments designed for improved emergency access and suppression effectiveness. However, these roadside treatments were not included in our analysis because they were not likely to directly influence landscape-scale fire growth patterns. Using the two categories of treatments (mechanical units and prescribed fire units), I derived three distinct site-specific landscape treatment scenarios (Figure 4.2A). The first site-specific treatment scenario was the mechanical units that included mastication treatments and thin + burn treatments, which covered the lowest percent of the study site (9\%). The second scenario was composed of the prescribed fire units, mostly on the south and southwest aspects, covering a medium percentage of the study site (17\%). The final site-specific treatment scenario was the total design, including all mechanical and prescribed fire units, which covered the highest percent (26\%) of the study site (USDA Forest Service 2010).

We also created nine spatially-optimized fuel treatment scenarios utilizing the Treatment Optimization Model (TOM) within FlamMap (v 3.0) (Finney 2006; Finney 
2007). These nine scenarios included three treatment types (prescribed fire, mastication, and thin + burn), each at a low, a medium, and a high intensity $(10 \%, 20 \%$, and $30 \%$ of the landscape treated, respectively). The percentage of area treated represented logical increases and closely matched the percentage of the landscape treated in each of the sitespecific treatment scenarios. The treatment intensity levels also mirrored those used in previous work with landscape fuel treatment arrangements on the Klamath NF (Schmidt et al. 2008). Finney et al. (2007) also demonstrated that cumulative yearly benefits from spatially-optimized treatments reach a maximum at the $30 \%$ treatment intensity.

To assign treatments across the landscape, the TOM compares fire behavior on two landscapes, an untreated and an ideal. The ideal landscape contains vegetation attributes altered to represent fuel treatments in all possible treatment locations. To generate our ideal landscapes, I used the FVS-Fire and Fuels Extension (FFE; Inland California variant; Rebain 2010) within ArcFuels (Ager et al. in press) to implement treatment vegetation alterations in all stands within our study site. I did this for each treatment type (prescribed fire, mastication, and thin + burn), resulting in three ideal landscapes. The ideal landscapes used the same treatment prescriptions as the sitespecific treatment scenarios (Table 4.1). While creating the idealized treatments in FVSFFE, I determined that the post-treatment fuel models assigned by FVS-FFE did not represent reasonable post-treatment conditions (Collins et al. 2010; Large 2010; Ager et al. in press). To overcome this, I assigned fuel models (Anderson 1982; Scott and Burgan 2005) to each stand based on pre-treatment conditions and expected post-treatment conditions for each type of treatment (Fites-Kaufman et al. 2007), overriding the fuel models assigned by FVS-FFE. Table 4.2 illustrates the crosswalk of pre-treatment and 
post-treatment fuel models. Current standard fuel models do not accurately represent the fuel bed generated by mastication treatments, requiring the creation of a custom fuel model to represent post-treatment mastication units (Kane et al. 2006; Knapp et al. 2008; Reiner and Decker 2009). I based the custom mastication fuel model on an average of slash fuel models, as described by Knapp et al. (2008).

FVS also required fuel moisture and weather conditions to simulate the prescribed fire and thin + burn treatments. I used FireFamilyPlus (v 4.1) (Rocky Mountain Research Station Fire Lab and Systems for Environmental Management 2002) and historical fire weather data from the Blue Ridge Remote Automated Weather Station (RAWS) to develop our fuel moisture parameters. Moderate values for wind and temperature were based on 20-year (1984 -2004) RAWS data for May through October, discussions with Klamath National Forest fire management staff, and values used by Large (2010), whose work was conducted in the Klamath Mountains (Table 4.3). The fuel moisture and weather parameter values used for prescribed fire simulations approximate the $50^{\text {th }}$ percentile level, which previous work has used to represent moderate fire behavior (Ager et al. 2010b; Large 2010). I also consulted local fire managers to match prescribed fire parameters with conditions under which they would consider prescribed fire operations (Table 4.3). 
Table 4.2 Fuel model crosswalks used to implement fuel treatments in creation of GIS landscapes.

\begin{tabular}{cccc} 
Pre-Treat Fuel Model & \multicolumn{3}{c}{ Post-Treat fuel Models } \\
& Prescribed Fire & Thin + Burn & Mastication \\
\hline 1 & 101 & 101 & 1 \\
5 & 121 & 121 & 14 \\
6 & 121 & 121 & 14 \\
11 & 201 & 201 & 14 \\
99 & 99 & 99 & 99 \\
102 & 101 & 101 & 102 \\
\hline 107 & 101 & 101 & 107 \\
121 & 101 & 101 & 14 \\
122 & 121 & 121 & 14 \\
141 & 121 & 121 & 14 \\
\hline 142 & 121 & 121 & 14 \\
145 & 121 & 121 & 14 \\
\hline 161 & 121 & 121 & 14 \\
165 & 161 & 161 & 14 \\
\hline 181 & 161 & 161 & 14 \\
182 & 181 & 181 & 14 \\
\hline 183 & 181 & 181 & 14 \\
184 & 181 & 181 & 14 \\
\hline 186 & 181 & 181 & 14 \\
188 & 183 & 183 & 14 \\
\hline 189 & 183 & 183 & 14 \\
\hline 202 & 183 & 183 & 14 \\
\hline 203 & 201 & 201 & 14 \\
203 & 201 & 201 & 14 \\
\hline & & & \\
\hline
\end{tabular}


Table 4.3 Weather and fuel moisture variables used in fire simulations

\begin{tabular}{rrccc}
\hline Weather & \multicolumn{3}{c}{ Rx fire $(\sim 50 \%)$} & Vildfire ( 97\%) \\
\hline & Wind speed & $(\mathrm{Km} / \mathrm{h})$ & 16.09 & 48.28 \\
Wind Direction & Azimuth & 238 & 238 \\
Temperature & ${ }^{\circ} \mathrm{C}$ & 21.11 & 32.22 \\
Fuel moisture & & & \\
& $1-$ hour & $(\%)$ & 4 & 2 \\
$10-$ hour & $(\%)$ & 5 & 3 \\
$100-$ hour & $(\%)$ & 10 & 5 \\
1000 -hour & $(\%)$ & 11 & 8 \\
Duff moisture content & $(\%)$ & 30 & 10 \\
Live woody moisture & $(\%)$ & 77 & 70 \\
content & & & \\
Foliar moisture content & $(\%)$ & 100 & 80 \\
\hline
\end{tabular}

Given constant wind and moisture parameters, the TOM used Finney's minimum travel time (MTT) algorithm to calculate arrival time contours and the paths where fire can move fastest across the landscape (Finney 2002; Finney 2004; Finney 2006), and then places treatments to optimally reduce the overall landscape ROS given the area treated (Finney 2007). The TOM calculates the arrival contours and flow paths for both landscapes and selects the locations from the ideal landscape that maximize reductions in ROS on the untreated landscape (Finney 2007). The program iterates through creating flow paths/arrival contours and placing treatments until it treats a percentage of the landscape defined by the user (Finney 2006; Finney 2007). Placing treatments in the path of a fire slows the heading spread of a wildfire so that the time to burn through a treatment unit equals the time to flank around a treatment unit, thereby reducing the fire's ROS.

The TOM assumed constant wind, weather, and fuel moisture parameters, derived from the same sources as the prescribed fire conditions, but at the $97^{\text {th }}$ percentile level (Table 4.3). I chose the $97^{\text {th }}$ percentile weather to represent an extreme fire event because the purpose of landscape level treatments, as described in the Eddy Gulch project, is to 
reduce the damage and spread of high severity fire events (USDA Forest Service, 2010). Previous studies have used this level of weather severity to represent the extreme wind, heat, and moisture conditions under which one can expect high severity fire events (Schmidt et al. 2008; Ager et al. 2010b; Large 2010).

The FlamMap treatment location outputs created with the TOM were converted into ArcGIS raster files within ArcFuels. I then used these raster layers to assign treatments to stands based on the percentage of stands covered by treatment cells when I overlaid the stand polygon layer with a treatment raster. Any stand with at least $1 / 3$ of its area overlapped by treatment cells received the treatment for that scenario.

\subsubsection{Modeling Procedure}

A separate FVS-FFE simulation was completed for each treatment scenario in order to represent immediate post-treatment conditions. Fuel model overrides used in creating idealized landscapes were also used to represent post-treatment fuel models in the treatment simulations (Table 4.3). Variables included in the output databases (canopy bulk density $\left(\mathrm{kg} \mathrm{m}^{-3}\right)$, height to live crown (m), total stand height $(\mathrm{m})$, canopy cover $(\%)$, and fuel model) were then used to build $30 \mathrm{~m}$ x $30 \mathrm{~m}$ raster files utilized in ArcFuels to build GIS landscape files representing post-treatment conditions for each scenario.

We placed each post-treatment landscape into Randig, a command line version of FlamMap developed by Mark Finney (USDA Missoula Fire Science Laboratory). Randig used the same MTT algorithm as FlamMap to generate fire sizes and pixel by pixel burn probabilities for a specified number of random ignitions. Like FlamMap, Randig uses a pre-determined burn period (duration in minutes) and static weather conditions. The 
weather conditions for the Randig simulations were the same as the $97^{\text {th }}$ percentile weather used previously in FlamMap and FVS-FFE to represent probable weather conditions leading to an extreme fire event (Table 4.3).

Each individual ignition was allowed to burn for a specified length of time, but Randig allowed for variation in simulation length between each ignition, with each simulation length assigned a specified percentage of the simulated ignitions. I used burn periods ranging from 600 to 1100 minutes in order to create a distribution of fire sizes that closely resembled an observed distribution of extreme growth events (Figure 4.4). The observed distribution was derived from observed single-day fire growth events $>500$ ha in the Klamath Mountains from 2002 to 2008. I obtained this data from 209 reports for large fires, accessed via https://fam.nwcg.gov/fam-web/. The observed data included only 12 hour daylight periods in order to limit the inclusion of overnight burnout operations that can artificially create large growth of wildfires. Large spread events due to burn-out operations during daylight may be included, but I had no way of determining when fire growth was attributable to control operations or to actual fire spread. Also, some large growth events likely have not been included because daily growth reports were only available when fires were under Type 1 or Type 2 management and it is possible that some large (> 500ha) spread events took place when fires were not under Type 1 or Type 2 management. 


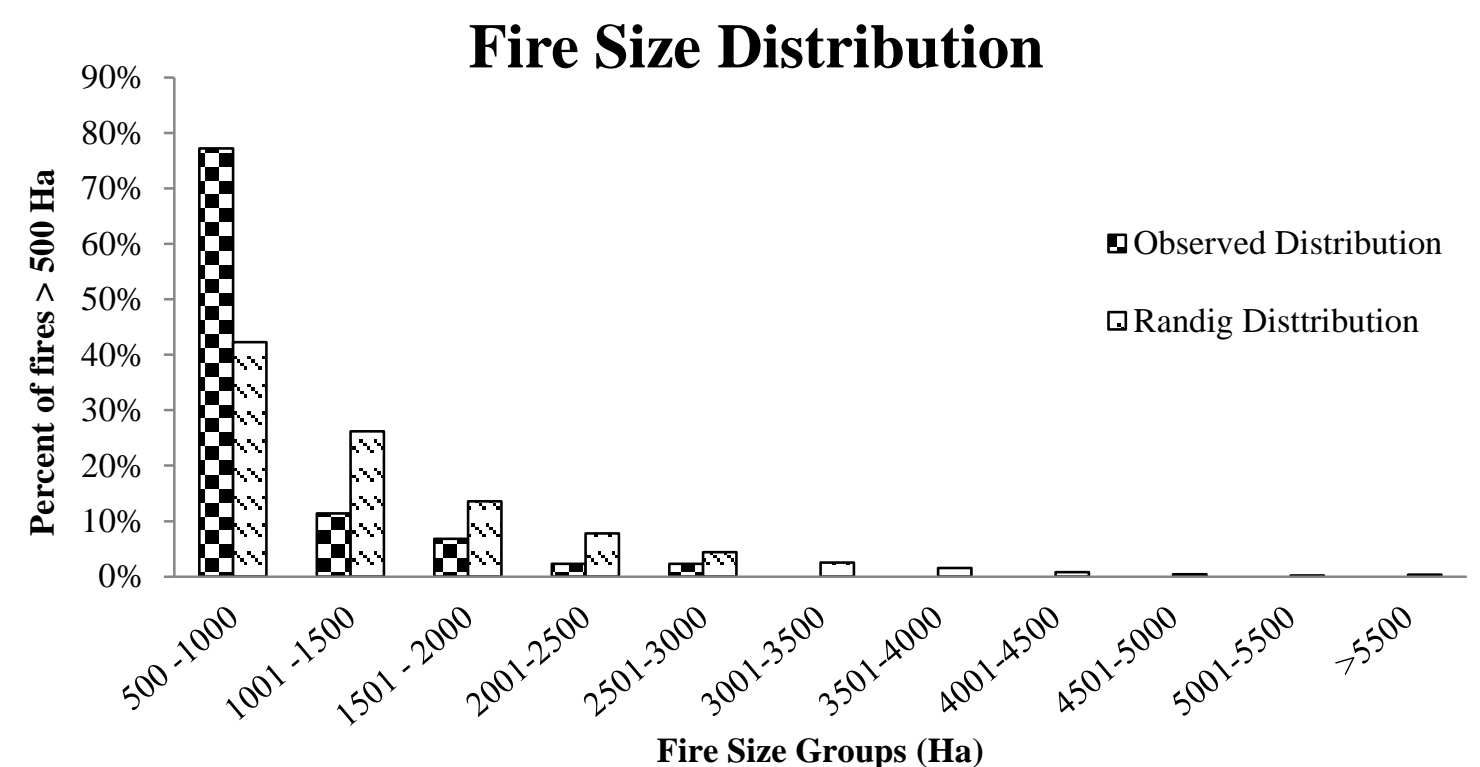

Figure 4.4 Distribution of observed fire size vs. simulated fire sizes using 10,000 ignitions in Randig on an untreated landscape. Observed fires come from day time single day growth periods from 2002 to 2008 , representing 44 daily growth events over $500 \mathrm{Ha}$.

The Randig simulations used a buffer larger than our actual study site (Figure 4.1) to eliminate edge effect within the study site. Allowing ignitions to burn past the boundary of the study site gave a more accurate result for fire size, including ignitions that originated within the study site but burned out. This large buffer also allowed ignitions to fall outside of the study site and burn in, preventing the edges of the study site from experiencing artificially reduced burn probabilities. 


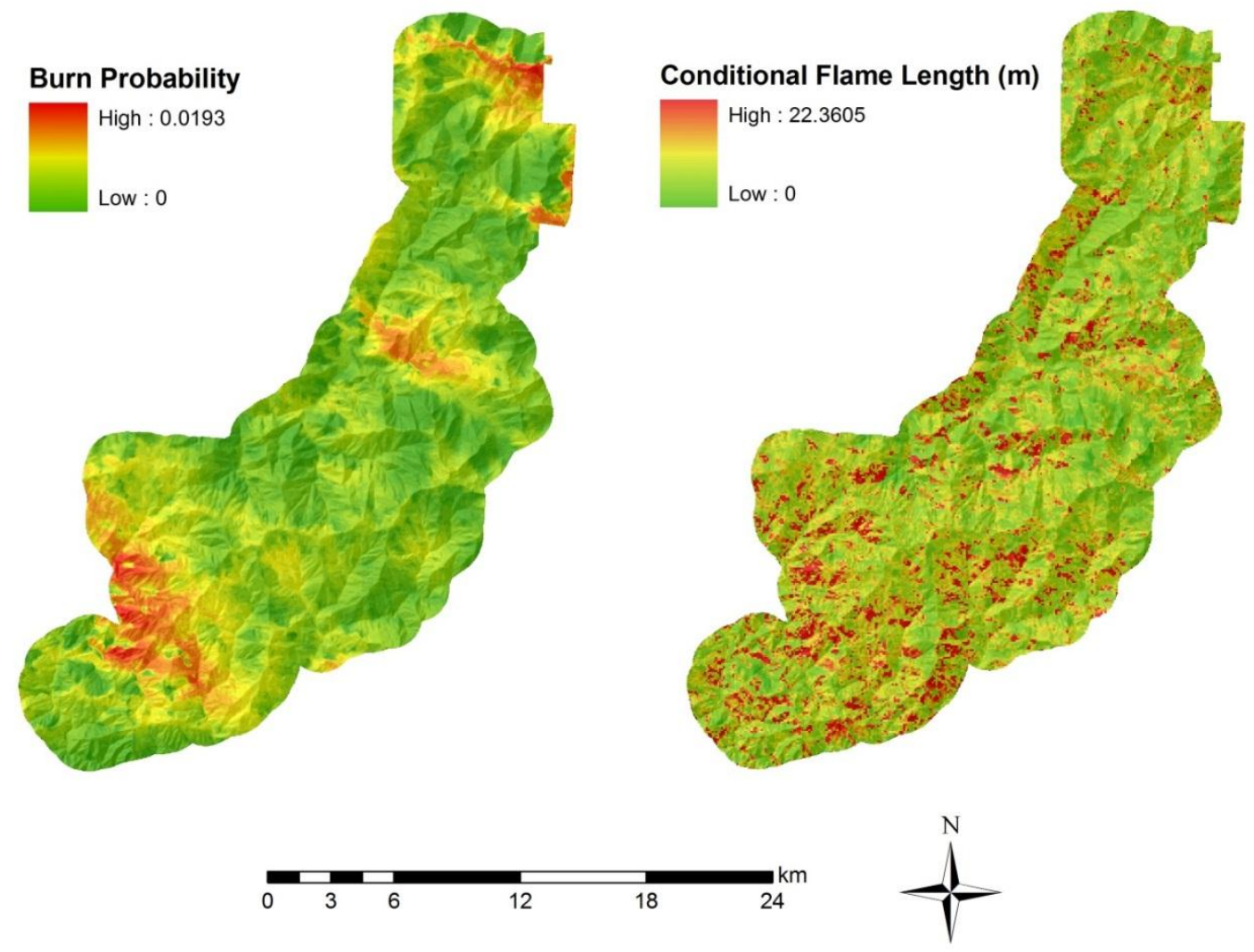

Figure 4.5 Burn probability and conditional flame length in the untreated scenario

Randig used the fire perimeters from each ignition to generate pixel by pixel burn probabilities based on the number of times a pixel burned versus the number of ignitions in the simulation. In our study a pixel with a $1 \%(0.01)$ burn probability experienced fire from 100 of the 10,000 ignitions. I considered burn probability as a measure of potential exposure to wildfire for each pixel, given a random ignition (Scott 2006). Using 10,000 ignitions on the untreated landscape resulted in a total of 9,213,942 ha receiving fire, which resulted in each pixel experiencing fire an average of 63 times. This allowed us to satisfy the assumption that the ignition saturation was high enough to generate a robust probability of each pixel burning given one random ignition anywhere on the landscape. Figure 4.5 illustrates a map of burn probability across the study site for the untreated 
scenario. I used the pixel by pixel burn probability values to calculate mean burn probability for each treatment scenario across the entire study site as well as for the area of WUI threat zones that fell within the study site. The WUI threat zone (Figure 4.1) was defined as a 1.5 mile buffer surrounding designated WUI communities and is a standard threat zone used by the Forest Serviced in designing fuel treatments to protect WUI communities (USDA Forest Service 2002).

Randig also reported the flame length for each pixel and fire based on the slope, fuels, moisture, wind and the expected fire type (heading, flanking or backing), and the direction of approach (Finney 2006; Ager et al. 2010b). Using this information, Randig reported the percentage of fires each pixel experienced that generated flame lengths in half-meter categories. Summing these categories for each pixel would result in a value of 1, representing $100 \%$ of the fires that burned that individual pixel. I used these categorical flame length probabilities to calculate the conditional flame length (CFL) for each pixel. CFL can be thought of as the average flame length for a pixel when it experienced a fire and is not related to the overall likelihood that the pixel will in fact experience fire given any one random ignition (Ager et al. 2010b). CFL for each pixel was calculated per Equation 4.1, [4.1] $C F L=\sum_{i=1}^{20}\left(F_{i} * P_{i}\right)$

where $F_{i}=$ the midpoint of the $i^{\text {th }}$ flame length category and $P_{i}=$ the proportion of time a given pixel experienced $F_{i}$.

Figure 4.5 illustrates the pixel by pixel CFL values for the untreated scenario. Once the CFL value was calculated for each pixel in the study site, I calculated the mean values for the entire study site and the WUI threat zone area within the study site. 
Statistical analyses for mean burn probability and mean CFL were precluded because the outputs represent the entire population. As a result, I did not report statistical significance for these variables but instead compared outputs across the entire population. I did statistically analyze the results of mean fire size using a Kruskal-Wallis nonparametric test and a Dunn's method for median separation at pooled alpha level of 0.05 with individual Bonferroni alphas of 0.00064 . This individual alpha was derived by dividing the pooled alpha of 0.05 by 78 , the total number of possible pairwise comparisons between the 13 scenarios. I used non-parametric statistical analysis because the fire size data did not conform to the assumptions of equal variance and normal distribution required for parametric ANOVA analysis.

\subsection{Results}

The untreated landscape had the highest mean burn probability of all scenarios for the entire study site (0.0057) and within the WUI threat zones (0.0058; Table 4.4, Figure 4.6). The untreated landscape also had the greatest mean CFL for the study site $(1.88 \mathrm{~m})$ and in the WUI threat zones (2.084 m; Table 4.5, Figure 4.7). The mean fire size (896.81 ha) for ignitions within the study for the untreated landscape was significantly larger than all treatment scenarios except the prescribed fire treatment type at the $10 \%$ treatment intensity ( $\mathrm{p}<0.001$; Table 4.6, Figure 4.8). 
Table 4.4 Maximum and mean burn probability values for the study site and WUI threat zones within the study site. WUI threat zones are 1.5 radius zones around designated WUI communities in or adjacent to the study site (USDA Forest Service 2002).

\begin{tabular}{|c|c|c|c|c|}
\hline \multirow{2}{*}{ Scenario } & \multicolumn{2}{|c|}{ Study Site } & \multicolumn{2}{|c|}{ WUI Threat Zone } \\
\hline & MAX & MEAN & MAX & MEAN \\
\hline Untreated & 0.0193 & 0.0057 & 0.0192 & 0.0058 \\
\hline \multicolumn{5}{|c|}{ Site-Specific Treatments } \\
\hline Mech. Units & 0.0190 & 0.0045 & 0.0148 & 0.0038 \\
\hline Rx Fire & 0.0193 & 0.0042 & 0.0160 & 0.0036 \\
\hline Total Design & 0.0189 & 0.0036 & 0.0160 & 0.0028 \\
\hline \multicolumn{5}{|c|}{ Spatially-optimized } \\
\hline \multicolumn{5}{|l|}{ Rx Fire } \\
\hline $10 \%$ & 0.0193 & 0.0053 & 0.0141 & 0.0053 \\
\hline $20 \%$ & 0.0166 & 0.0022 & 0.0078 & 0.0022 \\
\hline $30 \%$ & 0.0158 & 0.0023 & 0.0058 & 0.0019 \\
\hline \multicolumn{5}{|c|}{ Spatially-optimized } \\
\hline \multicolumn{5}{|l|}{ Mastication } \\
\hline $10 \%$ & 0.0184 & 0.0042 & 0.0142 & 0.0038 \\
\hline $20 \%$ & 0.0196 & 0.0025 & 0.0152 & 0.0020 \\
\hline $30 \%$ & 0.0191 & 0.0025 & 0.0099 & 0.0020 \\
\hline \multicolumn{5}{|c|}{$\begin{array}{l}\text { Spatially- } \\
\text { optimized Thin + Burn }\end{array}$} \\
\hline $10 \%$ & 0.0184 & 0.0052 & 0.0134 & 0.0048 \\
\hline $20 \%$ & 0.0166 & 0.0033 & 0.0113 & 0.0030 \\
\hline $30 \%$ & 0.0074 & 0.0016 & 0.0073 & 0.0016 \\
\hline
\end{tabular}


A

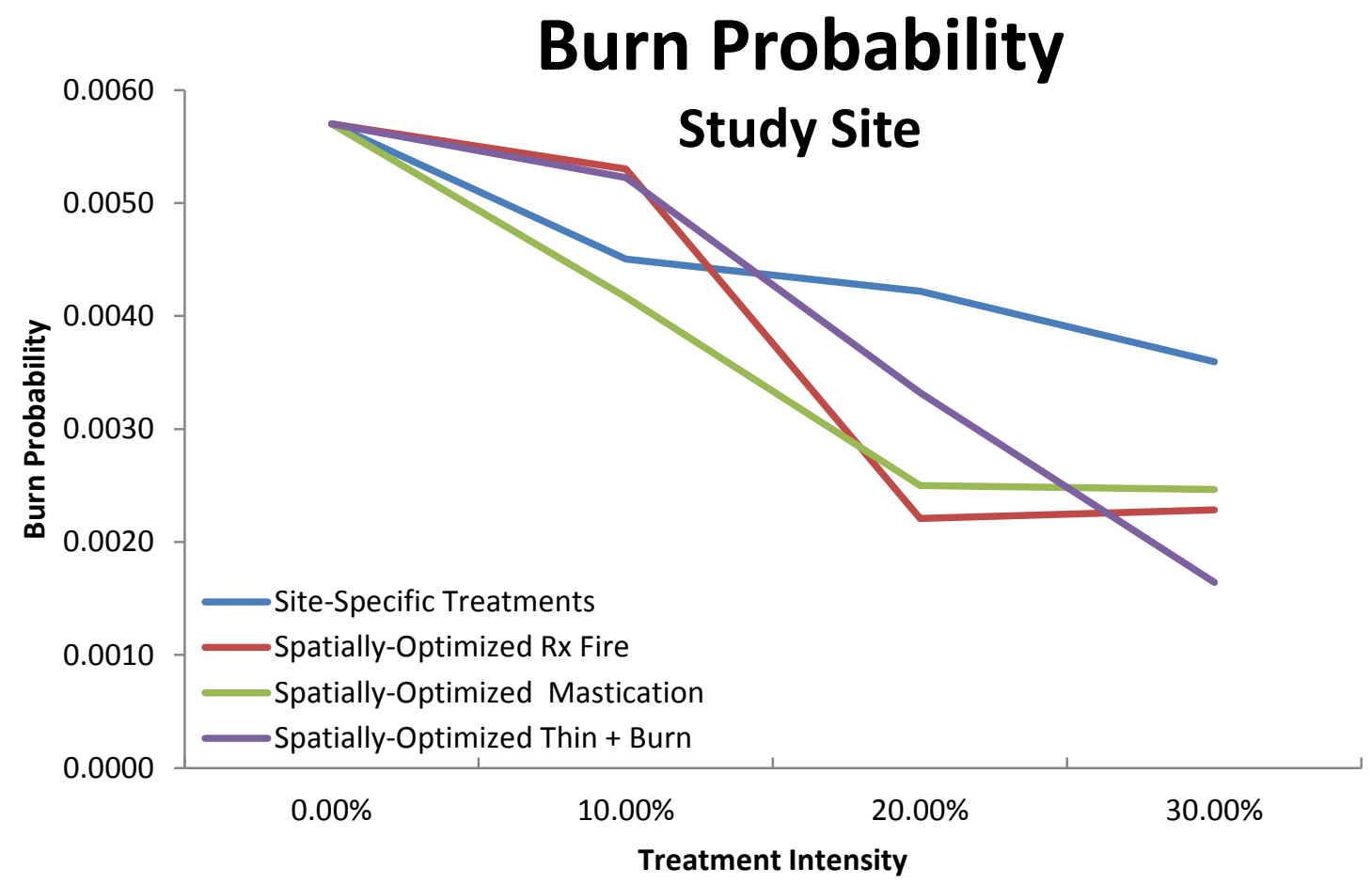

B

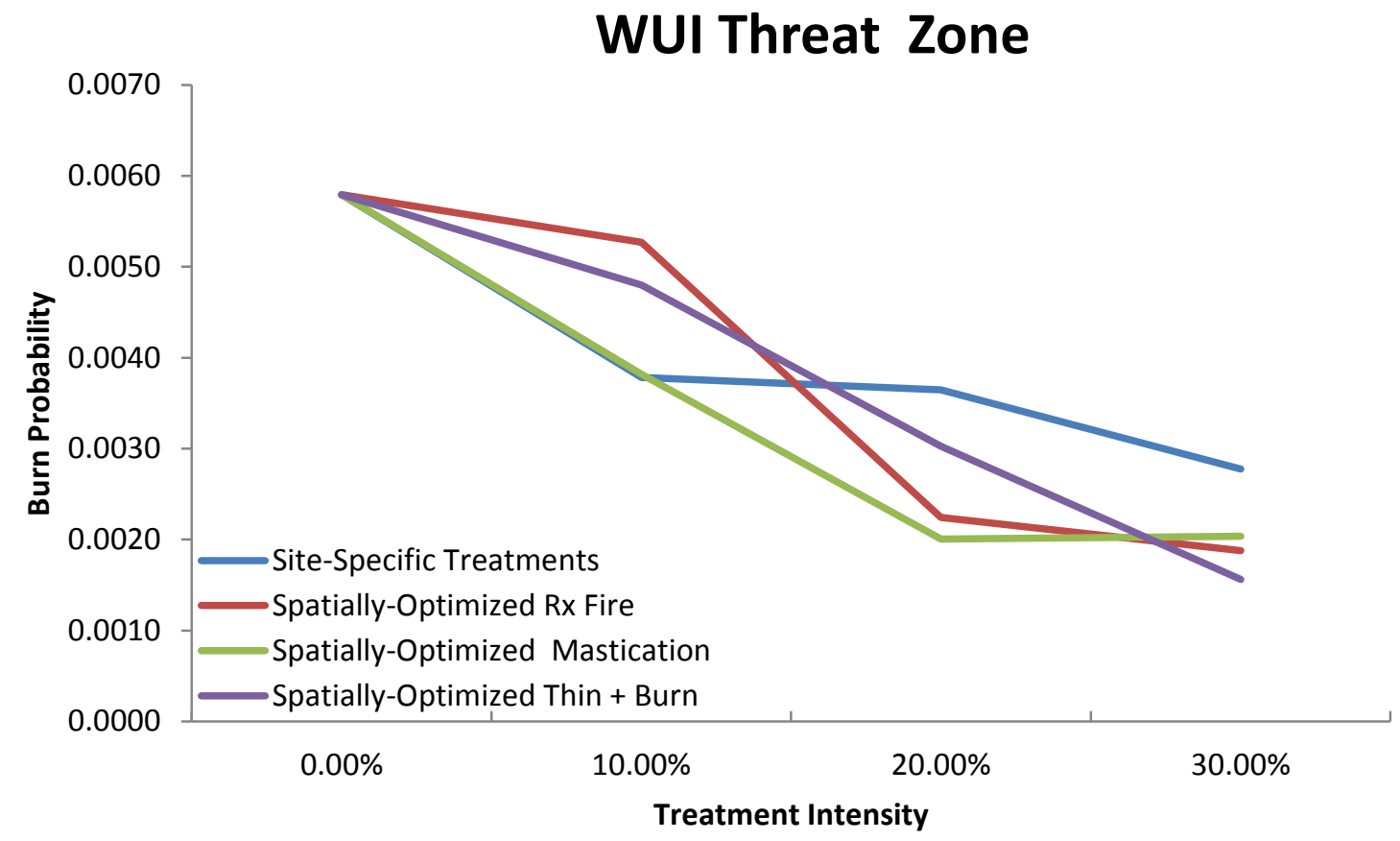

Figure 4.6 Mean burn probability for the entire study site (A) and within WUI threat zones (B) for each treatment type at increasing treatment intensities. Site-specific treatments are not precisely at the $10 \% .20 \%$ and $30 \%$ levels but are approximates. 
For the site-specific treatment scenarios, fire behavior metrics decreased as treatment area increased. For example, the mean burn probability across the study site for site-specific treatments ranged from a high of 0.0045 for the mechanical units (the lowest area treated) to a low of 0.0036 for the highest treatment intensity (total design; Table 4.4). Within WUI threat zones, the same pattern of burn probability appeared, with the highest value for the site-specific treatments present in the mechanical units (0.0038) and the lowest value with the total design (0.0028; Table 4.4). The pattern of CFL results within the site specific treatment scenarios was the same as burn probability; mechanical units had the largest value for the entire study site $(1.5164 \mathrm{~m})$ and within the WUI threat zones (1.7746 m; Table 4.5). With mean CFL's of $1.3545 \mathrm{~m}$ and $1.4869 \mathrm{~m}$ for the study site and WUI threat zone respectively, the total design had the lowest CFL values of the site-specific treatment scenarios. Mean fire size among the site-specific treatment scenarios decreased significantly $(\mathrm{p}<0.001)$ as the percent of the study site treated increased (Table 4.6, Figure 4.8), with the largest mean fire size present under the prescribed fire scenario (719.39 ha), and the smallest under the total design scenario (349.56 ha; Table 4.6). 
Table 4.5 Average conditional flame length (CFL; m) for the study site and WUI threat zones within the study site. WUI threat zones are 1.5 mile radius zones around designated WUI communities in or adjacent to the study site (USDA Forest Service 2002).

\begin{tabular}{lccc}
\hline \multicolumn{1}{c}{ Scenario } & Study Site & & WUI Threat Zones \\
\cline { 2 - 2 } MEAN (m) & & MEAN (m) \\
\hline Untreated & 1.8800 & & 2.0840 \\
Site-Specific Treatments & & \\
Mech. Units & 1.5164 & & 1.7746 \\
Rx Fire & 1.4848 & & 1.6323 \\
Total Design & 1.3545 & & 1.4869 \\
Spatially-Optimized Rx Fire & & \\
$10 \%$ & 1.6237 & & 1.7452 \\
$20 \%$ & 1.2290 & & 1.3574 \\
$30 \%$ & 1.2421 & & 1.2957 \\
Spatially-Optimized Mastication & & \\
$10 \%$ & 1.5009 & & 1.5779 \\
$20 \%$ & 1.2791 & & 1.3423 \\
$30 \%$ & 1.2658 & & 1.3023 \\
Spatially-Optimized Thin + Burn & & \\
$10 \%$ & 1.6219 & \\
$20 \%$ & 1.4139 & 1.7363 \\
$30 \%$ & 1.1997 & 1.5107 \\
\hline
\end{tabular}


A

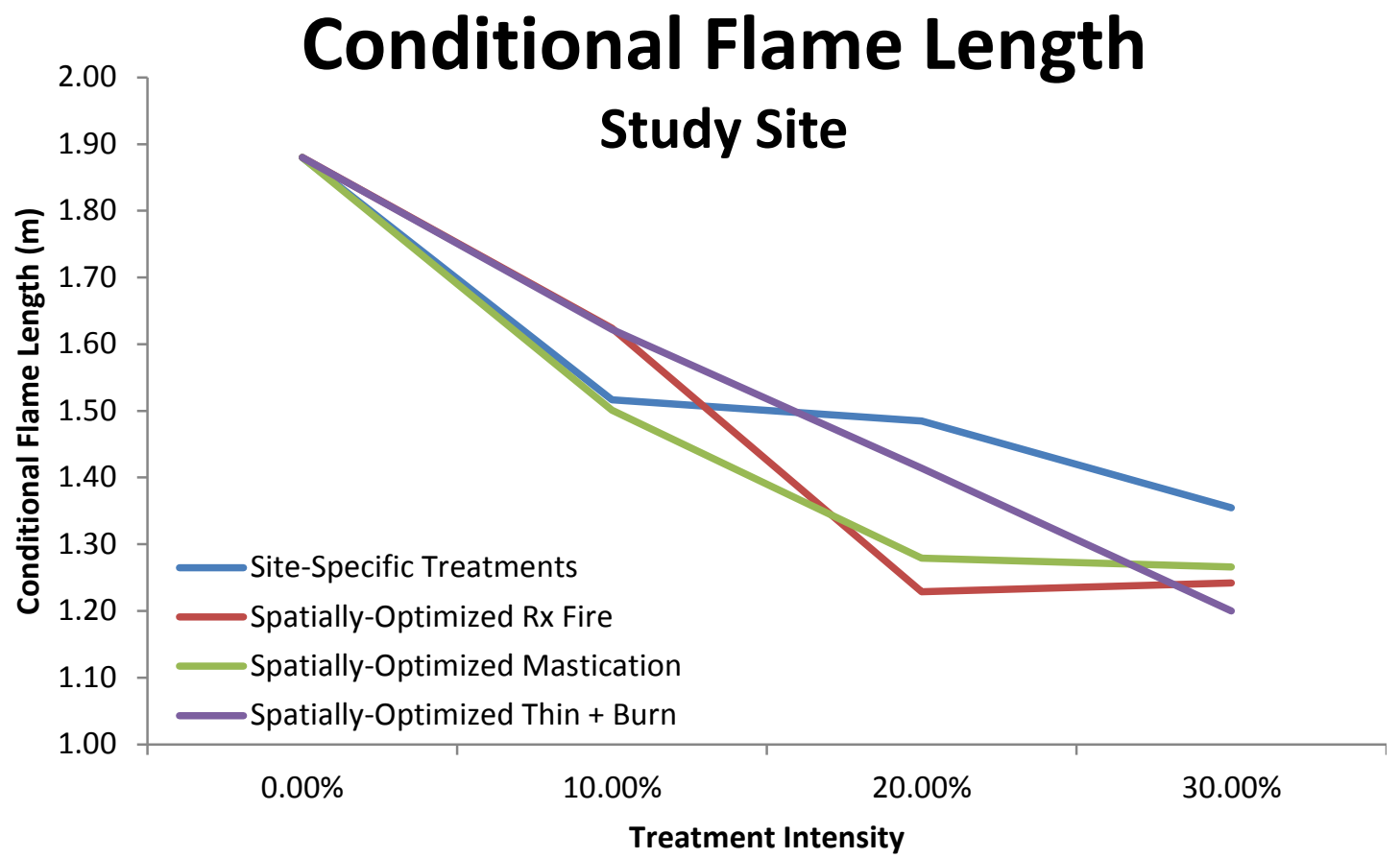

B

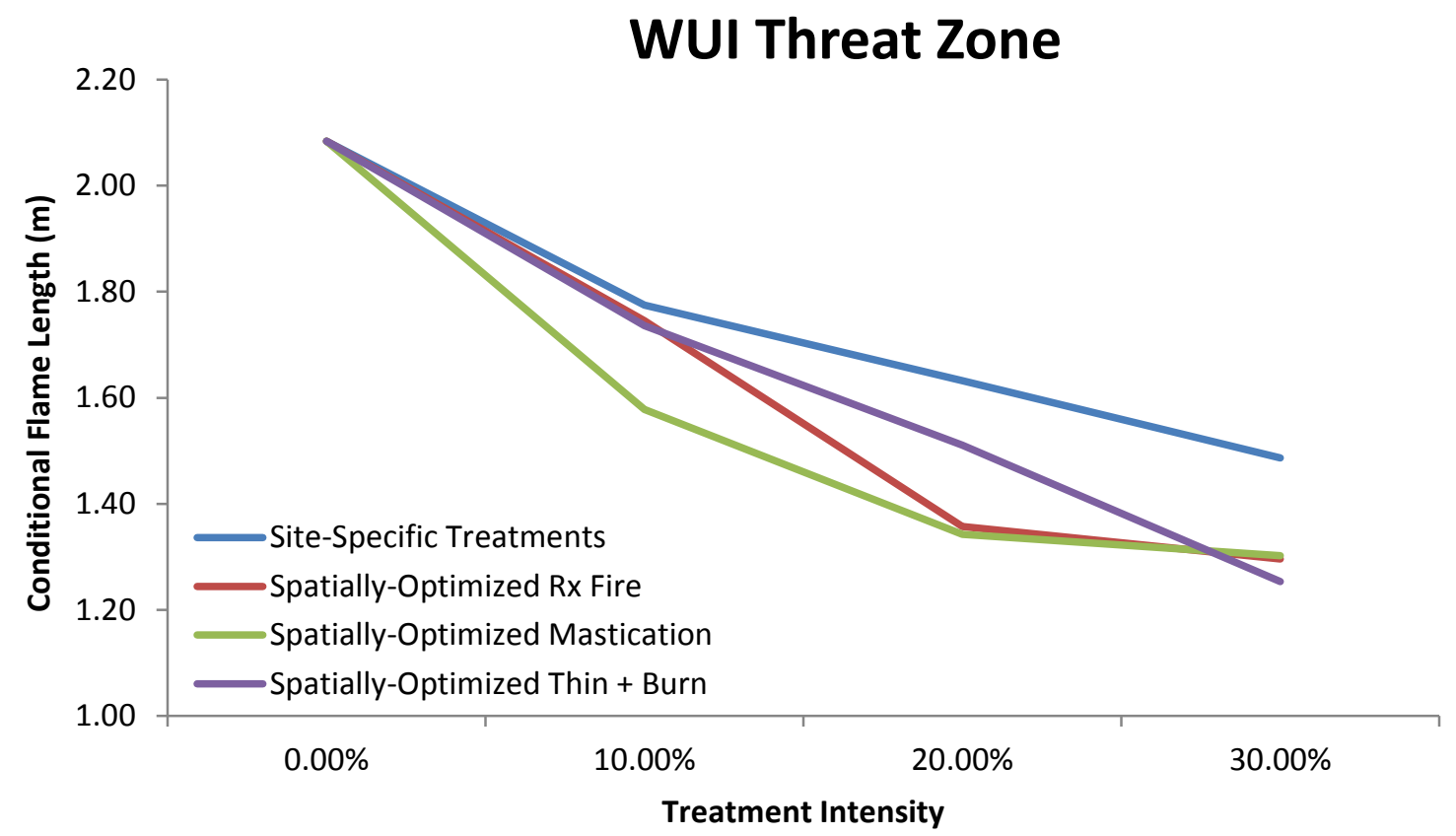

Figure 4.7 Mean conditional flame lengths within the entire study site (A) and the WUI threat zones (B) for each treatment type at increasing treatment intensities. Site-specific treatments are not precisely at the $10 \% .20 \%$ and $30 \%$ levels but are approximates. 
All spatially spatially-optimized treatment scenarios had study site and WUI threat zone mean burn probabilities that were lower than the untreated scenario. With a mean burn probability of 0.0053 for the study site and the WUI threat zones, prescribed fire at the $10 \%$ treatment intensity had the highest study site and WUI threat zone burn probabilities of the spatially-optimized treatments (Table 4.4). The lowest mean burn probabilities of the spatially-optimized treatments were under the thin + burn treatment type at the $30 \%$ treatment intensity, with a value of 0.0016 in both the entire study site and in the WUI threat zones.

Table 4.6 Fire size attributes for all treatment scenarios and the untreated scenario. Fire size of 500 ha and greater was considered as a major fire event in our calibration so a reduction in these large fires indicates effectiveness of treatments in reducing the potential severity of wildfires across the landscape. The number of ignitions is the number of random ignitions that landed inside our study site for each scenario during its Randig simulation.

\begin{tabular}{|c|c|c|c|c|c|c|}
\hline Scenario & $\begin{array}{c}\text { \# of } \\
\text { Ignitions }\end{array}$ & $\begin{array}{c}\text { Mean } \\
\text { Size } \\
\text { (ha) }\end{array}$ & $\begin{array}{c}\text { Median } \\
\text { Size } \\
\text { (ha) }\end{array}$ & $\begin{array}{l}\text { Std. } \\
\text { Error }\end{array}$ & $\begin{array}{l}\% \text { Fires } \\
>500 \text { ha }\end{array}$ & $\begin{array}{l}\text { Max } \\
\text { Size } \\
\text { (ha) }\end{array}$ \\
\hline Untreated & 2968 & 896.81 & 677.61 & 14.924 & $62.20 \%$ & 6038.64 \\
\hline \multicolumn{7}{|c|}{ Site-Specific Treatments } \\
\hline Mech. Units & 2895 & 719.39 & 524.97 & 13.402 & $51.85 \%$ & 5678.55 \\
\hline Rx Fire & 2971 & 638.41 & 457.38 & 12.246 & $46.55 \%$ & 5549.31 \\
\hline Total Design & 2866 & 568.23 & 349.56 & 12.611 & $38.63 \%$ & 5380.74 \\
\hline \multicolumn{7}{|c|}{ Spatially-optimized } \\
\hline $10 \%$ & 2976 & 797.18 & 611.01 & 13.069 & $57.90 \%$ & 5455.98 \\
\hline $20 \%$ & 2960 & 320.37 & 216.81 & 6.159 & $19.80 \%$ & 3311.73 \\
\hline $30 \%$ & 3013 & 346.15 & 223.11 & 7.506 & $20.88 \%$ & 3869.19 \\
\hline \multicolumn{7}{|c|}{$\begin{array}{l}\text { Spatially-optimized } \\
\text { Mastication }\end{array}$} \\
\hline $10 \%$ & 2764 & 698.12 & 529.83 & 12.430 & $52.79 \%$ & 5529.42 \\
\hline $20 \%$ & 2417 & 448.75 & 328.86 & 9.191 & $31.69 \%$ & 4432.68 \\
\hline $30 \%$ & 2441 & 457.73 & 312.84 & 10.094 & $29.70 \%$ & 4766.40 \\
\hline \multicolumn{7}{|c|}{$\begin{array}{l}\text { Spatially-optimized } \\
\text { Thin + Burn }\end{array}$} \\
\hline $10 \%$ & 2984 & 756.20 & 599.58 & 12.022 & $58.21 \%$ & 6334.74 \\
\hline $20 \%$ & 2956 & 506.50 & 344.52 & 9.696 & $35.55 \%$ & 5383.71 \\
\hline $30 \%$ & 2935 & 238.31 & 173.88 & 4.399 & $11.58 \%$ & 2347.11 \\
\hline
\end{tabular}


All mean CFL values for the spatially-optimized treatments were less than the mean CFL values for the untreated landscape. The prescribed fire treatment at the $10 \%$ treatment intensity had the largest mean CFL values both for the study site $(1.6237 \mathrm{~m})$ and within the WUI threat zones $(1.7452 \mathrm{~m}$; Table 4.5). The thin + burn treatment at the $30 \%$ intensity had the lowest mean CFL for the study site at $1.1997 \mathrm{~m}$ and the lowest mean CFL in the WUI threat zones at $1.2532 \mathrm{~m}$ (Table 4.5). Mean fire size across the spatially-optimized treatment scenarios was highly variable. Prescribed fire at the $10 \%$ treatment intensity had the largest mean fire size, 719.39 ha, which was not significantly different from the untreated landscape (Table 4.6, Figure 4.8). With a mean fire size of 238.31 ha, the thin + burn treatment at the $30 \%$ intensity significantly $(\mathrm{p}<0.001)$ reduced fire size more than any other treatment scenario.

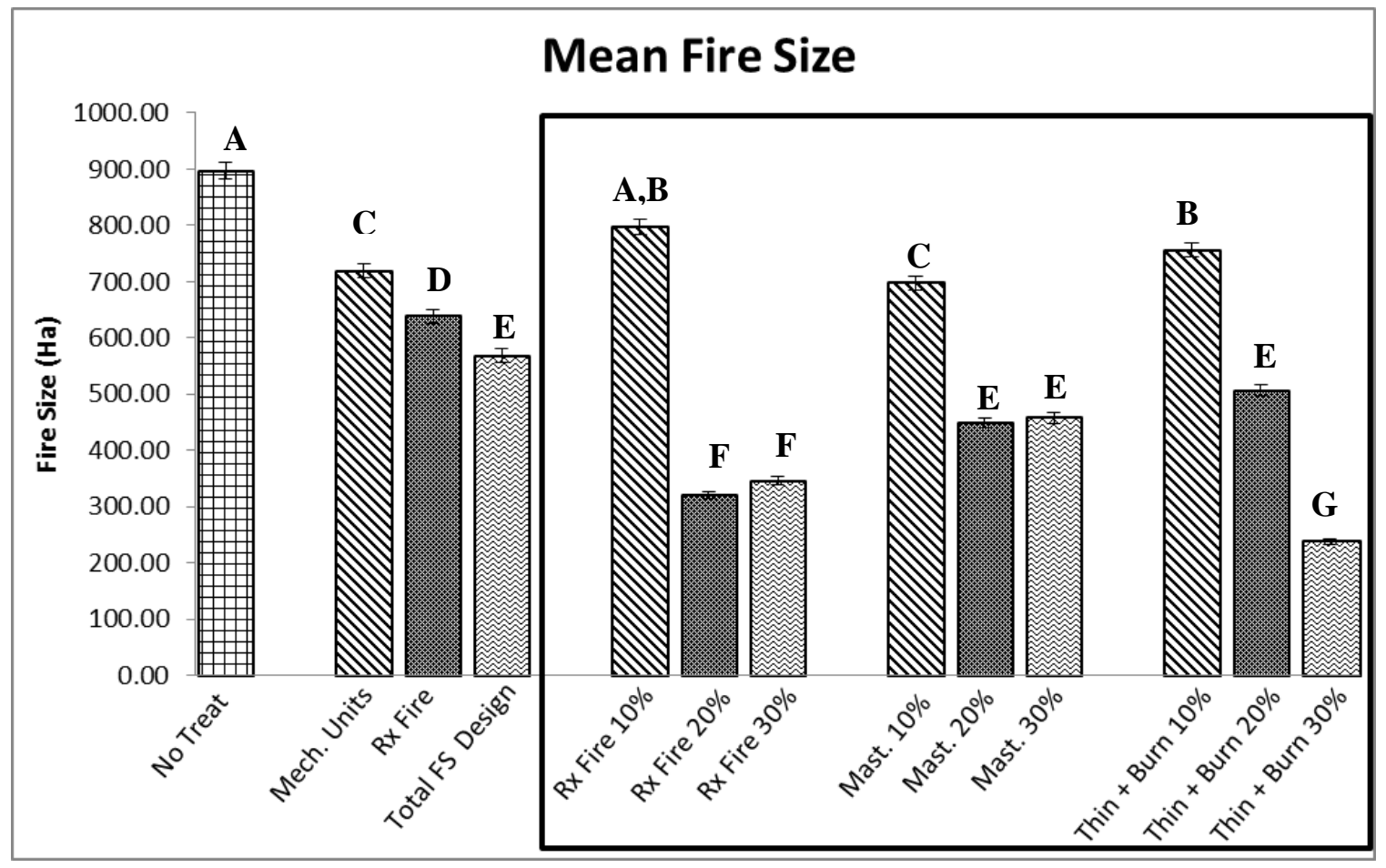

Figure 4.8 Mean fire size for each treatment scenario. Scenarios that share a letter have median values that did not significantly differ from one another. Significance was determined using a Kruskal-Wallis non-parametric test and a Dunn's multiple comparisons test with a pooled alpha of 0.05. Error bars represent +/- standard error. Treatments inside the solid box are spatiallyoptimized; treatments outside the box are site-specific treatment 


\subsection{Discussion}

The complex nature of modeling requires accepting a number of assumptions, including constant weather, a defined burn period, fire spread algorithms accuracy, and the accuracy of the growth and yield models. However, all the treatments were subject to the same assumptions, resulting in outputs that should be looked at as relative comparisons between treatments rather than precise predictive values. Our location represents an individual set of fuel loading values, topographic features, and assumed weather parameters, and therefore our results may not be representative of other locations. However, the process utilized here could be utilized on other landscapes to determine the potential impacts varied landscape-scale fuel treatment scenarios have on fire behavior and wildfire exposure. Having wildfire exposure potential can aid land managers in generating a risk assessment for a given area. Combining potential exposure with a set of expected outcomes for various levels of exposure generates a risk assessment profile for the resource being analyzed (Fairbrother and Turnley 2005). In this way the process demonstrated here could also aid in the creation of wildfire risk assessments.

Our results suggest that landscape-scale fuel treatments can reduce both potential wildfire exposures (as measured by burn probability), and fire intensity (as measured by CFL and fire size), organized in either a spatially-optimized pattern or designed as sitespecific treatments. The magnitude of the reduction depended upon the spatial arrangement of the treatments and the area treated, while the treatment type appeared to have less influence on the overall effectiveness (Figures 4.6-4.8). 
The mean burn probability across the entire landscape and within the WUI threat zone (USDA Forest Service 2002) of the site-specific mechanical treatments was very similar to or below the values of all three the spatially-optimized treatments at the $10 \%$ treatment intensity (Figure 4.6). At the lowest treatment intensity, the mean CFL value for the site-specific mechanical units was similar to or below the spatially-optimized treatments at their lowest intensity. This was true across the entire study area, but not within the WUI threat zones, where the spatially-optimized mastication treatments outperformed all others (Figure 4.7). Also at the lowest treatment intensity, mean fire size in the site-specific mechanical treatment design was equal to or significantly lower $(\mathrm{p}<$ 0.001) than all spatially-optimized treatments at their lowest treatment intensity (Figure 4.8).

However, as the treatment intensity increased, the site-specific designs no longer outperformed the spatially-optimized treatment designs at the analogous treatment intensity. At the highest treatment intensity (26\% and $30 \%$ for site specific and spatiallyoptimized, respectively), the site-specific treatments had the largest mean burn probability (Figure 4.6), the largest mean CFL (Figures 4.7), and the largest mean fire size (Figure 4.8) of all treatment types. The performance of the spatially-optimized designs at the increased treatment intensities confirms previous work on the performance of such treatments at the landscape-scale (Finney 2001; Schmidt et al. 2008; Ager et al. $2010 b)$.

The strong performance of the proposed site-specific treatments at the lowest treatment intensities is likely due to their spatial arrangement. The ridge top treatments that comprise the lowest treatment intensity for the proposed treatments are linear and 
have sections that run north to south and sections running east to west, resulting in compartmentalization of the ignitions. The spatially-optimized treatments are placed to maximize reductions in fire spread, subsequently reducing heading fires. At the lower intensity, it is likely that the spaces between the spatially-optimized treatments were sufficient to allow development of heading fire. In contrast, the linear nature of the proposed site-specific treatments did not allow a fire to flank around the treatment units into untreated corridors. The mechanical ridge top treatments also incorporate thin and burn treatment methods that remove fuel from all fuel strata (altering surface fuels, canopy base height, and canopy bulk density), thus generating the greatest reduction in fire behavior after a fire enters the treatment units. This greatly reduced forward rate of spread in these units, thereby reducing fire size given the fixed burn period duration.

The site-specific treatments did not lower fire behavior metrics more than the spatially-optimized treatments as the area treated increased, most likely due to two factors. The first is that as the size and frequency of spatially-optimized treatments increased the space between the treatment units decreased. This reduced corridors of heading fire spread, limiting spread rate, thus reducing CFL and average fire size. The second is the arrangement of the proposed treatments at the medium treatment intensity. In this scenario, the large prescribed fire units left the ridge tops untreated, leaving linear pathways for fire to spread unchecked as a heading fire. Though these units reduce the tested parameters because of their larger overall size, they do not perform as well as treatments spatially-optimized to reduce ROS covering amount of area. At the highest treatment intensity the proposed treatments did not have any improved spatial arrangement over the lower treatment intensities because this scenario was a combination 
of the two lower intensity scenarios. At the highest treatment intensity (30\% of the landscape treated), the spatially-optimized treatments did not have this limitation, and had an increased number of treatment units, subsequently limiting the locations for potential heading fire and reducing overall fire spread rates.

Reductions in fire intensity (as represented by CFL) are important for both protection of resource values and WUI structures. In forest vegetation types, more intense fires often result in more severe fire effects impacting the surrounding vegetation, resulting in higher mortality of large trees and degradation of late-successional habitat. More intense fires and the resulting high severity fire effects are particularly linked in areas such as the Klamath Mountains where the historic fire regime was characterized by frequent, low intensity fires (Taylor and Skinner 1995). Reduced flame lengths reduce the potential for crown fire activity, resulting in danger to structures during a wildfire event through ember production radiant heat (Cohen 1995; Cohen 2000; Murphy et al. 2007).

Reductions in fire size suggest that spatially-optimized treatments and sitespecific treatments both have the potential to protect areas of the landscape that are not included in the treatment units. This means that, given a severe fire event, fewer critical habitats will be consumed and there is a reduced chance of the large spread event impacting one of the bordering WUI communities. Again, the performance of the sitespecific scenario from the Forest Service proposal is similar to the performance of the spatially-optimized treatment scenarios at the lowest treatment intensity, having significantly lower mean fire size than all other treatment scenarios at their lowest intensity. Because of the reduced fire size and reductions in burn probability and CFL in WUI threat zones, land managers may be able to offer protection to WUI communities 
without specifically implementing treatments along WUI boundaries. The strong performance of the site-specific design at the lowest treatment intensity may offer land managers a level of confidence to implement landscape level treatments without having to adhere to strictly spatially-optimized treatments to protect resources by reducing the potential size of large fire spread events.

For the majority of the scenarios and for the majority of response variables, there was a non-linear trend as treatment intensity increased. The exception to this was the thin + burn treatment in regard to CFL across the study site. This suggests that treating $10 \%$ to $20 \%$ of the landscape provides the greatest reduction in fire behavior variables and that treating beyond this level does not generate the same level of reduction. This study also suggests that at lower treatment intensities the spatially-optimized treatments do not outperform the site-specific scenarios derived from the Forest Service proposal.

\subsubsection{Management Implications}

Given the often non-linear response of burn probability, fire intensity and fire size to increasing treatment intensity, and the performance of the site-specific treatments at lower intensities, our study suggests that there may be instances where ridge-top and topographically oriented fuel treatments are as effective as spatially-optimized treatment designs targeted at ROS reductions. This is not to say that spatially-optimized treatments are not effective or important to consider when planning fuel treatments. Including the principal of slowing fires by reducing heading fire spread and placing fuel treatments in expected paths of fire spread is important in placing landscape-level treatments even if they are not wholly spatially-optimized with the TOM model. If funding limits the 
amount of area to be treated to near $10 \%$ of the landscape, then using non-optimized ridge top treatments may be a valid option. If funding is sufficient for more than $10 \%$ $20 \%$ of the landscape to be treated, using a more spatially-optimized treatment design may be beneficial. If this is to be considered, it must be kept in mind that the cost of implementing spatially-optimized treatments may be considerably higher per-hectare due to the scattered nature of the treatment units. This may require moving from location to location as well as possible limitations due to topography and sensitive habitat types that may make spatially-optimized designs entirely impossible to implement.

When considering the Eddy Gulch Project proposal, it appeared that the ridge top mechanical treatments disrupted the fire growth as well as spatially-optimized treatments at the same amount of area treated. If the proposed Eddy Gulch project is to be implemented, prioritizing the linear ridge top treatment may be beneficial. The large scale prescribed fire units may be more beneficial coming secondarily, with the understanding that they will not create the same level of reductions in fire behavior parameters but will improve overall fuel loadings across the landscape and increase the ability of the landscape to remain resilient to future fire. 


\subsection{Final Conclusions}

The nature of simulation modeling and the inherent uncertainty of simulating fire and vegetative growth over a large area for a long period of time preclude the use of the results of this study as predictive values. However, because each simulation tested the same landscape independently, the relative outcomes can be thought of as comparative values. Given the results, I feel confident rejecting the null hypotheses and accepting the alternative hypotheses: varied landscape-scale fuel treatment scenarios differ in their effects on burn probability, conditional flame length, and mean fire size and varied landscape-scale fuel treatment scenarios differ in their effects on short-term onsite carbon loss and long-term onsite carbon storage. Given previous work simulating landscapescale fuel treatments, this result is not surprising. It confirms that varying arrangement, type, and intensity of fuel treatments can alter how fire behavior and carbon variables respond to treatment (Stratton 2004; Schmidt et al. 2008; Ager et al. 2010b).

The results for short-term onsite carbon loss and long-term onsite carbon storage varied widely with treatment type, arrangement, and intensity (Figures 3.6 and 3.7). Some treatment scenarios outperformed the untreated landscape, losing less onsite carbon in the short-term than an untreated landscape, while others lost more carbon than the untreated landscape (Figure 3.6). Overall, mastication had the lowest short-term carbon loss because it removed no carbon during treatments (Figure 3.6). The results were similar for long-term onsite carbon storage, with some scenarios storing more carbon than the untreated landscape and others storing less carbon than the untreated landscape. Prescribed fire appeared to have the largest long-term carbon storage (Figure 3.7). Each spatially-optimized treatment type and the site-specific treatments maximized long-term onsite carbon storage at the $20 \%$ treatment intensity (Figure 3.7 ). This suggests that land 
managers desiring to maximize long-term carbon storage may want to consider treating no more than $20 \%$ of their land area.

The results also suggest that all treatment types, arrangements, and intensities tested can reduce burn probability and flame length below the levels of an untreated landscape, with the amount of reduction primarily dependent upon treatment arrangement and intensity, with treatment type having a lower effect (Figures 4.6 \& 4.7). Mean fire size was significantly reduced in all scenarios but one, with the most important factors in reducing mean fire size being treatment intensity and arrangement (Figure 4.8). For the majority of the scenarios and for the majority of fire behavior response variables, there was a non-linear reduction in fire behavior as treatment intensity increased. The reduction in fire behavior was lower when moving from the $20 \%$ treatment intensity to the $30 \%$ than when moving from $10 \%$ to $20 \%$, indicating a diminishing return from treating more than $20 \%$ of the landscape. At the $20 \%$ treatment intensity, the site-specific treatments performed well in comparison to the spatially-optimized scenarios, indicating that land managers may be able to implement landscape-scale fuel treatments with the benefits of spatially-optimized designs without implementing them exactly as required by optimization models.

For the specific landscape in this study, the results suggest that treating $20 \%$ of the landscape with prescribed fire in a spatially-optimized pattern is the ideal scenario to balance between reductions in fire behavior parameters with maximization of carbon retention. No other treatment was able to limit fire behavior and still outperform the untreated landscape in short-term and long-term carbon as well as this scenario. 
The results suggest that common fuel treatment methods limit fire growth and intensity across a landscape and that there are impacts to carbon dynamics when fuel treatments are implemented. However, if planned appropriately, landscape-scale fuel treatments have the potential to improve carbon storage while simultaneously reducing fire behavior.

However, this study did have limitations that future research may be able to resolve. A complete analysis of the use of harvested wood products may improve the understanding of carbon storage levels resulting from thin + burn treatments. Also, accounting for carbon released during treatment implementation (e. g. vehicle emissions) may alter the short-term carbon losses from treatments. Finally, the spatially optimized designs may prove difficult to implement. A more rigorous analysis of placement practicality for spatially-optimized designs may result in altered treatment locations, potentially influencing the effect treatments have on fire behavior and carbon dynamics.

Because of the complex nature of interactions that influence fire behavior and carbon cycles, managers should be cautions if considering applying these results to a different location or landscape. However, the methods developed here can be applied to conduct a similar analysis of any given landscape so long as the data are available. It is my hope that land managers and decision makers across the western US utilize this method for investigating the tradeoffs associated with landscape-scale fuel treatment implementation. 


\subsection{References}

Agee JK. (1974). Fire management in the national parks. Western Wildlands 1: 27-33.

Agee JK. (2002). The fallacy of passive management: managing for firesafe forest reserves. Conservation in Practice 3 (1): 18-25.

Agee JK. (2007). Steward's fork: a sustainable future for the Klamath Mountains. Berkeley and Los Angeles: University of California Press.

Agee JK, Bahro B, Finney MA, Omi PN, Sapsis DB, Skinner CN, van Wagtendonk JW, Weatherspoon CP. (2000). The use of shaded fuel breaks in landscape fire management. Forest Ecology and Management 127: 55 - 66.

Agee JK, Skinner CN. (2005). Basic principles of forest fuel reduction treatments. Forest Ecology and Management 211: 83-96.

Ager AA, Finney MA, McMahan AJ. (2006). A wildfire risk modeling system for evaluating landscape fuel treatment strategies. In: Andrews, P.L., Butler, B.W. (comp.), Fuels Management-How to Measure Success. USDA Forest Service, Rocky Mountain Research Station Proceedings RMRS-P-41. p 149-162.

Ager AA, McMahan AJ, Barrett JJ, McHugh CW. (2007) A Simulation study of thinning and fuel treatments on a wildland-urban interface in eastern Oregon, USA. Landscape and Urban Planning 80:292-300.

Ager AA, Finney MA, McMahan A, Cathcar J. (2010a). Measuring the effect of fuel treatments on forest carbon using landscape risk analysis. Natural Hazards and Earth System Sciences 10: 2515-2526.

Ager AA, Vaillant NM, Finney MA. (2010b). A comparison of landscape fuel treatment strategies to mitigate wildland fire risk in the urban interface and preserve old forest structure. Forest Ecology and Management 259: 1556-1570. 
Ager AA, Vaillant NM, Finney MA. (in press). Applications of fire behavior models and geographic information systems for wildfire risk assessment and fuel management programs. Journal of Combustion.

Alexander JD, Seavy NE, Ralph CJ, Hogoboom B. (2006). Vegetation and topographical correlates of fire severity from two fires in the Klamath-Siskiyou region of Oregon and California. International Journal of Wildland Fire 15: 237-245.

Anderson HE. (1982). Aids to de197ining fuel models for estimating fire behavior. Gen. Tech. Rep. INT-122. Ogden, UT: U.S. Department of Agriculture, Forest Service, Intermountain Forest and Range Experiment Station. 22 p.

Andrews PL, Queen LP. (2001). Fire modeling and information system technology. International Journal of Wildland Fire 10: 343 - 352.

Boerner REJ, Huang J, Hart SC. (2008). Fire, thinning, and the carbon economy: Effects of fire and fire surrogate treatments on estimated carbon storage and sequestration rate. Forest Ecology and Management 255: 3081 - 3097.

Brown JK. (1974). Handbook for inventorying downed woody material. USDA Forest Service, Intermountain Forest and Range Experiment Station, General Technical Report INT-16. (Ogden, UT).

Busse MD, Hubbert KR, Fiddler GO, Shestak CJ, Powers RF. (2005). Lethal soil temperatures during burning of masticated forest residues. International Journal of Wildland Fire 14: 267 - 276.

Carle D. (2002). 'Burning questions: America's fight with nature's fire' (Praeger Publishers: Westport, CT). 
Climate Action Reserve. (2009). Forest project protocol, version 3.1.

http://www.climateactionreserve.org/how/protocols/adopted/forest/development/ Accessed 1 June, 2011.

Cohen JD. (1995). 'Structure Ignition Assessment Model (SIAM)'. USDA Forest Service, Pacific Southwest Research Station - General Technical Report PSWGTR-158.

Cohen JD. (1999). Reducing the wildland fire threat to homes: Where and how much?. In: Gonzales-Caban, Armando; Omi, Philip N., technical coordinators. Proceedings of the Symposium on Fire Economics, Planning, and Policy: Bottom Lines; 1999 April 5-9. San Diego, CA. Gen. Tech. Rep. PSW-GTR-173. Albany, CA: U.S. Department of Agriculture, Forest Service, Pacific Southwest Research Station. p. 189-195.

Cohen JD. (2000). Preventing disaster: home ignitability in the wildland-urban interface. Journal of Forestry 98: 15-21.

Collins BM, Stephens SL, Moghaddas, JJ, Battles, J. (2010). Challenges and approaches in planning fuel treatments across fire-excluded landscapes. Journal of Forestry 108(1): $24-31$

Collins BM, Stephens SL, Roller GB, Battles JJ. (2011). Simulating Fire and Forest Dynamics for a Landscape Fuel Treatment Project in the Sierra Nevada. Forest Science 57(2): 77-88.

Davis B, Miller C. (2004). Modeling Wildfire Probability using a GIS. In: Proceedings of the ASPRS 2004 Annual Conference, May 23-28, Denver, USA. 3p. 
Dicus CA, Scott ME. (2006). Reduction of potential fire behavior in wildland-urban interface communities in southern California: a collaborative approach. In: Andrews, P.L., Butler, B.W. (comps), Fuels Management-How to Measure Success: Conference Proceedings. Portland, OR, March 28-30, 2006, pp. $729-$ 738; Proceedings RMRS-P-41, USDA Forest Service, Rocky Mountain Research Station, Fort Collins, CO, 809 pp.

Dicus CA. (2009). Changes to simulated fire behaviour and societal benefits after two levels of thinning in a mixed-conifer wildland-urban interface community. Proceedings of the Royal Society of Queensland 115, 37-44. Brisbane, Australia.

Dicus CA, Delfino K, Weise DR. (2009). Predicted fire behavior and societal benefits in three eastern Sierra Nevada vegetation types. Fire Ecology 5(1): 67-78.

Dixon GE. comp. (2002). Essential FVS: A user's guide to the Forest Vegetation Simulator. Internal Rep. Fort Collins, CO: U. S. Department of Agriculture, Forest Service, Forest Management Service Center. 220p. (Last Revised: January 5, 2010). Accessed http://www.fs.fed.us/fmsc/fvs/.

ESRI Corp. (2009). ArcMap - ArcInfo: Version 9.3.1. Redlands CA.

Fairbrother A, Turnley JG. (2005). Predicting risks of uncharacteristic wildfires: Application of the risk assessment process. Forest Ecology and management 211: $28-35$.

Finkral AJ, Evans AM. (2008). The effects of a thinning treatment on carbon stocks in a northern Arizona ponderosa pine forest. Forest Ecology and Management 255: $2743-2750$ 
Finney MA. (2001). Design of regular landscape fuel treatment patterns for modifying fire growth and behavior. Forest Science 47: 219-228.

Finney MA. (2002) Fire growth using minimum travel time methods. Canadian Journal of Forest Research 32: 1420-1424.

Finney MA. (2004). Chapter 9, 'Landscape fire simulation and fuel treatment optimization.’ In: J.L. Hayes, A.A., J.R. Barbour, (tech. eds). Methods for integrated modeling of landscape change: Interior Northwest Landscape Analysis System. USDA Forest Service, Pacific Northwest Research Station - General technical Report PNW-GTR-610. p 117-131. Portland, OR.

Finney MA. (2006). 'An Overview of FlamMap Fire Modeling Capabilities.' In: Andrews, Patricia L.; Butler, Bret W. Fuels Management-How to Measure Success: Conference Proceedings. RMRS-P-41. Fort Collins, CO.

Finney MA. (2007). A computational method for optimizing fuel treatment location. International Journal of Wildland Fire 16: 702-711.

Finney MA, Andrews PL. (1998). Application and status of the FARSITE fire area simulator. $3^{\text {rd }}$ international conference on forest fire research; 14 th conference on fire and forest meteorology, 21-22 November 1998, Luco-Coimbra, Portugal. Vol. I, pp. 755-760.

Finney MA, McHugh CW, Grenfell IC. (2005). Stand- and landscape level effects of prescribed burning on two Arizona wildfires. Canadian Journal of Forest Research 35: 1714-1722. 
Finney MA, Seli RC, McHugh CW, Ager AA, Bahro B, Agee JK. (2007). Simulation of long-term landscape-level fuel treatment effects on large wildfires. Internation Journal of Wildland Fire. 16: 712-727.

Fites-Kaufman JA, Reiner A, Beckman S, Dailey S, Noonan E, Ewell C, Decker T. (2007). Fuel Treatment Effectiveness and Effects Monitoring in the Pacific Southwest Region: Manager's Summary. Pacific Southwest Region Fire and Aviation Management.

Fried JS, Torn MS, Mills E. (2004). The Impact of Climate Change on Wildfire Severity: A Regional Forecast for Northern California. Climatic Change 64: 169-191.

Frost, EJ, Sweeney R. (2000). Fire Regimes, Fire History and Forest Conditions in the Klamath-Siskiyou Region: An Overview and Synthesis of Knowledge. Prepared for the World Wildlife Fund Klamath-Siskiyou Ecoregion Program, Ashland, OR. $59 \mathrm{p}$.

Graham RT, Harvey AE, Jain TB, Tonn JR. (1999). 'The effects of thinning and similar stand treatments on fire behavior in western forests.' USDA Forest Service, Pacific Northwest Research Station - General Technical Report PNW-GTR-463. Portland, OR.

Graham RT, McCaffrey S, Jain TB. (2004). 'Science basis for changing forest structure to modify wildfire behaviour and severity'. USDA Forest Service, Rocky Mountain Research Station - General Technical Report RMRS-GTR-120. Fort Collins, CO. 
Hamma CC. (2011). Effects of wildland-urban interface fuel treatments on potential fire behavior and ecosystem services in the central Sierra Nevada mountains of California (Master's Thesis). Retrieved from: http://digitalcommons.calpoly.edu/cgi/viewcontent.cgi article=1493\&context=the $\underline{\text { ses }}$

Hamilton K, Bayton R, Turner G, Douglas H. (2007). State of the Voluntary Carbon Market 2007: Picking Up Steam. Retrieved from: http://cbey.research.yale.edu/uploads/File/StateoftheVoluntaryCarbonMarket17Ju ly.pdf

Heinsch FA, Andrews PL. (2010). BehavePlus fire modeling system, version 5.0: Design and Features. Gen. Tech. Rep. RMRS-GTR-249. Fort Collins, CO: U.S. Department of Agriculture, Forest Service, Rocky Mountain Research Station. $111 \mathrm{p}$.

Houghton RA, Hackler JL. (2000). Changes in terrestrial carbon storage in the United States: The roles of agriculture and forestry. Global Ecology \& Biogeography 9: 125- 144.

Huggett RJ, Abt KL, Shepperd W. (2008). Efficacy of mechanical fuel treatments for reducing wildfire hazard. Forest Policy and Economics 10: 408-414.

Hurteau MD, Koch GW, Hungate BA. (2008). Carbon accounting and fire risk reduction: toward a full scale accounting of forest carbon offsets. Frontiers in Ecology and the Environment. 6: 493-498. 
Hurteau MD, North M. (2009). Fuel treatment effects on tree-based forest carbon storage and emissions under modeled wildfire scenarios. Frontiers in Ecology and the Environment 7: 409-414.

Hurteau MD, North M. (2010). Carbon recovery rates following different wildfire risk mitigation treatments. Forest Ecology and Management 260: 930-937.

Hurteau MD, Brooks ML. (2011). Short- and Long-term Effects of Fire on Carbon in US Dry Temperate Forest Systems. BioScience 61:139 - 146.

Hurteau MD, Stoddard MT, Fule PZ. (2011). The carbon costs of mitigating high severity wildfire in ponderosa pine. Global Change Biology 17: 1516-1521.

Jenkins JJ, Dicus CA, Godfrey JE. (1998). Restoration of mixed conifer communities using prescribed fire in Bryce Canyon National Park. pp. 231-235 in Fire in ecosystem management: shifting the paradigm from suppression to prescription, Teressa L. Pruden and Leonard A. Brennan (eds.). Tall Timbers Fire Ecology Conference Proceedings, No. 20. Tall Timbers Research Station, Tallahassee, FL. Johnson MC, Peterson DL. (2005). Forest fuel treatments in western North America: Merging Silviculture and fire management. The Forestry Chronicle 81: 365 - 368. Johnson JF, Bengston DN, Nelson KC, Fan DP. (2006). Defensible space in the news: public discussion of a neglected topic. In: McCaffrey, S.M., tech. ed. The public and wildland fire management: social science findings for managers, pp169-174. Gen. Tech. Rep. NRS-1. Newtown Square, PA: U.S. Department of Agriculture, Forest Service, Northern Research Station. 
Kane JM, Knapp EE, Varner JM. (2006). 'Variability in Loading of Mechanically Masticated Fuel Beds in Northern California and Southwestern Oregon.' In: Andrews, P.L., Butler, B.W. (comps), Fuels Management - How to Measure Success: Conference Proceedings. Portland, OR, March 28-30, pp. 340-351; Proceedings RMRS-P-41, USDA Forest Service, Rocky Mountain Research Station, Fort Collins, CO, 809 pp.

Kane MK, Varner JM, Knapp EE. (2009). Novel fuelbed characteristics associated with mechanical mastication in northern California and south-west Oregon, USA. International Journal of Wildland Fire 18: 686-697.

Kasischke ES, Hyer EJ, Novelli PC, Bruhwiler LP, French NHF, Sukhinin AI, Hweson JH, Stocks BJ. (2005). Influences of boreal fire emissions on Northern hemisphere atmospheric carbon and carbon monoxide. Global Biogeochemical Cycles 19: GB1012.

Keane RE, Veblen T, Ryan KC, Logan J, Allen C, Hawkes B. (2002). 'The cascading effects of fire exclusion in the Rocky Mountains'. In: Rocky Mountain Futures: An Ecological Perspective. Island Press, Washington, DC, USA, pp. 133-153.

Keane RE, Agee, JK, Fule, P, Keeley JE, Key C, Kitchen SG, Miller R, Schulte LA. (2008). Ecological effects of large fires on US landscapes: benefit or catastrophe? International Journal of Wildland Fire 17: 696-712.

Keeley JE. (2009). Fire intensity, fire severity and burn severity: A brief review and suggested usage. International Journal of Wildland Fire 18: 116-126. 
Knapp EE, Busse MD, Varner JM, Skinner CN. (2008). Masticated Fuel Beds: Custom Fuel Models, Fire Behavior and Fire Effects. Final Report to the Joint Fire Science Program.

Large JA. (2010). Effects of Wildland Urban interface Fuel treatments on Fire Behavior and Ecosystem Services in the Klamath Mountains of California (Master's Thesis). Retrieved from:http://digitalcommons.calpoly.edu/cgi/query.cgi?x_force_carryover=\&conn ector_all=and\&connector_1=and\&field_1=lname\&op_1=eq\&value_1=Large\&ad vanced $=1 \&$ advanced $=1 \&$ format=cover_page \&query $=$ Search

Loehle C. (2004). Applying landscape principles to fire hazard reduction. Forest Ecology and Management 198: 261-267.

Martinson EJ, Omi PN. (2003). Performance of fuel treatments subjected to wildfires. (U.S. Department of Agriculture Forest Service) USDA Forest Service, Rocky Mountain Research Station. Proceedings RMRS-P-29. Fort Collins, CO.

Mignone BK, Hurteau MD, Chen Y, Sohngen B. (2009). Carbon offsets, reversal risk and U.S. climate policy. Carbon Balance and Management 4: 3 .

Miller C, Urban DL. (2000). Modeling the effects of fire management alternatives on Sierra Nevada mixed-conifer forests. Ecological Applications 10; 85-94.

Miller JD, Skinner CN, Safford HD, Knapp EE, Ramirez CM. (in press). Trends and causes of severity, size, and number of fires in northwestern California, USA. Ecological Applications; doi:10.1890/10-2108.1. 
Moghaddas JJ, Collins BM, Menning K, Moghaddas EEY, Stephens SL. (2010). Fuel treatment effects on modeled landscape level fire behavior in the northern Sierra Nevada. Canadian Journal of Forest Research 40: 1751-1765.

Mohr JA, Whitlock C, Skinner CN. (2000). Postglacial vegetation and fire history, eastern Klamath Mountains, California, USA. The Holocene 10: 587-601.

Murphy K, Rich T, Sexton T. (2007). 'An assessment of fuel treatment effects on fire behavior, suppression effectiveness and structure ignition on the Angora Fire.' USDA Forest Service RS-TP-025. U.S. Government Print Office, Washington, DC.

National Wildfire Coordinating Group. (2011). Glossary of Wildland Fire Terminology. PMS 205. Boise ID.

Noonan EK. (2003). A Coupled Model Approach for Assessing Fire Hazard at Point Reyes National Seashore: FlamMap and GIS. In Proceedings of the $2^{\text {nd }}$ International Wildland Fire Ecology and Management Congress: 16-20 November 2003, Orlando Florida. 3p.

North M, Hurteau M, Innes J. (2009). Fire suppression and fuels treatment effects on mixed-conifer carbon stocks and emissions. Ecological Applications 19: 13851396.

North M, Hurteau, M. (2011). High-severity wildfire effects on carbon stocks and emissions in fuels treated and untreated forest. Forest Ecology and Management 261: $1115-1120$. 
Nowak DJ, Walton JT, Dwyer JF, Kaya LGa, Myeong S. (2005). The Increasing influence of urban environments on US forest management. Journal of Forestry 103: 377-382.

Nowak DJ, Dwyer JF. (2007). 'Understanding the Benefits and Costs of Urban Forest Ecosystems'. In J. E. Kuser (Ed.) Urban and Community Forestry in the Northeast (pp. 25 -46). Springer, Netherlands.

Odion DC, Frost EJ, Strittholt R, Jiang H, Dellasala DA, Moritz MA. (2004). Patterns of Fire Severity and Forest Conditions in the Western Klamath Mountains, California. Conservation Biology 18:927- 936.

Pollet J, Omi PN. (2002). Effect of thinning and prescribed burning on wildfire severity in ponderosa pine forests. International Journal of Wildland Fire 11: 1-10.

Pyne SJ. (1982). 'Fire in America: a cultural history of wildland and rural fire' (Princeton University Press: Princeton, NJ.

Rebain, SA. comp. (2010). The Fire and Fuels Extension to the Forest Vegetation Simulator: Updated Model Documentation. Internal Rep. Fort Collins, CO: U. S. Department of Agriculture, Forest Service, Forest Management Service Center. 387p. (revised May 10, 2011).

Reiner A, Decker T. (2009). 'Fuel Loadings in Masticated areas on the San Jacinto District of the San Bernardino National Forest.' USDA Forest Service, Adaptive Management Services Enterprise Team, Sparks, NV.

Reiner AL, Vaillant NM, Fites-Kaufman J, Dailey SN. (2009). Mastication and prescribed fire impacts on fuels in a 25-year old ponderosa pine plantation, southern Sierra Nevada. Forest Ecology and Management 258: 2365-2372. 
Reinhardt ED, Keane RE, Brown, JK. (1997). First Order Fire Effects Model: FOFEM 4.0, User's Guide. Gen. Tech. Rep. INT-GTR-344. Ogden UT: U.S. Department of Agriculture, Forest Service Intermountain Research Station. 65p.

Reinhardt ED, Kean RE, Calkin DE, Cohen JD. (2008). Objectives and considerations for wildland fuel treatment in forested ecosystems of the interior western United States. Forest Ecology and Management 256: 1997 - 2006.

Reinhardt ED, Holsinger L. (2010). Effects of fuel treatments on carbon-disturbance relationships in forests of the northern Rocky Mountains. Forest Ecology and Management 259: 1427-1435.

Reinhardt ED, Holsinger L, Keane R. (2010). Effects of Biomass Removal Treatments on Stand-Level Fire Characteristics in Major Forest Types of the Northern Rocky Mountains. Western Journal of Applied Forestry 25(1):34-41.

Ritchie MW, Skinner CN, Hamilton TA. (2007). Probability of tree survival after wildfire in an interior pine forest of northern California: Effects of thinning and prescribed fire. Forest Ecology and Management 247: 200-208.

Rocky Mountain Research Station Fire Lab and Systems for Environmental Management. (2002). FireFamilyPlus User's Guide v. 3.0. Rocky Mountain Research Station, Fort Collins CO.

Rothermel RC. (1972). A mathematical model for predicting fire spread in wildland fuels. USDA Forest Service Research Paper. INT-115.

Rothermel RC. (1983). How to predict the spread and intensity of forest and range fires. Gen. Tech. Rep. INT-143. Ogden, UT: U.S. Department of Agriculture, Forest Service, Intermountain Forest and Range Experiment Station. 161 p. 
Sackett SS. (1975). Scheduling prescribed burns for hazard reduction in the Southeast. Journal of Forestry 73(3): 143-147

Schmidt DA, Taylor AH, Skinner CN. (2008). The influence of fuels treatment and landscape arrangement on simulated fire behavior, Southern Cascade range, California. Forest Ecology and Management 255: 3170-3184.

Schultz MG, Heil A, Hoelzemann JJ, Spessa A, Thonicke K, Goldammer JG, Held AC, Pereira JMC, van het Bolscher M. (2008). Global wildland fire emissions from 1960 to 2000. Global Biogeochemical Cycles 22: GB 2002.

Scott J. (2006). An analytical framework for quantifying wildland fire risk and fuel treatment benefit. In: Andrews, P.L., Butler, B.W. (comps), Fuels Management How to Measure Success: Conference Proceedings. Portland, OR, March 28-30, pp. 169-184; Proceedings RMRS-P-41, USDA Forest Service, Rocky Mountain Research Station, Fort Collins, CO, 809 pp.

Scott JH, Burgan RE. (2005). Standard fire behavior fuel models: a comprehensive set for use with Rothermel's surface fire spread model. USDA Forest Service General Technical Report RMRS-GTR-153.

Seely B, Welham C, Kimmins H. (2002). Carbon sequestration in a boreal forest ecosystem: results from the ecosystem simulation model FORECAST. Forest Ecology and Management 169: 123 - 135. 
Sexton T. (2006). U.S. Federal Fuel Management Programs: Reducing Risk to Communities and Increasing Ecosystem Resilience and Sustainability. In: Andrews, P.L., Butler, B.W. (comps), Fuels Management - How to Measure Success: Conference Proceedings. Portland, OR, March 28-30, pp. 9-12; Proceedings RMRS-P-41, USDA Forest Service, Rocky Mountain Research Station, Fort Collins, CO, 809 pp.

Skinner CN, Taylor AH, Agee JK. (2006). Klamath Mountains Bioregion, In N. G. Sugihara et al., (Eds.), Fire in California's Ecosystems (pp. 170 - 194). Univ. of California Press: Berkeley and Los Angeles, CA.

Skog KE, Nicholson GA. (1998). Carbon cycling through wood products: the role of wood and paper products in carbon sequestration. Forest Products Journal 48:7583.

Stephens SL. (1998). Effects of fuels and silvicultural treatments on potential fire behavior in mixed conifer forests of the Sierra Nevada, CA. Forest Ecology and Management 105: 21-34.

Stephens SL, Moghaddas JJ. (2005). Experimental fuel treatment impacts on forest structure, potential fire behavior and predicted tree mortality in Californian mixed conifer forest. Forest Ecology and Management 215: 21 - 36.

Stephens SL, Ruth W. (2005). Federal forest-fire policy in the United States. Ecological Applications 15: 532-542. 
Stephens SL, Moghaddas JJ, Hartsough BR, Moghaddas EEY, Clinton NE. (2009). Fuel treatment effects on stand-level carbon pools, treatment-related emissions, and fire risk in a Sierra Nevada mixed-conifer forest. Canadian Journal of Forest Research 39: 1538-1547.

Stratton RD. (2004). Assessing the effectiveness of landscape fuel treatments on fire growth and behavior. Journal of Forestry 102: 32-40.

Stratton RD. (2006). Guidance on spatial wildland fire analysis: models, tools, and techniques. Gen. Tech. Rep. RMRS-GTR-183. Fort Collins, CO: U.S. Department of Agriculture, Forest Se, Rocky Mountain Research Station. 15 p.

Tao Y, Allen WR. (2010). Fuel Loading and the Potential for Carbon Emissions from Fire Following Two Shelterwood Harvest Treatments in Southern Ohio. Genomics and Applied Biology 29(4); 628-638.

Tavoni M, Sohngen B, Bosetti V. (2007). Forestry and the carbon market response to stabilize climate. Energy Policy 35: 5346 - 5353.

Taylor AH, Skinner CN. (1995). Fire Regimes and Management of Old-growth Douglas fir Forests in the Klamath Mountains of Northwestern California. In: Proceedings of the Fire Effects on Rare and Endangered Species and Habitats Conference, pp203-208. Nov. 13-16, Coeu d'Alene ID.

Taylor AH, Skinner CN. (1998). Fire history and landscape dynamics in a latesuccessional reserve, Klamath Mountains, California, USA. Forest Ecology and Management 111: 285-301. 
Taylor AH, Skinner CN. (2003). Spatial patterns and controls on historical fire regimes and forest structure in the Klamath Mountains. Ecological Applications 13: 704719.

Teck R, Moeur M, Eav B. (1996). Forecasting Ecosystems with the Forest Vegetation Simulator. Journal of Forestry 94(12): 7-10.

Tiedemann AR, Klemmedson JO, Bull EL. (2000). Solution of forest health problems with prescribed fire: are forest productivity and wildlife at risk? Forest Ecology and Management 127: 1-18.

USDA Forest Service. (2002). Happy Camp Fire Protection Strategy Analysis. Klamath National forest, Happy Camp Ranger District. Accessed 9-18-11: http://www.fs.usda.gov/Internet/FSE_DOCUMENTS/stelprdb5269298.pdf

USDA Forest Service. (2009). "Vegetation Inventory: Data by Forest Download Page." Region 5 Remote Sensing Laboratory. Updated December 2009. http://www.fs.fed.us/r5/rsl/projects/inventory/invdownload.shtml\#knf_mdc_plat.

USDA Forest Service. (2010). Eddy Gulch Late Successional Reserve Fuels/Habitat Protection Project, Final Environmental Impact Statement. Pacific Southwest Region - R5-MB-212. Vallejo, CA.

USDA Forest Service, DoI, Bureau of Land Management. (1994). Record of decision for amendments to Forest Service and Bureau of Land Management planning documents within the range of the northern spotted owl. [Place of publication unknown.] $74 \mathrm{p}$. 
Vaillant NM. (2008). Sagehen Experimental Forest Past, Present, and Future: An Evaluation of the Fireshed Assessment Process. Ph.D. Dissertation. University of California, Berkeley.

Vaillant NM, Fites-Kaufman J, Reiner AL, Noonan-Wright EK, Dailey SN. (2009). Effect of fuel treatments on fuels and potential fire behavior in California, USA, national forests. Fire Ecology 5: 14-29.

van Wagtendonk JW, Sydoriak CA. (1987). 'Fuel accumulation rates after prescribed fires in Yosemite National Park'. In: Proceedings of the 9th Conference on Fire and Forest Meteorology. Vol. 9'. 21-24 April 1987, San Diego, CA. pp. 101-105. American Meteorology Society: Boston, MA.

van Wagtendonk JW. (1996). Use of a deterministic fire growth model to test fuel treatments. In Sierra Nevada Ecosystem Project: final report to Congress, volume II. Assessments and scientific basis for management options, pp1155-1165. University of California, Davis, Centers for Water and Wildland Resources, Davis, California, USA.

Varner JM, Hiers JK, Ottmar RD, Gordon DR, Putz FE, Wade DD. (2007). Overstory tree mortality resulting from reintroducing fire to long-unburned long leaf pine forests: the importance of duff moisture. Canadian Journal of Forest Research 37: $1349-1358$. 
Weatherspoon CP. Skinner CN. (1996). Landscape-Level Strategies for Forest Fuel Management. In Sierra Nevada Ecosystem Project: final report to Congress, volume II. Assessments and scientific basis for management options, pp14711482. University of California, Davis, Centers for Water and Wildland Resources, Davis, California, USA.

Weaver H. (1943). Fire as an ecological and silvicultural factor in the Ponderosa Pine region of the Pacific slope. Journal of Forestry 41(1): 7 - 15.

Westerling AL, Hidalgo HG, Cayan DR, Swetnam TW. (2006). Warming and earlier spring increase western U.S. forest wildfire activity. Science 13: 940-943.

Whittaker RH. (1960). Vegetation of the Siskiyou Mountains, Oregon and California. Ecological Monographs 30: 279-338.

Wiedinmyer C, Hurteau M. (2010). Prescribed fire as a means for reducing forest carbon emissions in the western U.S. Environmental Science and Technology 44: 19261932. 